Florida International University FIU Digital Commons

6-1-1999

\title{
The relationship between acculturation and the effects of caregiving of the elderly among Cuban- Americans
}

Georgia de las Pozas

Florida International University

DOI: $10.25148 /$ etd.FI14062221

Follow this and additional works at: https://digitalcommons.fiu.edu/etd

Part of the Medical Specialties Commons, and the Occupational Therapy Commons

\section{Recommended Citation}

de las Pozas, Georgia, "The relationship between acculturation and the effects of caregiving of the elderly among Cuban-Americans" (1999). FIU Electronic Theses and Dissertations. 3017.

https://digitalcommons.fiu.edu/etd/3017 


\title{
FLORIDA INTERNATIONAL UNIVERSITY
}

\author{
Miami, Florida
}

THE RELATIONSHIP BETWEEN ACCULTURATION AND THE EFFECTS OF

CAREGIVING OF THE ELDERLY AMONG CUBAN-AMERICANS

\author{
A thesis submitted in partial fulfillment of the \\ requirements for the degree of \\ MASTER OF SCIENCE \\ in
}

OCCUPATIONAL THERAPY

by

Georgia de las Pozas

1999 
To: Dean DeLois P. Weekes

College of Health Sciences

This thesis, written by Georgia de las Pozas, and entitled The Relationship between Acculturation and the Effects of Caregiving of the elderly among Cuban-Americans, having been approved in respect to style and intellectual content, is referred to you for judgment.

We have read this thesis and recommend that it be approved.

Alma Abdel-Moty

Paulette Johnson

Gail Ann Hills, Major Professor

Date of Defense: June 1, 1999

The thesis of Georgia de las Pozas is approved.

Dean DeLois P. Weekes College of Health Sciences

Dean Richard L. Campbell Division of Graduate Studies

Florida International University, 1999 


\section{DEDICATION}

I dedicate this thesis to my family. To my mother for her unconditional support, faith in my abilities, and love. Without her, this project would have never been completed. To my sister and brother for their continuous encouragement. Finally, to my children Eric and Danny who are my strength and my joy. 
ABSTRACT OF THE THESIS

THE RELATIONSHIP BETWEEN ACCULTURATION AND THE EFFECTS OF CAREGIVING OF THE ELDERLY AMONG CUBAN-AMERICANS

by

Georgia de las Pozas

Florida International University, 1999

Miami, Florida

Professor Gail Ann Hills, Major Professor

The purpose of this study was to establish the perceived caregiving effects among thirty Cuban-born individuals caring for elderly relatives and the relationship of these effects with acculturation.

Most common difficulties were lack of private time, or social life, and decreased emotional and physical health. Satisfactions were mostly derived from fostering the elders' welfare. A strong positive relationship was found between caregivers' difficulties and stability of the caregiving dyad $(r=-0.642, p<.001)$. Caregivers involved in more unstable caregiver-care receiver dyads had more stress associated with caregiving difficulties. The acculturation factors of language, electronic media, and social relations, and the stability of the caregiving dyad accounted for 54 percent of the variation in caregivers' difficulties $(p<.001)$ but only 21 percent of the variation of caregivers' satisfaction $(p<.221)$.

These findings provided preliminary data of caregiving characteristics among Cuban-Americans and the importance of including acculturation in studies involving minorities. 
I. INTRODUCTION ........................................................

Cuban-Americans as an ethnic sub group ............................... 3

Cuban-Americans and caregiving ................................ 3

Application of the Model of Human Occupation ...................... 5

Statement of the problem ..................................................... 7

Purpose of the study ........................................................... 8

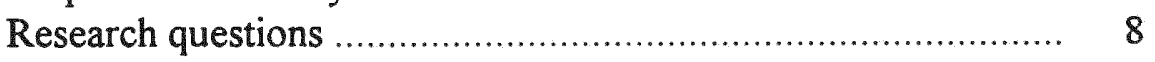

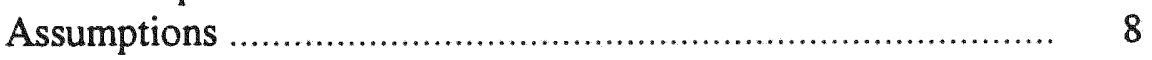

Operational definitions .................................................. 9

II. LITERATURE REVIEW ................................................ 11

Elderly in the United States ................................................ 11

Hispanics ............................................................ 12

Cuban-Americans ........................................ 13

Family caregiving of the elderly .......................................... 14

Effects of caregiving on the caregiver .......................... 16

Negative effects of caregiving:

caregiving burden ...................................... 18

Instruments to measure negative effects ........... 24

Positive effects of caregiving ......................... 25

Theoretical framework ....................................................... 27

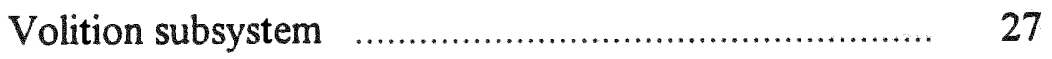

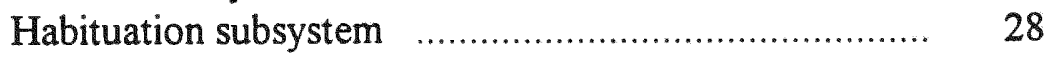

Performance subsystem …........................................ 29

The environment .................................................... 29

Cuban culture and caregiving ........................................... 33

Cuban familism .................................................. 33

Caregiving of elderly. Cubans .................................... 34

Acculturation and caregiving .................................... 37

Measurement of acculturation ........................ 39

Limitations in caregiving and acculturation studies ................. 41

III. METHODOLOGY ...................................................... 44

Research questions ........................................................ 44

Subjects .......................................................................... 44

Criteria for inclusion ............................................. 44

Data collection techniques .............................................. 45

Instruments ............................................................... 46

Patient-Caregiver Functional Unit Scale (PCFUS) ........ 47

Scoring of the PCFUS .................................... 48 
Carers' Assessment of Difficulties Index (CADI) ......... 48

Carers' Assessment of Satisfaction Index (CASI) ......... 48

Short Acculturation Scale for Hispanics (SASH) ......... 49

Research design ............................................................. 49

Type of design ..................................................... 49

Variables ............................................................. 49

Statistical analysis ........................................................... 50

Limitations of the study ..................................................... 51

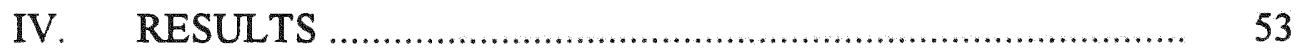

Demographic date ......................................................... 53

Caregiver information ........................................ 53

Care receivers' information ...................................... 58

Characteristics of the caregiving situation ................... 59

Duration of caregiving ................................... 59

Common reasons for becoming a caregiver ..... 59

Caregivers' tasks ............................................ 60

Family support ............................................ 61

Perceived effects of caregiving ............................................ 64

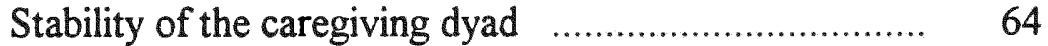

Caregivers' difficulty ................................................. 68

Caregivers' satisfaction ............................................ 69

Acculturation ............................................................ $\quad 72$

Statistical analysis ................................................. 75

Relationship between acculturation and the

effects of caregiving ................................................ $\quad 77$

Additional findings ............................................................ $\quad 83$

Relationship between acculturation and other

caregiving and demographic variables

Relationship between caregivers' difficulties and other demographic and caregiving variables $\ldots \ldots . . . \quad 85$

Other caregivers' feelings associated with caregiving .... $\quad 89$

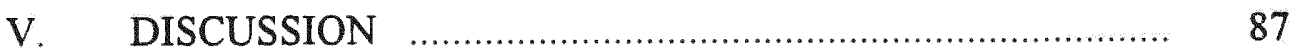

Caregiver characteristics $\quad$.................................................... $\quad 88$

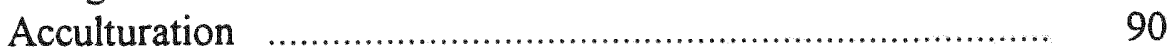

Caregiving situation ...................................................... 92

Perceived effects of caregiving …....................................... 94

Relationship between variables ........................................ 96

Recommendations ......................................................... 99

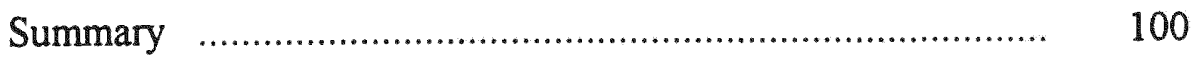

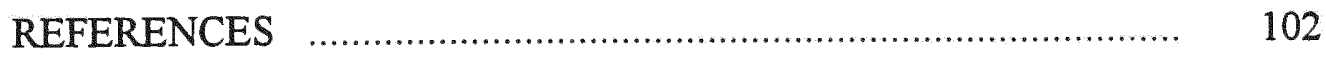

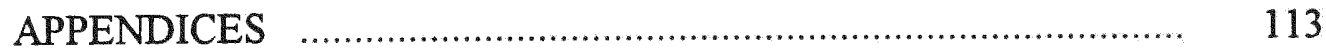




\section{LIST OF TABLES}

TABLE

PAGE

1. Caregiver Demographic Information ….............................. 55

2. Caregiver Acculturation Information ……........................ 57

3. Characteristics of the Care Receivers ….................................. 58

4. Most Common Reasons for Becoming a Caregiver ................. 59

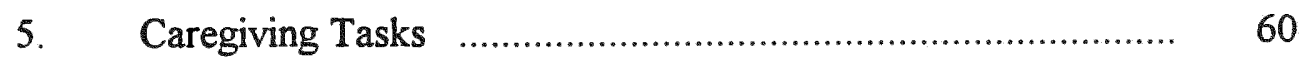

6. Environmental Accommodations for Caregiving ..................... 61

7. Availability of Family Support for the Caregivers _.................. 61

8. Care Receiver Relatives Able to Share and/or Take Over with Caregiving

9. Caregiving Tasks of Relatives Sharing with Caregiving $\ldots . . . \ldots . . .63$

10. Degree of Help that Care Receivers Need to Perform ADLs and IADLs Tasks Determined by the PCFUS

11. ADLs and IADLs' Tasks that Caregivers Help with as Determined by the PCFUS

12. Difficulties Caregivers Had (or Would Have) in Helping the Care Receiver

13. Most Common Difficulties in Caregiving Measured by CADI ...

14. Most Common Satisfactions in Caregiving Measured by CASI

15. Means and Standard Deviations for Acculturation on the Three Factors of the SASH

16. Means and Standard Deviation for Items in the Three Factors of the SASH

17. Pearson Correlations between Scores on Total and

Each Factor of the SASH and Other Indicators of Acculturation 
18. Pearson Correlations between Total Each Acculturation

Factor (SASH), Caregiving Stability (PCFUS), Caregivers'

Difficulties (CADI), and Caregivers' Satisfaction (CASI)

19. Multiple Regression of Level of Stress of Caregivers'

Difficulties (CADI) on Total Acculturation (SASH) and

Stability of the Caregiving Dyad (PCFUS)

20. Multiple Regression of Level of Stress of Caregiver

Difficulties (CADI) on Acculturation Factors and

Stability of the Caregiving Dyad (PCFUS)

21. Multiple Regression of Caregivers' Satisfaction (CASI)

on Total Acculturation (SASH) and Stability of the

Caregiving Dyad (PCFUS)

22. Multiple Regression of Caregivers' Satisfaction (CASI) on Acculturation Factors and Stability of the

Caregiving Dyad (PCFUS)

23. Pearson Correlations between Caregiving Situation

Variables (Length of Care, Availability of a Relative

to Share with Caregiving, and the Need to Move)

and Total Acculturation (SASH) and each SASH Factor

24. Pearson Correlations between Demographic Variables

(Age, Educational Level and Household Income of the Caregiver) and Total Acculturation (SASH) and each

SASH Factor

25. Pearson Correlations between Caregivers' Difficulties (CADI) and Gender of the Caregiver, Length of Stay in the U. S., and the Need to Move 


\section{CHAPTER I}

\section{Introduction}

The U. S. health care system is undergoing radical changes. Enrollment in all types of health maintenance organizations (HMO's) reached 51 million by the end of 1994, nearly $20 \%$ of the population (Davis \& Shoen, 1996). The Medicare elderly are now a major target for managed care expansion. One in eleven Medicare patients has joined an $\mathrm{HMO}$, and the Congressional Budget Office estimates this will increase to one in five under the proposed new legislation (Davis \& Shoen, 1996). Managed care, by cutting costs and placing limitations on health care, is responsible for increasing demands on family caregivers (Biegel \& Blum, 1990).

In the next fifteen years the United States is going to face a demographic explosion of people older than 65 . In 1994, one out of every ten elderly persons was from an ethnic minority group. By the year 2050, this proportion should rise to two out of ten. The proportion of elderly who are Hispanic was $4 \%$ in 1994 and this proportion is expected to climb to $16 \%$ by the year 2050 . Florida has the highest percentage of elderly people in the United States (19\% of the total population). Immigration, mostly Hispanics, contributed to Florida's high percentage (Economics and Statistics Administration, U.S. Department of Commerce, 1995). Therefore, this country and Florida in particular, face enormous demands to provide formal and informal care of the elderly. Caring for minority elders of different ethnic and cultural backgrounds is going to be a special challenge for all health professionals.

An ethnic group has certain characteristics based on cultural criteria, such as a sense of peoplehood, shared history, a common place of origin, and language (Holzberg, 
1982). Health care professionals and other service providers need to be aware of the need to differentiate between subgroups within large ethnic groups. Ignoring the characteristics of smaller ethnic groups may cause the adoption of incorrect assumptions, such as all Asians are highly educated, or all Hispanics have the same educational and economic background (Gelfand, 1994). Establishing needs and implementing appropriate intervention for ethnic groups demand that therapists distinguish the differences between Hispanic subpopulations (Schur, Bernstein \& Berk, 1987).

Another important issue to consider is that few ethnic groups have kept the traditional lifestyles and values that they had prior to immigrating to the United States. The immigration history, the continuing social, economic, and political constraints imposed by the American mainstream culture forces changes in the traditional cultural behaviors and values (Sokolovsky, 1990).

Acculturation is an adaptive process by which members of one culture change behaviors and values when exposed to another culture (Burman, Telles, Karno, Hough, \& Escobar, 1987). Acculturation is a continuum and may occur at an individual level or at a population level (Burman et al., 1987, Szapocznik, Scopetta, Kurtines, \& Aranalde, 1978). At one end is the traditional position with a strong orientation to the original culture and at the other end is the assimilated position. Individuals at the assimilated end, although more adapted to the mainstream culture, still hold many original ethnic values, such as familism (Sabogal, Marin, Otero-Sabogal, Marin, \& Perez-Stable, 1987). Various degrees of biculturalism may be present between the two extremes (Szapocznik, Kurtines, \&. Fernandez, 1980). 


\section{Cuban-Americans as an ethnic subgroup}

Hispanics in the United States form a heterogenous ethnic group with Spanish or Latin-American heritage who may or may not use the Spanish language in their homes (Caudle, 1993). Vargas (1992) reported that Hispanics have a powerful sense of identity based on the use of Spanish and a common heritage of music, literature and other arts. However, different ethnic subgroups can be distinguished among Hispanics that differ in culture, socioeconomic status, and history. The largest subgroups are Mexican-Americans, Puerto Ricans, and Cuban-Americans (Caudle, 1993).

Wallace and Lew-Ting (1992) found that most Cuban elderly immigrants compared with other Hispanics, were female, immigrated at an older age, had more education, and were the least acculturated. Cubans are concentrated in Florida, particularly in Dade county, where in 1990 they were $45.3 \%$ of the total Hispanic population and of these, $14.7 \%$ were more than 65 years old (Reddy, 1993). CubanAmericans living in South Florida retain their culture to a higher degree and have different characteristics than other Hispanics living in the United States (Perez, 1994).

Even among Cubans, differences between waves of immigration are present. Cubans that immigrated later, such as the ones that came through the Mariel boatlift, had a lower socioeconomic and educational background (Gelfand, 1994; Hernandez, 1992; Perez, 1994).

\section{Cuban-Americans and caregiving}

Women bearing the burden of caregiving are a universal and cross-cultural phenomena, but the expectation for caregiving among Hispanics is extremely high compared with what is observed in other cultures (Horowitz, 1985). In a study conducted 
at the University of Miami, Mintzer and collaborators (1992) found that Cuban-American daughters maintain their elderly mothers with Alzheimer's disease at home for a longer time, when compared with white non-Hispanic daughters. In the future this tendency may be affected by the increased incorporation of Cuban-American women into the work force (Taylor Seeman, 1997).

For Cuban-American women, caregiving and homemaking have been the traditional way for them to express love to their parents, husbands, children and grandchildren. Often caregiving for a frail elderly relative is the only way for a Cuban woman to acquire social status within the family. Caregiving may become a source of pride, and often the caretaker's only positive experience (Hernandez, 1992).

Traditionally, caregiving studies considered the negative effects of caregiving on the caregiver. Much of the research has concentrated on the caregivers' burden. The measurement of burden, as a negative effect of caregiving on the caregivers, is a central feature of most caregiving studies (Biegel, Song \& Chakravarthy, 1994; Schulz, 1990). Variables that may predict levels of burden can be objective, subjective, and conditioning (Biegel et al., 1994). Objective variables or stressor variables include illness characteristics such as nature of the onset, length of an illness, illness stage, the prognosis, and hospitalization history. Functional impairment, and behavioral problems of the care receiver are also objective variables (Biegel et al., 1994; Schulz, 1990). Subjective variables include those related to the caregiver's perception of the emotional, physical, and financial effects of caregiving (Biegel et al., 1994). Demographic characteristics of the caregiver-caregiving dyad, health status and, other roles of the caregiver are considered conditioning variables that may affect the caregiver's level of burden (Biegel et al., 1994). 
The positive effect of caregiving on caregivers has received less attention than negative factors. Lawton and collaborators (1989) suggested the use of caregiving appraisal as a more comprehensive term to include all positive, neutral, and negative subjective appraisals. George and Gwyther (1986) measured caregiver well-being using instruments designed for the general population and not particularly for caregivers. According to these authors, the use of well-being measurements offered the advantages of being independent from the caregiving role, permitting comparison between caregivers with established population norms, and that the different dimensions of well-being can be measured separately.

\section{Application of the Model of Human Occupation}

The Model of Human Occupation (MOHO) developed by Kielhofner (1995a) provides a theoretical framework for analyzing the caregiving process within any context. This model applies principles from general systems theory to the study of human occupation. According to this model, human systems operate as open systems interacting with the environment through chosen occupational behaviors performed within the three subsystems: volitional, habituation and mind-brain-body performance subsystems.

The volitional subsystem determines the occupational choices of the individual; the habituation subsystem defines recurrent patterns of behavior associated with routine tasks; and the mind-brain-body performance subsystem provides the physical and psychological elements needed for performing skilled tasks. All subsystems are influenced by the physical, and social environment. Culture, as part of the social environment, is a pervasive influence in all elements of the model (Kielhofner, 1995a).

Family members may assume the role of caregiver because they have the 
convictions and sense of obligation to do so, and they have the belief that they are capable of performing the role adequately. Caregiving is the occupational behavior associated with the caregiver's role and the organization of tasks associated with caregiving depends on the habituation subsystem. Occupational behaviors are developed through a dynamic interaction between internal biological and psychological factors within the physical and social environment. During the caregiving process, a dynamic relationship is established between two dyads: the caregiver and the care recipient. Any factor influencing the systems of the caregiver or the care recipient may have an impact on the caregiving process. How individuals perceive the impact of caregiving will depend on factors such as motivation, capabilities, value system, attitudes, habits, coping mechanisms, among others.

Ethnicity and culture influence occupational behaviors. In addition, we can assume that traditional cultural values and expectations change with the exposure to other cultures. Environmental press is a force that shapes behavior and is defined as the environment expectations of the individual (Kielhofner, 1995c). Therefore, acculturation can be considered a variable that may cause changes in the environmental press shaping caregiving behavior.

The way Cuban-American families care for their elderly members is going to be different from the traditional Cuban way because the occupational forms associated with caregiving may be changing due to acculturation. However, more acceptance of cultural pluralism, in addition to the establishment of immigrants in bicultural communities, may facilitate the maintenance of the original Cuban culture. Effective cultural adaptation requires skills to function within both cultures (Szapocznik, Kurtines \& Fernandez, 1980). This is very relevant for Cuban-American family caregivers living in Dade County, a true 
bicultural community.

\section{Statement of the problem}

The lack of research on elderly Cubans and their caregivers, who are often elderly themselves has been previously reported (Hernandez, 1992; Mintzer et al., 1992). Such studies are needed to address the concerns of this population, concerning ethnic and cultural factors as they relate to family caregiving issues (Hernandez, 1992) Although several recent studies have focused on Hispanic caregivers of the elderly (Clark \& Huttlinger, 1998; Delgado \& Tennstedt, 1997a, 1997b; John, Resendiz \& De Vargas, 1997) only one study has been found in the literature in which acculturation is assessed by means of as assessment scale. Polich and Gallager-Thompson (1997) studied the relationship of acculturation with psychological distress among Hispanic caregivers.

Often investigators group together more than one subgroup of Hispanics, without consideration of their different subcultures (Ailinger, 1989; Cox \& Monk, 1990, 1993 or without specifying to which subgroup they are referring (Cox \& Gelfand, 1987; GallagerThompson et al., 1992; Tirrito \& Nathason, 1994). Differences between Hispanic ethnic groups have been found in family characteristics (Perez, 1994; Zsembik, 1992), acculturation (Krause \& Goldenhar, 1992; Wallace and Lew-Ting, 1992), use of health care (Schur, Bernstein \& Berk, 1987), perceived needs for social services (Tran \& Dhooper, 1996), and social stress (Tran, 1997). These results suggest the importance of studying different Hispanic subpopulations.

Cuban families in the United States have fewer children and fewer relatives than other Hispanics which may put caregivers at a higher risk for strain (Guarnaccia. Parra, Deschamps, Milstein, \& Aregiles, 1992). Hernandez (1992) reported that the adult 
children in Cuban families may be actively involved in caring for their parents, but not the grandchildren. This is different than what occurs among other Hispanics. The large population of Cuban-Americans in Dade County provides a good source for obtaining information about caregiving characteristics in this group.

\section{Purpose of the study}

The purpose of this study was to obtain information related to perceived impact of caregiving among Cuban-American caregivers of elderly family members and to determine if acculturation influenced the perceived effects of caregiving. This information will be useful to health care professionals in the successful treatment of elderly patients, discharge planning, and coordination of support for caregivers.

\section{$\underline{\text { Research questions }}$}

The research questions to be answered with this study are:

(1) What are the perceived effects of caregiving of the elderly among CubanAmerican caregivers?

(2) Is there a relationship between acculturation and the perceived effects of caregiving of the elderly among Cuban-Americans caregivers?

\section{Assumptions}

This study is based on the following assumptions: (a) The instruments will be appropriate for the type of study, (b) the participants will answer the questionnaires truthfully, (c) Cuban-American caregivers have unique characteristics when compared with other Hispanics and non-Hispanics groups, (d) cultural values within an ethnic group experience change due to exposure to the host culture, and (e) acculturation is a valid measurement of cultural change. 


\section{Operational definitions}

In this study the following operational definitions will be used:

Acculturation: Process of cultural change and accommodation experienced by members of an ethnic migrant group involving adoption of the host culture (Szapocznik, Scopetta, Kurtines, \& Aranalde, 1978).

Biculturism: Phenomena that occur in bicultural communities by which individuals are able to use effectively the resources of each culture (Szapocznik, Kurtines, \& Fernandez, 1980).

Burden or perceived burden: Extent to which caregivers perceived their emotional or physical health, social life, and financial status as suffering as a result of caring for their relative" (Zarit, Todd and Zarit, 1986, pp. 261).

Caregivers: Persons responsible for the care of an elderly person. This care may include physical work, emotional support or sensitivity provided to the care recipient.

Caregivers' difficulties: Negative effects of caregiving as perceived by the caregivers. Caregivers' satisfaction: Positive effect of caregiving as perceived by the caregivers. Cuban-Americans: Cuban-born, or US-born individuals who identify themselves as of Cuban origin.

Culture: Collection of folkways, beliefs and objects associated with a given group (Litterst, 1985).

Dwelling: Place where caregiver and care receiver live. It is assumed that the care receiver may live in an efficiency apartment attached to the main house.

Ethnic group: Group that shares common characteristics based on cultural criteria, such as a sense of peoplehood, shared history, religion, a common place of origin, and language 
(Holzberg, 1982).

Familism: Active involvement of the family as the central source of assistance and interaction (Brody, 1985).

Family caregivers: Family members who assume the role of caregiving. Spouses and adult children are major family caregivers. Other relatives are secondary family caregivers. Formal caregivers: Caregivers that receive pay for their services.

Frail elder: Person aged 65 years of age or older who is dependent in at least two activities of daily living.

Hispanics: Refers to Spanish-speaking individuals originating from a variety of Latin American and South American countries.

Informal caregivers: Caregivers that are not paid for their services. They can be family members or not.

Perceived effect of caregiving: For the purpose of this study it includes the stability of the caregiving dyad and the positive, and negative effects of caregiving.

Primary caregiver: Family caregiver that provides for more than half the care of the elder. Network: Informal support system of the primary caregiver that helps the caregiver to provide the care. The help may be in different forms, such as physical and/or emotional support, providing transportation, running errands, or helping with the medical decisions. 


\section{CHAPTER II}

\section{Literature Review}

\section{Elderly in the United States}

The population of the Unites States is growing older. Although currently the elderly population is growing at a moderate rate, the rate of growth is expected to increase rapidly by the year 2015 (Economics and Statistics Administration, U.S. Department of Commerce, 1995). Between the years 1900 and 1994, the elderly increased by a factor of 11 , from 3 million to 33 million. For the same period the total population only increased by a factor of 3 (Hobbs, 1996). According to the Census Bureau's "middle series" projections, by the year 2050 , the elderly population will double. In 2050,80 million Americans will be elderly, as many as 1 in 5 . Most of the growth is expected between years 2010 and 2030, corresponding to the "baby boom" generation turning 65 years old. While during the period between 1990 and 2010 , the elderly are expected to grow $1.3 \%$ annually, during the years 2010 to 2030 , the number of elderly is expected to grow $2.8 \%$ annually (Economics and Statistics Administration, U.S. Department of Commerce, 1995).

Between 1960 and 1994 the general population growth was $45 \%$ while the elderly population, those 65 years and older, increased 100 percent. The "oldest-old"population, those aged 85 years and older, had a $274 \%$ increase during the sane time period. By the year 2050, it is expected that $5 \%$ of the United States population will be 85 years old or older, and this group will account for $24 \%$ of the total elderly population (Economics and Statistics Administration, U.S. Department of Commerce, 1995). The most impressive characteristic of the elderly within this age group is the increasing number of females in the 
male/female ratio as age increases. The ratio was 82 males per 100 females for persons 65 to 69 years old. For persons 85 to 89 years old the ratio was 44 , and only 26 for persons 95 to 99 years old (Hobbs, 1996).

In 1994, approximate $15 \%$ of the elderly were from ethnic/racial minorities. More racial and ethnic diversity is expected in the future. By the year 2050, the proportion of White non-Hispanic elderly will be $67 \%$, the Black non-Hispanic will be $10 \%$, and the Asian and Pacific Islanders will be 7\%. By the same year, the Hispanic elderly, excluding the population from Puerto Rico, is expected to be $16 \%$ of the total elderly population. From 1990 to 2050 , the proportion of elderly would increase from 8 to $14 \%$ for Blacks; 6 to $13 \%$ for American Indians, Eskimos, and Aleuts; from 6 to $15 \%$ for Asians and Pacific Islanders; and from 5 to $14 \%$ for Hispanics (Hobbs, 1996).

\section{Hispanics}

According to data from the U.S. Census Bureau, the three major groups of Hispanics in the United States in 1994 were Mexican-Americans (64\%), Puerto Ricans (10\%), and Cuban-Americans (4\%) (Campbell, 1996). Excluding the data from Puerto Rico the Hispanic population is younger than the non-Hispanic White. The median age of the Hispanic population in 1993 was 26.7 years while for the non-Hispanic White population it was 35.5 years. The Cuban population had the highest median age (43.6 years) followed by Central and South Americans (28.6 years), Puerto Ricans (26.9), and Mexicans (24.6 years) (Del Pinal, 1996).

Educational level also differs substantially among Hispanic subgroups. Mexican young adults 25 to 34 years old are the least likely to have a high school diploma or higher level of education (52.7\%), while Cuban young adults are more likely to have bachelors' 
degrees (25.1\%) than Mexican or Puerto Rican adults (Del Pinal, 1996).

Hispanics are a diverse ethnic group of Spanish descent, whose ancestors in the United States have been established since the 15 th century or immigrated most recently from Mexico, Central or South, America, and the Caribbean (Caudle, 1993). Hispanics have a powerful sense of identity based on the use of Spanish and a common heritage of music, literature and other arts (Vargas, 1992).

From a socio-cultural perspective Latin Americans belong to any of four groups: from the Caribbean islands, that is, Cuba, Puerto Rico and the Dominican Republic; from countries with a large Indian majority such as Peru, Bolivia and Guatemala; from countries with a majority population of European origin, such as Argentina and finally from countries such as Mexico and Nicaragua where Indians and/or persons from African and European origin formed a multi-cultural population (Vargas, 1992). Hispanics from all the major groups are represented in the United States.

Cuban-Americans. Cuban immigration to the United States started during the 1840 s and 1850 s because of the rebellion against Spanish colonialism. These Cuban communities in Tampa and Key West declined by the 1930s._Presently, most of the people of Cuban origin or descent were born in Cuba, arrived in the United States after 1959 (Perez, 1994) and are concentrated in Florida, particularly in Dade county. In 1990, Cuban-Americans were $45.3 \%$ of the total Hispanic population and $14.7 \%$ of them were 65 years and older (Reddy, 1993).

Four major waves of immigration have occurred since 1959. The first wave from 1959 to 1961, the second from 1961, after the Bay of Pigs Invasion to 1965, the third from 1965 to 1973 and the fourth after 1980 with the Mariel boatlift. The characteristics 
of the Cubans from the different waves are different. Cubans from the first wave were the only ones that came voluntarily, hoping to return to Cuba. Cubans, in particular the ones arriving during the first waves after 1959 , had a higher socio-economic status and more education than other Hispanic immigrants (Perez, 1994). Cubans from the fourth wave have benefitted from the success of earlier immigrants and their families. Cubans have the lowest unemployment rate of all Hispanics (7.3\%) (Del Pinal, 1996). Perez (1994) sustained that the high per capita of business ownership makes Miami a true ethnic enclave where new immigrants have employment opportunities within their own culture.

Wallace and Lew-Ting ( 1992) found that Cuban elders, compared with other Hispanics, immigrated at an older age, had more education, had a higher proportion of women, were older and had less English abilities. The higher proportion of elderly and middle-aged Cubans are a consequence of the conditions of migration. The Cuban government facilitated the departure of the elderly who were mostly a dependent population, alienated by the changes of the Cuban revolution (Perez, 1994).

\section{Family caregiving of the elderly}

In all cultures family is considered the most reliable accepted form of care (Zarit, Pearlin, \& Schaie, 1993) and is increasingly becoming a normative life event (Pearlin and Zarit, 1993). Briefly, a caregiver is a person who provides direct care (as for children or the chronically ill) (Webster Dictionary, 1995). For this family member, the action of caregiving includes not only the physical work or financial assistance provided to the care receiver but the emotional support and sensitivity to this person (Aldous, 1994).

Family caregiving is one of the forms of informal caregiving. Informal caregivers are those who are not paid for their services as opposed to formal caregivers who receive 
reimbursement for their services. Friends and neighbors may also be informal caregivers. Major family caregivers are usually the spouse or adult children while secondary family caregivers are other family members from the extended family (Kahana, Kahana, Johnson, Hammond, \& Kercher, 1994). Informal caregiving has been considered the behavioral expression of the commitment to assist relatives and family unable to care for themselves, whereas caring is considered the affective component associated with caregiving (Pearlin, Mullan, Semple, \& Skaff, 1990).

With increased age, more elderly people will be affected by chronic illnesses, in particular those in the 85-year and older group. Therefore, more elders will become dependent on others for help in their activities of daily living (ADLs) and instrumental activities of daily living (IADLs) (Pearlin, Mullan, Semple, \& Skaff, 1990; Pearlin \& Zarit, 1993). Among the non-institutionalized elderly in $1990-91,9 \%$ of the persons aged 65 to 69 years old needed assistance in ADLs and IADLs, while $50 \%$ of the persons in the "oldest-old" age group needed assistance (Economics and Statistics Administration, U.S. Department of Commerce, 1995).

Most of the care for the dependent and/or frail elderly in the community is provided by family members, usually the spouse or an adult child (Biegel \& Blum, 1990; Chiriboga, Weiler \& Nielsen, 1990; Hasselkus, 1989; Kahana, Kahana, Johnson, Hammond, \& Kercher, 1994). Caregiving by the family has been reported as one of the most critical factors in preventing early institutionalization of the elderly (Shulz, 1990) Frequently, the caregiver role is assumed by only one person, usually a woman (Aldous, 1994; Hooyman, 1990; Kahana et al., 1994; Schulz, Williamson, Morycz, \& Biegel, 1993). Wallhagen (1992) found that often caregivers were elderly persons themselves 
with their own medical problems.

The beginning of the caregiving process in the elderly has been found to occur when the elder needs assistance because of some level of physical, mental, emotional, or economic impairment. Four different types of assistance are provided by caregivers: emotional support, direct service provision, mediation with formal organizations and providers, and financial assistance (Horowitz, 1985). Cicirelli (1983) reported that caregivers defined emotional support as the most important type of assistance.

\section{Effects of caregiving on the caregiver}

Caregiving is considered a multi factorial phenomenon and this complexity is evident in the growing body of literature referring to outcomes of caregiving. Caregiving has been found to be influenced by many interrelated factors. Changes in one parameter result in the variation of other associated factors, placing the caregiver in a situation of having to make continuous adjustments over sometimes long periods of time (Zarit, Pearlin, \& Schaie, 1993). The factors that affect caregiving outcomes may be related to the care recipient (Wallhagen, 1992), the care giver (McNaughton, Patterson, Smith \& Grant, 1995) and, the interaction between the two (Davis, 1992).

According to Deimling (1994), caregiving effects should be assessed and organized into three categories. The first category includes the global physical and mental health, and the well-being caregivers experience without relating them to the caregiver's role; the second category consists of the negative effects that caregivers attribute to caregiving; and the third category includes the positive effects attributable to caregiving.

Research on the negative effects of caregiving on the caregiver has been extensive (George, 1990; Jutras \& Lavoie, 1995; Pearlin \& Zarit, 1993) but not all authors agree on 
the definitions and measurement of caregiving effects (Horowitz, 1985). Impact on the family can be positive and negative, although much of the research has concentrated only on the negative effects (Horowitz, 1985; Jutras \& Lavoie, 1995; Nolan, Grant, \& Keady, 1996).

The effects of caregiving on the caregiver have been referred to in the literature using different terminology. Some of these terms include: caregiving burden (Barusch \& Spaid, 1996; Cox \& Monk, 1990, 1993; Reinhard \& Horowitz, 1995; Zarit, Reever, \& Bach-Peterson, 1980; Zarit, Todd, \& Zarit, 1986 ), caregiving strain (Cantor, 1983; Pearlin \& Schooler, 1978; Stull, 1996), caregiving impact (Lawton, Kleban, Moss, Rovine, \& Glicksman, 1989), costs of care (Korberg \& Cairl, 1986; Kosberg, Cairl, \& Keller, 1990), consequences of care (Korberg \& Cairl, 1986), caregiving appraisal (Lawton et al., 1989), objective and subjective demands of caregiving (Wallhagen, 1992), and caregiving reaction (Given et al., 1992). Most of these terms include only negative effects of caregiving. The measurements for caregiving appraisal (Lawton et al., 1989) and caregiving reaction (Given et al., 1992) include subscales to measure positive effects.

Recently, Daly and Fredman (1998) have developed the Patient-Caregiver Functional Unit Scale (PCFUS). This instrument focuses in the caregiver-care receiver dyad and measures the stability of the caregiving situation. Total scores range from +28 (stable) to -28 (unstable). The PCFUS obtains information on fourteen ADL/IADL activities including if the patient needs help and if this help is physically and/or emotionally demanding. An advantage of this instrument is that it is based on function not diagnosis, which permits comparison of caregiving situations for frail elderly patients with different conditions. 
Reliability and validity of the PCFUS were evaluated in a study among caregivers of elderly adults from three sources: caregivers who have recently placed their relatives in a nursing home, caregivers of community-dwelling elderly persons, and a control group of elderly adults without severe cognitive or physical problems. Reliability was calculated based on 20 patient-caregiver dyads. Inter-rater reliability was 0.984 and test-retest reliability was 0.885 . Lower PCFUS scores (more unstable) were found to be associated with higher burden scores as measured by the Burden Interview, but not associated with sociodemographic factors. These findings suggested to the authors the PCFUS was a valid instrument to assess unstable patient-caregiver dyads (Daly \& Fredman, 1998).

Negative effects of caregiving: caregiving burden. Zarit, Reever, \& Bach-Peterson (1980) developed the concept of burden as a research construct. No consensus exists concerning the definition, measurement causes and correlates of burden (Shulz, 1990). Burden has been described as " the extent to which caregivers perceived their emotional or physical health, social life, and financial status as suffering as a result of caring for their relative" (Zarit, Todd and Zarit, 1986, pp. 261). Schulz (1990) defined burden as the time and effort provided by the caregiver to the person in his or her care.

Measurement of caregivers' burden has been a central feature of most caregiving studies (Biegel, Song \& Chakravarthy, 1994; Schulz, 1990). Based on stress theories, caregiving may be considered a stressor, while burden and decreased subjective well-being are the individual's perception of the impact of caregiving. Burden may be viewed as the primary outcome of caregiving or a predictor of other outcomes, such as the decision to institutionalize the elder (Biegel et al., 1994). Other authors have argued that because burden is mostly a subjective measurement, distinguishing it from depression of caregivers 
may be difficult (Stommel, Given, \& Given, 1990). Variables that may predict levels of burden can be objective, subjective, and conditioning or contextual.

Objective variables or stressor variables include illness characteristics such as nature of the onset, length of an illness, illness stage, the prognosis and, hospitalization history (Biegel, Song \& Chakravarthy, 1994). Also patient coping (Schulz, 1990), functional impairment, and behavioral problems of the care receiver are objective variables (Biegel et al., 1994; Schulz, 1990).

Most research suggests a moderate relationship between the illness status of the patient and caregiving outcomes (Schulz, 1990). Severity of patients' symptoms has been negatively correlated with caregiver well-being (George \& Gwyther, 1986) and moderate to strong relationships have been reported between elder impairment and caregiver burden and depression (Poulshock \& Deimling, 1984). However, in one study conducted by Zarit, Reever, and Bach-Peterson (1980), no relationship was found between burden and patient characteristics.

Subjective variables include those related to the caregiver's perception of emotional demand, the effect on his or her physical status, and in the financial and work areas (Biegel, Song \& Chakravarthy, 1994). Currently it is accepted that caregivers experience stress or strain, but the relationship between caregivers' symptoms of illness and the variables associated with caregiving is unclear (Orbell \& Gillies, 1993). Family caregivers may experience many losses, some of them directly or indirectly related to caregiving and some related to their own developmental stage. These losses are a source of stress for the caregiver (Chiriboga, Weiler \& Nielsen, 1990; Kahana, Kahana, Johnson, Hammond, \& Kercher, 1994). Individual case studies have suggested that caregivers are 
prone to develop illnesses, sometimes even fatal (Medalie, 1994). However, the results from research studies linking caregiving with reported illnesses, health care utilization, health-related behaviors, or indicators of cardiovascular functioning have not provided consistent evidence of an association between caregivers' stress and physical morbidity (Schulz, O'Brien, Bookwala \& Fleissner, 1995).

Jutras and Lavois (1995) conducted a study comparing health indicators in three groups: coresidents of elderly people with impairment, individuals living with a nonimpaired elder, and individuals who were not living with an elderly person. Results showed few differences in physical health between coresidents and the two comparison groups. Out of 21 physical problems covered in the study, statistical differences were obtained in the number of coresidents of impaired elders reporting diabetes, and hay fever compared with the group of individuals living with unimpaired elders. With respect to psychological well-being, coresidents systematically presented poorer health indicators.

Results from a national survey of caregivers of frail elders showed that wife caregivers had poorer health than husband caregivers. The variables that predicted selfrated health differently affected wives and husbards caregivers. A common predictor was caregiver emotional strain. Unique predictors for wife caregivers were unmet needs, depression of care recipients, and non-White caregivers. Unique predictors for husband caregivers were caregiving duration and perceived role conflict in personal and social life (Mui, 1995).

Depression has been found to be a predictor of burden. In a study of 307 selfselected caregivers, Stommel, Given, and Given (1990) found that caregiver depression was the strongest single predictor of burden. Based on this result, the authors considered 
that the interpretation and evaluation of the objective processes of caregiving by the caregivers explain the differences in experienced burden. Depression is the most frequent psychiatric condition presented by caregivers (Chiriboga, Weiler, Nielsen, 1990; Livingston, Manela \& Katona, 1996; Mintzer et al., 1992; Wallhagen, 1992).

Depression may also be considered a reaction to caregiving. In one study, Wallhagan (1992) found that personal demands on caregivers were perceived as more difficult and were associated to a greater extent with caregiver life satisfaction and depression than task demands. Some examples of personal demands were constant monitoring, unacceptable behaviors and having to change habits due to the care receiver (Wallhagen, 1992). In another study, depression was related to caregiving burden, the higher correlation being with physical burden contributing to $28 \%$ of its variance (Caserta, Lund, and Wright, 1996). Other authors suggest that depression was mostly associated with caregiver characteristics rather than with care receivers' demands. Given and collaborators (1992) reported that caregiver depression was negatively correlated with caregiver esteem and positively associated with finances, family support, health, and schedule. Zanetti and collaborators (1998) had similar results. These authors studied one hundred and three caregiver-care receiver dyads and found that relationship with the patient, caregivers' health and competence were independent predictors of caregivers' depressive symptoms Finally, other authors sustain that depression is best viewed as a cumulative response to life events, which would include long-term caregiving (Stommel, Given, \& Given, 1990).

In one of the few longitudinal studies in caregiving, Schulz and collaborators (1993) found that the level of depressive symptoms among continuous female caregivers 
of Alzheimer's patients was consistently higher when compared with non-caregivers. Male caregivers at the beginning of the study had normative levels of depressive symptoms with a significant increase in depression over time. Predictors of depression were patient problem behaviors, perceived availability of social support, caregiver gender, and concern about financial resources.

Caregiving places continuous and changing demands on caregivers (Zarit, Pearlin, \& Schaie, 1993). Caregivers of patients with Alzheimer's disease are exposed to multiple and severe long- term stressors (Pearlin, Mullan, Semple, \& Skaff, 1990) and it is reasonable to assume that their physical and mental health would be compromised (Schulz et al., 1993).

Patient disruptive behaviors, associated with dementia-type illnesses, cause more stigmas than other physical illnesses and may result in a decreased social network (Shulz, 1990). In an investigation to determine the predictors of burden among caregivers of people suffering from mental illness, Biegel, Song and Chakravarthy (1994) found that the strongest predictor of overall burden was the frequency of behavioral problems of the patient. This result is supported by other studies that have found that unacceptable and disruptive behavior of the care recipient place more demands on the caregiver (Killeen, 1990; Reinhard \& Horwitz, 1995; Wallhagen, 1992).

One set of research results suggest that few associations of stress and morbidity are unique to caregiving. Distinctive to caregiving were the associations between patient problem behaviors and morbidity of the caregiver, and between patient cognition impairment and physical morbidity (Schulz, O'Brien, Bookwala \& Fleissner, 1995).

Demographic characteristics, health status, and other roles of the caregiver are 
conditional or contextual variables (Biegel, Song \& Chakravarthy, 1994). Schulz (1990) considered that contextual variables needed to include also the personality attributes of the caregiver and social support. According to Matthews (1993), the lack of understanding of the broad social context surrounding the caregiving process is partly because contextual variables have been the least investigated.

Adult children may present role conflicts due to caring for elderly parents while caring for their own children (Kahana, Kahana, Johnson, Hammond, \& Kercher, 1994). Daughters caring for their elderly parents may suffer from greater disruption of their lives, more competing demands from other roles, give more overall assistance, in particularly personal care, and report more stress due to caregiving than sons caregivers (Horowitz, 1985; Kahana \& Young, 1990).

Some variables pertain to the characteristics of the interaction between the two members of the dyad: the caregiver and the care receiver. Family bonds, attitudes, and types of relationships between caregivers and care recipients may affect the outcomes of caregiving (Kahana \& Young, 1990; Kahana, Kahana, Johnson, Hammond, \& Kercher, 1994). Spousal caregivers and adult child caregivers are affected in different ways with caregiving. Adult children may reverse their roles with their parents (Aldous, 1994; Kahana et al., 1994). Johnson (1983) reported that care recipients were more satisfied with care provided by spouses than children.

Most studies comparing adult children with spousal caregivers have found that spousal caregivers report the highest level of stress (Horowitz, 1985). George and Gwyther (1986) reported that spouses had poorer physical and mental health even when difference of age was statistically controlled (George \& Gwyther, 1986). With respect to 
caregiving burden, the research results are inconclusive. In one study, Johnson (1983) reported that spouses were less burdened and more accepting of their caregiving role while in another study Caserta, Lund and Wright (1996) found that spouses were likely to report more burden.

Instruments to measure negative effects. The literature refers to many different instruments to measure burden. Among them are the following: The Burden Interview (BI) (Zarit, Todd, \& Zarit, 1886), the Burden Assessment Scale (BAS) (Reinhard, Gubman, Horwitz, \& Minsky, 1994), the Screen for Caregiver Burden (SBC) (Vitaliano, Russo, Young, Becker, \& Maiuro, 1991), and the Caregiver Burden Inventory (CBI) (Novak and Guest, 1989).

One of the most used instruments to measure burden has been the Burden Interview (BI) developed by Zarit and his associates (Zarit, Todd and Zarit, 1986). This is a 22 -item self-report inventory that measures burden as it is associated with functional and behavioral impairments. The instrument strengths include the broad scope of situations that could be sources of burden, high internal consistency and test-retest reliability, and good content and construct validity. Another strength is that the instrument measures the subjective effect on the caregiver (Vitaliano, Young, \& Russo, 1991). Limitations are the omission of measurements to evaluate caregiver-centered problems (Vitaliano, Young, \& Russo, 1991), and that only a single global score for burden is obtained which limits the capabilities for clinical intervention. (Kosberg, Cairl, \& Keller, 1990).

The Caregiver Burden Inventory (CBI) constructed by Novak and Guest (1989) is a self-report multidimensional measure of caregiving burden derived from responses from caregivers of patients diagnosed with Alzheimer's disease, senile dementia, or organic 
brain syndrome. Excluded were clear and obvious cases of stroke or multi infarct dementia with no indication of Alzheimer's or related disorder. The strength of the scale is based on the wide range of caregiver problems included on its subscales, and its clinical application (Deimling, 1994).

The final CBI consists of 24 items loaded on the following five factors: timedependence burden, developmental burden, physical burden, social burden, and emotional burden. Items include affective responses (subjective effects) and task-related sources of burden (objective effects). These factors accounted for $66 \%$ of the variance of the data. Internal consistency reliability (Coefficient Alpha) of the factors was between 0.73 and 0.86 (Novak \& Guest, 1989).

Kosberg, Cairl, and Keller (1990) have used The Cost of Care Index (CCI) (Kosberg \& Cairl, 1986) to support their conceptual model of burden. This model has a set of predictor variables of burden grouped in the following six categories: caregiver characteristics, caregiver formal support, caregiver informal support, caregiver functioning, consequences of caregiving, and patient functioning. The dependent variables of the model are the global Cost of Care Index and its five component scores: personal and social restrictors, physical and emotional problems, economic costs, caregiving value, and care recipient as provocateur (Kosberg, Cairl, and Keller, 1990). This last component refers to the personality traits of the care recipient that may trigger mistreatment by a care provider (Kosberg \& Cairl, 1986).

Positive effects of caregiving. The emphasis in caregiving research has been on the negative effects of caregiving on the caregiver (Deimling, 1994; Horowitz, 1985; Lawton, Kleban, Moss, Rovine, \& Glicksman, 1989; Nolan, Grant, \& Keady, 1996; Schulz, 1990), 
but positive effects of caregiving may counteract the negative effects (Schulz, 1990). In the majority of caregiving studies, positive effects of caregiving, when included at all, have been only a small component of the investigation (Nolan, Grant, \& Keady, 1996). However, this situation appears to be changing as evidenced by growing research in the gratifications of caregiving (Grant, Ramcharan, McGrath, Nolan, \& Keady, 1998).

Lawton and his associates (1989) incorporated a subscale of caregiving satisfaction in the Caregiving Appraisal Instrument. Their attempt to represent a broad item pool was only partially successful, but results suggested that research in this direction should be continued. Caserta, Lund, and Wright (1996) used the Caregiving Satisfaction subscale of the Caregiving Appraisal Instrument (Lawton, Kleban, Moss, Rovine, \& Gliksman, 1989) to measure positive effects of 160 caregivers of elderly relatives with Alzheimer's disease, other dementias and stroke. Their results indicated that lower caregiver satisfaction was associated with a greater emotional burden.

Other scales that have been developed to measure positive effects: the Caregiving Uplifts (Kinney \& Stephens, 1989), and the Uplifts Index (Pruchno \& Resch, 1989). Both measurements are complements to measurements of caregiver strain or burden. More recently, Fulton Picot, Youngblut, and Zeller (1997) have developed the Picot Caregiver Rewards Scale (PCRS). This scale was tested in a non random sample of 83 female Black caregivers and a random sample of 256 Black and White female and male caregivers. Results suggested that the final 16 -item scale was a reliable and valid unidimensional measurement of caregivers' rewards.

According to Nolan, Grant, and Keady (1996), caregiving satisfaction may be derived from the interpersonal dynamics between caregiver and care receiver, the intra 
personal dynamics of both, and from the need to promote positive consequences of caregiving. These authors refer to the later dimension as outcome dynamic.

Interpersonal dynamics include satisfaction derived from maintaining or providing small pleasures to the care receiver. In one study in England, this factor was found to be the most common source of satisfaction (Nolan \& Grant, 1992). Other sources of satisfaction from this dimension are seeing care receivers happy, maintaining elders selfesteem and dignity, forming closer and improved relationships, and receiving the appreciation from the care receiver and other persons (Nolan, Grant, \& Keady, 1996).

Intra personal sources of satisfaction are those related to motivation and values such as religious and family beliefs, developing a sense of competency, mastery, and achievement, and fulfilling a sense of duty. Sources of satisfaction derived from positive outcomes are giving the best possible care, avoiding institutionalization of the care receiver, and developing new interests and skills (Nolan, Grant, \& Keady, 1996).

\section{Theoretical framework}

The Model of Human Occupation (MOHO), as developed by Kielhofner (1995a) provides a theoretical framework for analyzing the caregiving process within a particular environment. In this model, concepts derived from general systems theory are applied to human beings. According to this model, humans operate as self-organized open systems interacting with the environment through occupational behavior. Occupational behavior is chosen, patterned and performed by the three subsystems that form the human system: volitional, habituation and mind-brain-body performance subsystems (Kielhofner, 1995a). Volition subsystem

The volition subsystem predisposes and enables individuals to anticipate, choose, 
experience and interpret occupational behavior. Occupations are chosen during volitional processes occurring at three different areas: personal causation, values, and interests. Personal causation is a collection of all the people's knowledge about capabilities and efficacy in occupations. It gives the individual a sense of ability to act and modify the environment (Borell, Burke, Helfrich, Kielhofner, \& Nygard, 1995). Caregivers take the role when motivated by a sense of mastery or the appreciation that they have the capabilities to assume the role. Values are a coherent collection of socio-cultural convictions about what is important in life and how to behave accordingly (Borell et al., 1995). Values act as motivators and they give meaning to the caregiving process. Interests determine what is enjoyable and satisfying in an occupation (Borell et al., 1995).

\section{Habituation subsystem}

Through the habituation subsystem the information from the environment is organized so that recurrent patterns of behavior are displayed more or less automatically under the appropriate stimuli. The pattern of activities is influenced by habits and roles. Habits, acquired through experience, preserve the way to do things. They determine the way a given activity is performed, how time is typically used and the style of behavior. Roles are internalized awareness of a certain social identity and corresponding obligations. Roles provide expectations about performance and time use while providing structure to life (Kielhofner, 1995b). This subsystem influences the caregiver's perception of his or her role according to cultural and social background.

Traditionally, roles were divided into three categories: personal-sexual, familialsocial, and occupational (Heard, 1977). The occupational roles were the only ones to be considered within the occupational therapy domain (Matsutsuyu, 1971). Caregiver was 
not considered among the defined occupational roles. Other authors have disagreed with categorizing caregiver as a role by itself because the action of caregiving is embedded in other established roles, such as spouse and parent. However, when the care receiver suffers chronic and progressive dependency, caregiving may become the dominant component of the relationship (Pearlin, Mullan, Semple, \& Skaff, 1990). Oakley and collaborators (1986) considered that any given role could have personal-sexual, familialsocial, and occupational dimensions. Using the Model of Human Occupation as a theoretical framework, we may consider caregiver as an occupational role. Caregiving, defined as the "responsibility for the care of someone such as a child, spouse, relative, or friend," is the occupational behavior associated with the role (Kielhofner, 1995b, p74).

\section{Performance subsystem}

The third subsystem formally referred as mind-brain-body performance subsystem provides the caregiver the physical and mental capabilities necessary to assume the role. This subsystem includes the physical and mental components that provide the capacity for occupational performance. Information from the environment (external and internal) is processed in the following manner: reception, planning, and programing plans of action. Action is executed by the body's systems (Fisher \& Kielhofner, 1995).

\section{The environment}

Caregiving is also influenced by the social and physical environment. The social environment at the different levels (local, state and national government), culture, and cohort may influence both the informal and formal support systems (Hooyman, 1990; Kahana, Kahana, Johnson, Hammond, \& Kercher, 1994). Physical environmental barriers inside and outside the home can add to the burden of caregivers (Kahana et al., 1994). 
Kahana and collaborators (1994) suggested that the caregiving paradigm should be expanded to take into consideration the personal and social contexts of care along three axes: the individuals or groups involved in caregiving (spatial axis), the temporal aspects of caregiving (temporal axis), and the processes associated with caregiving (transactional axis).

Caregiving behavior, as all occupational behaviors, is shaped by the environment in two fundamental ways. In the first place, the environment affords a range of opportunities for performance, providing potentials for behaviors from which the individual can choose and take action. In second place, the environment presses for certain behaviors and over time, press will influence which skills and habits the individual will develop. By acting together, both processes create opportunities and constraints for action in the form of behavioral pathways (Kielhofner, 1995c).

Caregiving is a multidimensional occupational behavior that entitles a dyadic relationship between the person assuming the caregiver's role and the care recipient. Consequently, during the caregiving process, two human systems are interacting between themselves and with the environment. Perception of burden and caregivers' satisfaction are two of the parameters that can describe the effect of the caregiving behavior on the caregiver (Deimling, 1994). Both parameters influence the outcome of the process of caregiving. Factors associated with the subsystems of either dyad, the social and physical environment, and their interactions affect caregiving. Culture, as a force that shapes both the environment and the human system (Kielhofner, 1995c), may modulate the effects of caregiving on the caregiver.

Culture is a central multidimensional concept for social scientists and has been 
defined in many ways. Krefting (1991, pp. 2) called culture a "blueprint or organizing framework to guide daily behavior" learned through a socialization process. Sankar (1993, pp. 437) defined culture as "a group's common-sense notion that how they experience the world is how the world operates." Litterst (1985) stated that culture has been defined "as a system of shared meanings, the collection of folkways, beliefs and objects associated with a given people."

The collective political, social, and economic experiences are important factors in the formation of cultural group and subgroup identities (Taylor, 1994). The multidimensional nature of culture explains why it is such a pervasive force in the environment and in all aspects of human life. Kielhofner (1995c) stated that culture influenced, the social and physical environment by shaping how the world was organized and viewed by humans.

The dimensions of culture are the regional, community, family and individual levels. The regional dimension is determined by geography, natural resources and language. The community level is smaller and is influenced by neighborhood, type of housing, economic background, ethnicity and social services among other factors (Krefting, 1991). Often individuals with a shared ethnic identity live in the same geographical region (Holzberg, 1982). The two smaller dimensions are the family and the individual with different cultural experiences interpreted in unique ways (Krefting, 1991). In addition, most cultures have subcultures with different characteristics that influence the behaviors and beliefs of the individuals identifying themselves as to a particular group (Kielhofner, 1995c).

Ethnicity and language are two important components of cultural identity. Any 
definition of ethnicity needs to have the following components: identification of the group by others, by themselves, and behavior patterns unique to the group (Gelfand, 1994). Ethnicity, as defined by Sokolovsky (1990) is a "social differentiation derived from cultural criteria, such as a shared history, a common place of origin, language, dress, food preferences, and values that engender a sense of exclusiveness and self-awareness of membership in a distinct social group."

Each culture develops conventionalized ways of doing things. These are the occupational forms defined "as rule-bound sequences of action, oriented to a purpose, sustained in collective knowledge, culturally recognizable, and named" (Kielhofner, 1995c, pp. 102). Culturally prescribed occupational forms shape occupational behavior. Occupational behaviors within a particular group can be very complex because culture does not necessarily influence individuals in a homogeneous way. In today's world, increased mobility and communication facilitates the exposure of individuals to different environments with different cultural influences (Kielhofner, 1995c).

Ethnic cultures in the United States evolve in response to the challenges of their new environment (Gelfand, 1994). Cultural values and behaviors are a reflection of ethnic alliance or identification and participation with a particular ethnic group (Gelfand, 1994). Through the process of acculturation, immigrants incorporate to different degrees the elements of the host culture into their individual culture. Consequently, customs, habits, language usage, life style, and values change (Szapoczik, Scopetta, Kurtines \& Aranalde, 1978). Measurements of acculturation may include language preference, generation level, attitudes and values, citizenship status and, years of education, among other parameters (Negy \& Woods, 1992). 


\section{Cuban culture and caregiving}

The present Cuban culture in the United States is a culture of integration, formed by: (1) The fusion of the Iberian and the African culture evident in the Cuban religious beliefs (Queralt, 1984), and (2) The influence of the unique relationship between Cuba and the United States (Perez, 1994).

\section{Cuban familism}

In Hispanics, the family provides practical and emotional support to elderly people (Cox \& Gelfand, 1987) and emphasis is placed on the family unit rather than the individual (Cox \& Monk, 1993). Familism, or the commitment to family implies a strong value for the exclusiveness of the family structure (Luna et al., 1996). Attitudinal aspects of family refer to beliefs and attitudes regarding extended and nuclear families while the behavioral component refers to the behaviors associated with the feelings. In a study comparing Hispanics of Mexican, Cuban, and Central American background, it was found that the high level of perceived family support is the most distinctive dimension of Hispanic familism, despite ethnic subgroup and acculturation. Other dimensions of familism were familial obligations and family as behavioral and attitudinal referents (Sabogal, Marin, Otero-Sabogal, Marin. \& Perez-Stable, 1987). Montoro Rodriguez and Kosloski (1998) found that familial obligations and family support were positively associated with acculturation while family as referents was not.

In a study of caregivers of Mexican American elders, caregiver burden was influenced by familism (John, Resendiz, \& De Vargas, 1997). Results indicated that the caregivers' determination to care for their elders was more determined from ethnocultural family values than by financial considerations. 
The family is very important to Cubans and a high involvement is expected among family members (Queralt, 1984; Sabogal, Marin, Otero-Sabogal, Marin. \& Perez-Stable, 1987; Szapozcnik et al., 1978). Respect for their elders, love for the mother, paternal authority, and overprotection of children are all values present in the traditional Cuban families. Among Hispanics, Cubans have had a tendency to move toward more nuclear families, but during periods of crisis, the extended family rallies together to offer support (Queralt, 1984). However, Hernandez (1992) reported that for many Cubans who arrived in the United States during the Mariel boatlift familism was not a part of their value system. This group of Cubans were not welcomed by the Cuban community.

A particular Cuban family, as a cultural unit, is affected by several factors summarized by Hernandez (1992).

1. The year of immigration. As stated before, the characteristics of Cubans that arrived to the United States are different for the various waves of immigration.

2. The age at which the family members immigrated. This will determine English ability and degree of acculturation providing insight into possible family conflicts (Hernandez, 1992).

3. The pattern of immigration of the family. Cubans from the same family usually did not immigrate at the same time. Family members were left behind, sometimes only reuniting after many years. Political differences before immigration were also usual within a family. Both factors may be a source of tension and mental distress (Hernandez, 1992; Queralt, 1984).

\section{Caregiving of elderly Cubans}

Women bearing the burden of caregiving is a universal and cross-cultural 
phenomena, but the expectation among Hispanics is extremely high compared with what is observed in other cultures (Horowitz, 1985). Caregiving and homemaking have been the way for the traditional Cuban woman to express love to her family. Caregiving for a frail elderly relative often becomes a source of pride and the only positive experience for the caregiver (Hernandez, 1992). Davis (1994) reported that caregiving holds great meaning for Puerto Rican women, is perceived as bonding and unifying, and that the caregiver role is intertwined with the women's ethnic identity.

Overall not enough information is available on minority caregivers (Clark \& Huttlinger, 1998; Cox \& Monk, 1990, Mintzer et al., 1992), and the impact of ethnicity in caregiving (Clark \& Huttlinger, 1998; Polich \& Gallager-Thompson, 1997; Tirrito \& Nathason, 1994). In a study of 118 daughters caring for mothers older than 65 years of age living in the community, Tirrito and Nathason (1994) compared the quality of the relationships between the daughters and their elderly mothers in six ethnic groups: Asian, Black, Hispanic, Irish, Italian, and Jewish. The sample number varied between 13 for Blacks and 29 for Irish. The authors measured closeness-interaction, values, perception of burden, filial assistance, and role strain. Results indicated that daughters from extended family (Asian, Black, and Hispanic) had higher scores for closeness and filial assistance and the closer the relationship, the greater assistance the daughters provided their mothers. Level of assistance was associated with burden and all daughters suffered strain and burden.

In a comparison between 31 Black and 19 Hispanics (11 were born in Puerto Rico) caregivers of dementia victims, Cox and Monk (1990) found that both groups believed that parents should expect children to assist them, but Hispanics felt more 
strongly that children should live close to the parents and assist them on daily tasks. The use of professional help by Hispanics implied to them that the caregiver was not assuming proper responsibility. Mean scores for depression were also higher for Hispanics than for Blacks and above the norm for Puerto Ricans suggesting that they were clinically depressed.

In a more recent study, the same authors found that from a sample of 86 Hispanic caregivers most of them agreed that children's duties are to assist their parents, that married children should live close to parents to provide care, and that parents should expect adult children to assist them. When attitudes were correlated with feelings of burden and depression, the authors found that people who more strongly supported the norm of performing tasks for the patient, and those more against using professional assistance were more depressed. A moderate correlation between feelings of burden and the preference for professional help was explained by suggesting that caregivers seeking professional assistance were doing so because of increased stress (Cox \& Monk, 1993).

Tran (1997) compared caregiving stress, measured by the question "Is having to take care of a sick spouse or relative a serious problem for you these days?", as one of five social stress variables between elderly Mexican, Cuban, and Puerto Rican Americans. This author found that $16 \%$ of elderly Cuban Americans experienced caregiving stress compared to $20.7 \%$ Mexican Americans, and 20.4\% Puerto Rican Americans. More recently, Delgado and Tennstedt (1997a, 1997b) studied Puerto Rican caregivers of elderly relatives. As part of one study, they interviewed 194 elderly caregivers. The majority of the caregivers were women $(79.9 \%)$, primarily daughters and wives. Over half of the caregivers did not have help with the care of the elder, and for $50 \%$ of the 
caregivers the initial reason for providing care was being available to help. The total number of hours of informal care was associated with the number of disabilities the elder had, the caregiver's gender, and relationship to the elder, and the coresidence. These authors concluded that more disabled older Puerto Ricans who had female caregivers received more informal care (Delgado \& Tennstedt, 1997a).

Hernandez (1992) reported a lack of research on elderly Cubans and their caregivers, often elderly themselves. Results from a study of the elderly in Dade county indicated that while non Cuban Hispanics almost exclusively relied on daughters for help with ADLs and IADLs, Cuban Hispanic elders received help from other relatives as well. However, daughters still constituted the most frequent helper (Goltsin, 1998).

Mintzer and collaborators (1992) conducted a comparison study of CubanAmerican and White non-Hispanic daughters caring for their mothers suffering from Alzheimer's disease. The authors reported that to their knowledge this was the first empirical study to compare Cuban-American Caregivers with White non-Hispanic while controlling socioeconomic factors. Results showed that Cuban-American daughters had more symptoms of depression than the White non-Hispanic matched patients but no statistical difference was found in the level of caregiver depression. The principal finding of this study was that the Cuban-Americans daughters were maintaining their mothers at home. The authors suggested that ethnicity should be considered a potential mediating variable in future caregiving research Acculturation and caregiving

Cubans' original intention was to return to Cuba after the fall of Fidel Castro's regime. Therefore, they resisted acculturation by the development of social networks to 
preserve their cultural values (Tacher, 1987). This is supported by results obtained by Krause and Goldenhar (1992) who reported that Cuban-Americans were less likely to use English than other Hispanic groups. Nevertheless, many authors agree that values and attitudes for Cubans, as for other ethnic groups, are evolving attributes that manifest themselves as reflections of the interaction between mainstream and traditional ethnic cultures (Queralt, 1984; Szapocznik, Scopetta, Kurtines, \& Arnalde, 1978; Szapocznik, Kurtines, \& Fernandez, 1980).

Acculturation seems to affect some of the dimensions of familism among Hispanics. Familial obligations defined as the perceived obligation to provide material and emotional support to members of extended family, and the family as behavioral and attitudinal referents have a strong negative correlation with acculturation. The same study showed that some familism values were still statistically different between highly acculturated Hispanics and White non-Hispanics (Sabogal, Marin, Otero-Sabogal, Marin. \& Perez-Stable, 1987).

Several studies indicate that acculturation affects other types of behavior that could in turn influence family caregiving in Hispanics. Acculturation has been found to be associated with decision making roles in Mexican-American wives (O'Guinn, Imperia, \& MacAdams, 1987), intergenerational conflict and disruption of the traditional family (Szapocznik, Kurtines, \& Fernandez, 1980), financial strain and increased social isolation (Krause \& Goldenhar, 1992), coping strategies (Mena, Padilla, \& Maldonado, 1987), and parents' expectations of assistance from their children (Cox \& Gelfand, 1987). In the particular case of Cuban-Americans living in Dade county biculturism, defined as the ability of the individual to interact within two cultural contexts effectively, may reduce 
detrimental effects of acculturation (Szapocznik, Kurtines, \& Fernandez, 1980).

Regardless of the evidence suggesting a relationship of acculturation and familism, only one recent empirical study approaches the relationship between acculturation and caregiving using a scale to measure acculturation (Polich \& Gallagher-Thompson, 1997).

These investigators examined the role of acculturation, caregiver burden, and family support in predicting depression in a sample of 42 Hispanic caregivers of relatives with Alzheimer disease. Interestingly the authors found that neither acculturation or years in the U.S. predicted depression. However two indicators of burden, perceived impact of caregiving on health of the caregiver and dissatisfactions with family support predicted depression.

Measurement of acculturation. The simplest measure of acculturation among Hispanics just provides a label of Hispanics versus non-Hispanics (Dana, 1996). Other more complicated psychometric methods have been developed for different populations of Hispanics such as Mexican Americans (Cuellar, Harris \& Jasso, 1980; and Cuellar, Arnold \& Maldonado, 1995), Cuban Americans (Szapocznik, Kurtines, \& Fernandez, 1980), and Mexican, Central-Americans (Marin, Sabogal, Marin, Otero-Sabogal, \& Perez-Stable, 1987, Marin \& Gamba, 1996).

Marin and collaborators (1987) developed a short acculturation scale for Hispanics. The instrument was developed using factor analysis of responses provided by 363 Hispanics and 228 non-Hispanics. Of the Hispanic sample, 44\% were MexicanAmericans, $6 \%$ were Cubans, $2 \%$ were Puerto Ricans, and $47 \%$ were other Hispanics, mostly from Central America.

The Hispanic factor analysis produced three factors that accounted for $67.6 \%$ of 
the total variance. The first factor, labeled "Language Use and Ethnic Loyalty" accounted for $54.5 \%$ of the variance. The second factor, "media" accounted for $7 \%$ of the variance, and the third factor, "Ethnic Social Relations" accounted for $6.1 \%$ of the variance. The final instrument consisted of 12 items. Five items loaded heavily on language (alpha coefficient of 0.90 ), three items loaded on the second factor (alpha coefficient of 0.86 ), and four items in factor three (alpha coefficient of 0.78). Alpha coefficient for the 12 items was 0.92 . These coefficients are similar to the ones reported for other Hispanic acculturation scales (Marin, Sabogal, Marin, Otero-Sabogal, \& Perez-Stable, 1987).

The 12-item scale had a high positive correlation with subjects' generation (0.65), length of residency in the United States (0.70), and ethnic self-identification (0.76). Negative correlation was obtained with the age of arrival $(-0.69)$. No differences were found between values obtained for Mexican-Americans and Central Americans. Due to the small sample size, Cubans and Puerto Ricans were not tested separately (Marin, Sabogal, Marin, Otero-Sabogal, \& Perez-Stable, 1987).

All acculturation studies should include socio-economic status. Cox and Gelfand (1987) pointed out that many differences in intergenerational assistance could be explained by the relative socio-economic status of the different ethnic groups. In a study of ethnic and gender differences in the perceived needs for social services among three elderly Hispanic groups, Tran and Dhooper (1996) found that when educational level was controlled, ethnic differences were more likely to appear among the less educated respondents. This finding was supported by Krause and Goldenhar (1992) who reported that educational attainment and financial strain were factors influencing the levels of psychological distress in elderly Hispanics. According to Lockery (1991) many differences 
in the perception of the elderly's support systems may be a result of interactions between socio-economic status, the level of the elder's need, the availability of family members, extent of acculturation, length of time in this country, and the circumstances of the group's or individual's arrival to this country.

\section{Limitations in caregiving and acculturation studies}

Caregiving and acculturation studies have some common limitations. Operational definitions of primary caregivers and burden (Schulz, 1990) and of acculturation (Negy \& Woods, 1992) vary throughout the literature. These variations account for the many instruments designed to measure the variables involved.

Deimling (1994) considered that one limitation of caregiving effects' studies have been the difficulties in distinguishing between effects caused directly by the caregiving activities and effects not related to caregiving. George and Gwyther (1986) discussed the advantages of using measurements constructed to evaluate the general population. This would permit comparisons between caregivers and the general population, and between caregivers and non-caregivers of similar demographic characteristics. These authors argued that because specific caregiver measurements are designed for this population they cannot be used with non-caregivers, therefore assessment of relative burden associated with caregiving cannot be determined.

Another limitation for caregiving specific assessments that these authors discussed was the inability to relate the stressor independently (caregiving) to the outcome (impact). This effect occurs because the instruments' design confound both variables by requiring respondents to relate the two central components (caregiving and impact). A third limitation is the inadequacy of a total summary score to measure burden (George \& 
Gwyther, 1986). This problem has been addressed by other researches who have developed multidimensional scales (Kosberg \& Cairl, 1986; Lawton, Kleban, Moss, Rovine, \& Glicksman, 1989; Novak \& Guest, 1989).

Most of the data obtained in caregiving and acculturation studies are through selfreport questionnaires. Self-report methods of gathering data give information related to the subjects' perception of their reality but it may also provide inaccurate information due to bias of the subjects, their psychological state, and their need to please the examiner (Hills Maguire, 1996). Imprecise or faulty data related to a private event may be obtained when the provider of information is the only individual observing the event (Critchfield, Tucker \& Vuchinich, 1998). Problems related with self-report may be more critical in studies involving Hispanics. Marin and Marin (1991) summarized the following potential problems in interpreting data for this population: tendency to give extreme responses instead of middle response categories in a rating scale, tendency to give acquiescence responses which is a type of extreme response in which the individual answers "yes" to any question, tendency to give socially desirable responses, and tendency to exhibit a lower level of self-disclosure. Finally, another reason for giving inaccurate information may be fear of losing benefits (Hills Maguire, 1996).

Probably the most important methodological flaw in informal caregiving research is the selection of caregivers (Barer \& Johnson, 1990). Recruitment of caregivers is difficult because of their lack of free time due to the typical demands of caregiving. Most caregivers are recruited through support groups, list of patients receiving formal support, or advertisements. These caregivers tend to be more negatively affected than caregivers in the general population. Consequently, results cannot be generalized to the general 
population (Jutras \& Lavoie, 1995; Schulz, 1990).

Another methodological weakness in caregiving research is in the approach of the researchers studying caregiving effects. Most of the authors have been concerned with measuring negative effects of caregiving (Jutras \& Lavois, 1995) without taking into consideration that negative effects may be counteracted by benefits derived from caregiving (Schulz, 1990). Caregiving positive effects may also be underestimated because of the characteristics of the instruments used in the study, which are designed to prove negative impact of caregiving for advocacy reasons (Jutras \& Lavois, 1995).

Other limitations are the cross-sectional nature of most studies, therefore, no causal relationships can be inferred; small sample size; the information obtained is mostly self-reported which could be biased or inaccurate; studies are largely focused on caregivers of dementia patients making it difficult to generalize results to caregivers of physically impaired patients (Jutras \& Lavois, 1995); caregivers of individuals in different stages of a disease process are combined in a single group; and absence of the explanation of the inclusion criteria for the samples (Raveis, Siegel, \& Sudit, 1990).

The lack of satisfactory instruments for assessing acculturation has been a problem with acculturation studies, partly due to the different operational definitions of acculturation. Although language preference and increased generational status have been used to measure acculturation, these authors point out that learning the language of the host country, does not necessarily imply the lost of ethnic cultural values. Other problems are the cut-off values attributed to the different levels of acculturation, the definitions of low versus high acculturation, and research that does not account for socio-economic status (Negy \&Woods, 1992). 


\section{CHAPTER III}

\section{Methodology}

\section{$\underline{\text { Research questions }}$}

The objective of this study was to obtain preliminary information related to the perceived effects of caregiving of the elderly among Cuban-American caregivers and to determine if acculturation influenced the perception of caregiving effects. The research questions to be answered with this study were:

(1) What are the perceived effects of caregiving of the elderly among CubanAmerican caregivers?

(2) Is there a relationship between acculturation and the perceived effects of caregiving of the elderly among Cuban-American caregivers?

\section{$\underline{\text { Subjects }}$}

A convenience sample of 30 caregivers recruited through personal contacts was used in this study. All participants were volunteers. Subjects' eligibility was determined by a six-question questionnaire (Appendixes A and B). After verifying eligibility, subjects were interviewed either at their home or at a location where they would feel comfortable. Criteria for inclusion

Subjects eligible to participate in the study met the following criteria:

- The caregiver was providing care to a family member living in the community.

- The family member being cared for was 65 years or older.

- The caregiver and the care receiver lived in the same dwelling. In some occasions the care receiver lived in an added apartment within the caregiver's house.

- The family member being cared for had not been diagnosed with some type of 
dementia.

- The family member being cared for had not been hospitalized for a major illness during the previous month.

- The caregiver and care recipient were of Cuban origin.

\section{Data collection techniques}

The principal investigator contacted known caregivers known by the researcher or referred by family, friends, or colleagues. Contact was made personally or by phone. In the cases of referred caregivers, they had previously agreed to be contacted by the principal investigator and knew they would be asked to participate in a study. Language preference was determined during the first contact. In addition, the purpose of the study and the anonymous nature of the study were explained. Afterwards, they were asked if they wanted to participate in the study and a meeting were then scheduled. Caregivers who did not meet the inclusion criteria were thanked for their cooperation.

Interviews were conducted only by the principal investigator following the same protocol. Initially, rapport with the caregiver was established by exchanging pleasantries and often meeting with the care recipient. This was followed by the interviews, which started by giving the caregiver written material in English or Spanish explaining the purpose of the study (Appendixes C and D). Language preference was confirmed and recorded. Again assurances were given concerning the protection of the anonymity of every caregiver, and their right to end their participation at anytime.

All instruments included in the questionnaire were originally constructed for caregivers to answer by checking or marking the response that applied to their situation. For this study each question was read aloud in the preferred language and each answer 
was recorded in the same language as the interview was being conducted. Questions that were not understood were explained until the caregiver could demonstrate understanding. Questions from the Carers' Assessment of Difficulties Index (CADI) were mostly the ones that needed clarification. Difficulties in understanding the meaning of some questions were more common for older caregivers, without at least some college education. All interviews were conducted without breaks. Administration of the questionnaires and instruments used were expected to take 30 to 40 minutes. However, interviews lasted from 40 to 60 minutes. During the interview most caregivers gave extended information about their feelings, families, and friends beyond the scope of this study. On these occasions, after accepting these concerns as legitimate, the interviewer carefully redirected the caregiver back to the questionnaire. Most encounters lasted approximately 2 hours.

\section{Instruments}

A self-report instrument (caregiver questionnaire) was developed to collect data for this study. The instrument, with a brief description of the study, were translated into Spanish through a double translator procedure (Brislin, 1970). According to Marin and Marin (1991) this procedure, although not without limitations, may be the best translation method available. The English and Spanish versions of the questionnaire are included in Appendixes $\mathrm{E}$ and $\mathrm{F}$. The questionnaire consisted of five sections.

Section I contained questions regarding caregiver and care receiver demographics, and how the family is managing the caregiving situation. Section II consisted of the Patient-Caregiver Functional Unit Scale (PCFUS) (Fredman \& Daly, 1998). This instrument is a self-report scale designed to measure the stability of the caregiving dyad. The core of this instrument is the Katz ADL/IADL scale (Katz, Ford, Moskowitz, 
Jackson, \& Jaffe, 1963) which measures the functional status of elders living in the community. Section III addressed the caregivers' perceived difficulties of caregiving measured by a version of the Carers' Assessment of Difficulties Index (CADI) (Nolan \& Grant, personal communication). This version is a modification of the original CADI published by Nolan and Grant in 1992. Section IV contained the Carers' Assessment of Satisfaction Index (CASI) (Nolan \& Grant, 1992), a self-report instrument that measures perceived satisfaction of caregiving. At the end of section IV, three open-ended questions were included to offer the caregivers the option of adding some thoughts about their caregiving role. The CADI and CASI were developed in England and were revised to guarantee that the wording was understood by subjects familiar with American English. Section V consisted of the Short Acculturation Scale for Hispanics, a self-report scale developed by Marin and collaborators (1987) to measure acculturation among Hispanics.

\section{Patient-Caregiver Functional Unit Scale (PCFUS)}

The PCFUS is a self-report instrument that measures stability of a caregiving dyad. It is based on the function of the care receiver making it useful to compare caregiving situations in which the persons being cared for have different diagnoses. This instrument focuses on concrete functional tasks taken from the Katz ADL/IADL scale. The PCFUS measures the care receiver's functional ability, amount of help provided by the caregiver for $14 \mathrm{ADL} / \mathrm{IADL}$ tasks, and if helping with each task is emotionally and/or physically difficult for the caregiver (Daly \& Fredman, 1998). The value of the PCFUS is that it identifies possible mismatches between the care receiver's needs and the caregiver's emotional and/or physical difficulties in providing help with each ADL and IADL. A higher degree of mismatches between the caregiver and the care receiver suggests a more 
unstable caregiving dyad (Daly \& Fredman, 1998).

Scoring of the PCFUS. Care receivers are given scores depending on the degree of independence in performing each $\mathrm{ADL} / \mathrm{IADL}$ task. Performing independently scores " 2 ", if the care receiver needs help, the score is " 1 ", and if the care receiver is completely dependent, the score is " 0 " for the task. For each task the caregiver provides help the score is " 1 " and the score is " 0 " if no help is provided. If the task is physically or emotionally difficult it scores "- 1 ", if the task is not emotionally and physically difficult it scores " 0 ", and if the task is both the score is " -2 " for the task. A total global score is calculated by a computer algorithm. Global scores range from +28 meaning a stable caregiving dyad to -28 for an unstable caregiving dyad (Daly \& Fredman, 1998).

\section{Carers' Assessment of Difficulties Index (CADI)}

This is a self-report questionnaire that measures the caregivers' perceived difficulties of caregiving. The instrument consists of 30 statements and the caregiver checks if the statement does not apply and if it applies, how stressful the item is: not stressful, stressful, or very stressful. The caregiver may also add other difficulties and rate them. A total score for CADI was determined by taking the average of all applicable items. Caregivers with higher scores meant more stress from difficulties associated with caregiving.

\section{Carers' Assessment of Satisfaction Index (CASI)}

This is a self-report questionnaire that measures the caregiver's perceived satisfaction with caregiving. The instrument consists of 30 statements and the caregiver checks if the statement applies and if it does, how satisfying the item is: Of no real satisfaction, providing quite a lot of satisfaction, or providing a great deal of satisfaction. 
The caregiver may also add and rate other aspects that give them satisfaction. A total score for CASI was determined by taking the average of all applicable items. Caregivers with a higher score meant more satisfaction associated with caregiving.

\section{Short Acculturation Scale for Hispanics (SASH)}

This is a self-report questionnaire that measures acculturation among Hispanics (Marin, Sabogal, Marin, Otero-Sabogal, \& Perez-Stable, 1987). It is a 12-item Likertformat instrument (between 1-5) developed using factor analysis. Items are grouped in three factors: language use (5 items), media ( 3 items), and ethnic social relations ( 4 items). Language items and media questions are answered on a scale ranging from "Only Spanish" (1) to "Only English" (5). Ethnic social relations questions are answered on a scale ranging from "All Latinos/Hispanics" (1) to "All Americans" (5). Lower global scores indicate individuals closer to Hispanic/Latino culture (less acculturized) and higher scores indicate individuals closer to American mainstream culture (more acculturized)

\section{$\underline{\text { Research design }}$}

\section{Type of design}

This investigation was a non-experimental study with a correlational design because the purpose was to establish the relationship between the variables of interest.

\section{Variables}

The primary variables in this study were acculturation (independent variable) and the effects of caregiving for the elderly among Cuban-American caregivers. The effects of caregiving were measured as stability of the caregiving dyad (PCFUS), negative effects (difficulties) of caregiving (CADI), and positive effects (satisfactions) of caregiving (CASI). 
To decrease confounding factors, the inclusion criteria ensured that care receivers were at least 65 years old, lived in the same dwelling as the caregiver, had not been diagnosed with any type of dementia, and had not suffered a major change in medical condition during the 30 days prior to the interview.

Because caregiving effects and acculturation factors are related to socioeconomic factors, demographic information was included about the caregivers and care receivers such as gender and age, racial identification, religion, educational level of the caregiver, and household income. Other information pertinent to acculturation among Cuban immigrants was obtained: place of birth, year and age of arrival to the U. S., and length of stay in the U. S. Similarly to other authors, a residence index was calculated by dividing the caregiver's length of stay in the U.S. by the caregiver's current age ( Marin et al., 1987; Szapocznik et al., 1978; Triandis et al., 1982). In addition, questions regarding family support were included because of their potential influence on the effects of caregiving.

\section{Statistical analysis}

Data was coded for processing and SPSS software was used for statistical analysis. All answers in Spanish were translated into English using the same double translation method described previously. Open-ended questions were categorized and frequency of each category was calculated. Descriptive statistics were calculated for all demographic data, acculturation, caregiver-care receiver stability, caregivers' difficulties, and caregivers' satisfaction. Cronbach's alpha was calculated to determine reliability of the acculturation scale. Validity of the scale was determined by correlating total acculturation (total SASH), and the three factors: language, electronic media, and social relations with 
other variables used as acculturation indicators: age of arrival, language chosen for the interview, and residence index calculated as the length of stay in the U. S. divided by current age (Marin et al., 1987; Szapocznik et al., 1978; Triandis et al., 1982).

To answer the first research question total scores, frequencies and central tendency measures were determined for acculturation, stability of the caregiving dyad, difficulties, and satisfaction.

To establish if there was a relationship between acculturation and the effects of caregiving for elderly Cuban-Americans, a Pearson correlational analysis was performed between acculturation and the three dependent variables: stability of the caregiving dyad, difficulties, and satisfaction. Multiple regressions were calculated to determine if acculturation could explain the variation in caregivers' difficulties and satisfaction. Stability of the caregiving dyad was added to these equations since it may influence the perceived effects of caregiving.

\section{Limitations of the study}

One important limitation of this study was the small size of the sample $(n=30)$. Other limitations were derived from the use of self-report measures for gathering data and the use of a convenient sample of caregivers personally contacted or referred to the principal investigator. Caregivers selected through this procedure did not constitute a representative sample of caregivers of Cuban origin. The sample did not include caregivers of Cuban origin born in the United States. In addition, the degree of acculturation of the participants could be characterized as mostly Hispanic as determined by SASH. Scores were concentrated at the more Hispanic end of the acculturation continuum. These limitations do not permit generalizations beyond the scope of this study. Finally, because 
of the correlational design of the study, only associations between the variables were established but cause-effect relationships were not demonstrated. 


\section{CHAPTER IV}

\section{Results}

The purpose of this study was to obtain preliminary information concerning the effects of caregiving for elderly relatives among Cuban-Americans and the possible relationship between acculturation and the perceived impact of caregiving on the caregiver. Demographic information, characteristics of the caregiving situation, stability of the caregiving dyad, perceived difficulties and satisfactions of caregiving, and acculturation were measured.

\section{Demographic data}

\section{Caregiver information}

Thirty caregivers participated in this study. Twenty-eight of the participants were female (93.3\%) and $2(6.7 \%)$ were male. Subjects' ages ranged from 40 to 80 years old, with the average age being $59.2(\mathrm{SD}=10.6)$. Twenty-nine caregivers identified themselves as White $(96.7 \%)$ while one $(3.3 \%)$ self-identified as "mulatto." Twenty-four $(80 \%)$ were Catholic.

Of the 30 caregivers, $9(30.0 \%)$ had graduated from college and $5(16.7 \%)$ had post-graduate college. Of the rest, $2(6.7 \%)$ had completed less than eight years of schooling, 5 (16.7\%) had not completed high school, $2(6.7 \%)$ had graduated from high school, $2(6.7 \%)$ had some post-high school education or trade school, and $5(16.7 \%)$ had some college. Fifteen caregivers (50\%) were employed full time, $3(10 \%)$ were employed part time, $7(23.3 \%)$ were retired with benefits and working some and one $(3.3 \%)$ was retired receiving benefits but not working, $2(6.7 \%)$ were unemployed without benefits, and $2(6.7 \%)$ were housewives. 
Twenty-eight caregivers gave information about household income. Only one (3.6\%) of them had a household income less than $\$ 10,000$ a year, and $4(14.3 \%)$ had more than $\$ 50,000$. The other 23 caregivers reported household income ranging from $\$ 10,000$ to $\$ 49,999(82.1 \%)$. Caregivers' demographic information is summarized in Table 1 . 
Table 1

Caregiver Demographic Information $(n=30)$

\begin{tabular}{|c|c|c|}
\hline Characteristics & $\mathrm{n}$ & $\%$ \\
\hline \multicolumn{3}{|l|}{ Gender } \\
\hline Male & 2 & 6.7 \\
\hline Female & 28 & 93.3 \\
\hline \multicolumn{3}{|l|}{ Age } \\
\hline $40-49$ & 5 & 16.7 \\
\hline $50-59$ & 9 & 30.0 \\
\hline $60-69$ & 11 & 36.7 \\
\hline $70-79$ & 4 & 13.3 \\
\hline 80 and older & 1 & 3.3 \\
\hline \multicolumn{3}{|l|}{ Racial group } \\
\hline White & 29 & 96.7 \\
\hline Other (Mixed "mulatto") & 1 & 3.3 \\
\hline \multicolumn{3}{|l|}{ Religion } \\
\hline Catholic & 24 & 80.0 \\
\hline Protestant & 3 & 10.0 \\
\hline Other & 1 & 6.7 \\
\hline None & 2 & 3.3 \\
\hline \multicolumn{3}{|l|}{ Education level } \\
\hline Less than 8 years & 2 & 6.7 \\
\hline Did not complete high school & 5 & 16.7 \\
\hline Graduated from high school & 2 & 6.7 \\
\hline Some post high school/trade school & 2 & 6.7 \\
\hline Some college & 5 & 16.7 \\
\hline Graduated from college & 9 & 30.0 \\
\hline Post-graduate college & 5 & 16.7 \\
\hline \multicolumn{3}{|l|}{ Employment status } \\
\hline Employed full time & 15 & 50.0 \\
\hline Employed part time & 3 & 10.0 \\
\hline Unemployed without benefits & 2 & 6.7 \\
\hline Retired (with benefits \& working some) & 1 & 3.3 \\
\hline Retired (with benefits, but not working) & 7 & 23.3 \\
\hline Housewife & 2 & 6.7 \\
\hline
\end{tabular}


Table 1. (continued)

\begin{tabular}{lcr}
\hline Characteristics & $\mathrm{n}$ & $\%$ \\
\hline Income $^{\mathrm{a}}$ & & \\
Less than $\$ 9,999$ & 1 & 3.6 \\
$\$ 10,000-\$ 14,999$ & 8 & 28.6 \\
$\$ 15,000-\$ \$ 29,999$ & 6 & 21.4 \\
$\$ 30,000-\$ 39,999$ & 3 & 10.7 \\
$\$ 40,000-\$ 49,999$ & 6 & 21.4 \\
$\$ 50,000$ or more & 4 & 14.3 \\
\hline
\end{tabular}

${ }^{a}$ Total $\mathrm{n}=28$

Demographic information related with acculturation was also gathered (Table 2).

Of the 30 caregivers, $9(30.0 \%)$ chose to answer the interview in English. All 30

caregivers were born in Cuba. Thirteen caregivers (43.3\%) arrived in the U.S. between the ages of 20 and 29 years old. Five arrived (16.7\%) younger than 20 years old, $4(13.3 \%)$

arrived between 30 and 39 years old, $7(23.3 \%)$ between 40 and 49 , and one (3.3\%)

between 50 and 59 years old. The average age of arrival was 30.2 years $(\underline{S D}=12.5)$.

Twenty-eight caregivers (93.3\%) arrived in the U.S. after the 1959 Cuban Revolution and $24(80.0 \%)$ arrived before the Mariel boatlift of 1980 . Average length of stay determined as the years lived in the U.S. was 29.3 years $(\underline{\mathrm{SD}}=10.5)$. 
Table 2

Caregiver Acculturation Information ( $\mathrm{n}=30$ )

\begin{tabular}{lrr}
\hline \multicolumn{1}{c}{ Variable } & $n$ & $\%$ \\
\hline Language chosen for the interview & & \\
English & 21 & 70.0 \\
Spanish & & \\
Age of arrival to the U.S. & 2 & 6.7 \\
$0-9$ & 3 & 10.0 \\
$10-19$ & 13 & 43.3 \\
$20-29$ & 4 & 13.3 \\
$30-39$ & 7 & 23.3 \\
$40-49$ & 1 & 3.3 \\
$50-59$ & & \\
Year of arrival to the U.S. & & \\
Before 1959 & 2 & 6.7 \\
Between 1959 and 1961 & 3 & 10.0 \\
Between 1962 and 1965 & 9 & 30.0 \\
Between 1966 and 1973 & 9 & 30.0 \\
Between 1974 and 1979 & 9 & 3.3 \\
Between 1980 and 1989 & 1 & 16.7 \\
After 1990 & 5 & 3.3 \\
\hline
\end{tabular}


The first section of the interview included questions regarding the care receiver, caregiving situation, caregiving tasks, caregivers family support systems. These results are summarized in Tables 3 to 9.

Care receivers' information

The age of care recipients ranged from 68 to 95 years old with an average of 83.4 years $(\underline{S D}=7.4)$. Twenty-two $(73.3 \%)$ of the care recipients were female. Twenty-one (70.0\%) were caring for a parent and of them $19(90.5 \%)$ were daughters. Five (16.7\%) were caring for their husbands (Table 3).

Table 3

Characteristics of the care receivers $(n=30)$

\begin{tabular}{lrr}
\hline \multicolumn{1}{c}{ Characteristics } & $\mathrm{n}$ & $\%$ \\
\hline Age of the care receiver & 1 & 3.3 \\
$65-69$ & 9 & 30.0 \\
$70-79$ & 10 & 33.3 \\
$80-89$ & 10 & 33.3 \\
90 and older & & \\
Gender of the care receiver & 8 & 26.7 \\
Male & 22 & 73.3 \\
Female & & \\
Relationship of the care receiver to the caregiver & 21 & 70.0 \\
Parent & 5 & 16.7 \\
Husband & 2 & 6.7 \\
Mother or father-in-law & 2 & 6.7 \\
Other & & \\
\hline
\end{tabular}


Duration of caregiving. Twenty-eight (93.3\%) of the participants had been caring for their elderly relative for longer than a year, one (3.3\%) for less than one year but longer than six months, and one $(3.3 \%)$ for less than six months but longer than one month.

Common reasons for becoming a caregiver. Caregivers gave more than one reason for assuming the caregiving role. The most common reasons are summarized in Table 4 . Eight $(26.7 \%)$ felt that no other relative would be willing to take the role. Seven $(23.3 \%)$ were relatives that had always lived with their elderly relative. Six (20.0\%) stated that no other daughters were available. Five $(16.7 \%)$ gave as the reason that they were the spouses.

Table 4

Most Common Reasons for Becoming a Caregiver $(n=30)$

\begin{tabular}{llc}
\hline \multicolumn{1}{c}{ Reasons } & $\mathrm{n}$ & $\%^{\mathrm{a}}$ \\
\hline No other relative able or willing & 8 & 26.7 \\
Always lived together (does not include spouse) & 7 & 23.3 \\
No other daughters available & 6 & 20.0 \\
Spouse & 5 & 16.7 \\
Other & 6 & 20.0 \\
\hline
\end{tabular}

${ }^{\mathrm{a}}$ Percentages add to more than $100 \%$ because more than one answer was possible. 
Caregivers' tasks. The most common tasks associated with caregiving are listed in Table 5. Eleven (36.7\%) of the caregivers reported that giving medication and providing transportation were tasks that they did that defined them as caregivers. Other tasks were helping with household chores $(n=8,26.7 \%)$, helping with $\operatorname{ADLs}(n=7,23.3 \%)$, and accompanying their relative to medical appointments $(n=6,20.0 \%)$. In addition 12 $(40.0 \%)$ of the caregivers or care receivers had to move in order to facilitate caregiving, and 18 caregivers $(60.0 \%)$ had to modify the home in some way to accommodate their elderly relative (Table 6).

Table 5

Caregiving Tasks $(n=30)$

\begin{tabular}{lcc}
\hline \multicolumn{1}{c}{ Tasks } & $\mathrm{n}$ & $\%^{\mathrm{a}}$ \\
\hline Give medications & 11 & 36.7 \\
Provide transportation & 11 & 36.7 \\
Help with household chores & 8 & 26.7 \\
Help with ADLs & 7 & 23.3 \\
Accompany to medical appointments & 6 & 20.0 \\
Legal guardian & 3 & 10.0 \\
Financial aid & 2 & 6.7 \\
\hline
\end{tabular}

${ }^{\mathrm{a}}$ Percentages add to more than $100 \%$ because more than one answer was possible. 
Table 6

Environmental Accommodations for Caregiving ( $\mathrm{n}=30$ )

\begin{tabular}{lll}
\hline \multicolumn{1}{c}{ Accommodations } & $\mathrm{n}$ & $\%$ \\
\hline Caregiver or care receivers & & \\
Needing to move & 12 & 40.0 \\
Not needing to move & 18 & 60.0 \\
Caregivers that & & \\
$\quad$ Made environmental modifications & 18 & 60.0 \\
Did not make environmental modifications & 12 & 40.0 \\
\hline
\end{tabular}

Family support. Twenty-one caregivers (70.0\%) felt that they had relatives who shared with the caring of the care receivers, and twenty caregivers $(66.7 \%)$ felt that if they were unavailable there were relatives able to take over (Table 7). Twelve $(57.1 \%)$ of the 21 caregivers felt that the same relatives that shared with the caregiving would take over the care receivers' care if they were unavailable.

Table 7

Availability of Family Support for the Caregivers $(n=30)$

\begin{tabular}{lrr}
\hline \multicolumn{1}{c}{ Support } & $\mathrm{n}$ & $\%$ \\
\hline Caregivers & & \\
$\quad$ With relatives who share caregiving & 21 & 70.0 \\
With no relatives to share caregiving & 9 & 30.0 \\
Caregivers & & \\
$\quad$ With relatives able to takeover & 20 & 66.7 \\
$\quad$ With no relatives able to takeover & 10 & 33.3 \\
\hline
\end{tabular}


Daughters were the relatives most involved in sharing or available to take over.

Eight daughters (28.6\%) out of 28 relatives were sharing with caregiving, and $10(50.0 \%)$ daughters out of 20 were available to take over if needed. Other relatives involved with sharing were sons in law $(21.4 \%)$, husbands (14.3\%), and grandchildren (14.3\%). Less frequently involved in sharing and availability for taking over were sons, nieces, nephews, sisters, and daughters in law (Table 8).

Table 8

Care Receiver Relatives Able to Share and/or Take Over with Caregiving

\begin{tabular}{lcr}
\hline \multicolumn{1}{c}{ Relatives } & $\mathrm{n}$ & $\%$ \\
\hline Available to share $(\mathrm{n}=28)$ & & \\
Daughter & 8 & 28.6 \\
Son-in-law & 6 & 21.4 \\
Husband & 4 & 14.3 \\
Grandchild & 4 & 14.3 \\
Son & 2 & 7.1 \\
Niece/nephew & 2 & 7.1 \\
Sister & 1 & 3.6 \\
Daughter-in-law & 1 & 3.6 \\
Available to take over $(\mathrm{n}=20)$ & & \\
Daughter & & 50.0 \\
Son & 10 & 15.0 \\
Grandchildren & 3 & 10.0 \\
Son-in-law & 2 & 10.0 \\
Husband & 2 & 5.0 \\
Daughter-in-law & 1 & 5.0 \\
Niece & 1 & 5.0 \\
\hline
\end{tabular}


Tasks in which relatives help are summarized in Table 9 . The most common role performed by other relatives sharing with the care of their elderly relative was taking over for brief periods of time. This was reported in eight of the situations (28.6\%). In the same proportion relatives shared with helping with the ADLs of the care recipient. In five situations $(17.8 \%)$ the relative sharing provided company to the elderly relative. Other tasks were to help with household chores (10.7\%), and provide transportation (10.7\%).

Two out of the 28 relatives $(7.1 \%)$ provided emotional support to the caregivers, one (3.6\%) provided financial help, and one (3.6\%) gave medication.

Table 9

Caregiving Tasks of Relatives Sharing with Caregiving $(n=28)$

\begin{tabular}{lll}
\hline \multicolumn{1}{c}{ Tasks } & $\mathrm{n}$ & $\%^{\mathrm{a}}$ \\
\hline Taking over for brief periods of time & 8 & 28.6 \\
Helping with ADLs & 8 & 28.6 \\
Providing company & 5 & 17.8 \\
Helping with household chores & 3 & 10.7 \\
Providing transportation & 3 & 10.7 \\
Providing emotional support to caregiver & 2 & 7.1 \\
Providing financial help & 1 & 3.6 \\
Giving medication & 1 & 3.6 \\
\hline Percentages add to more than $100 \%$ because more than one answer was possible.
\end{tabular}




\section{Perceived effects of caregiving}

To answer the first research question of this study, the perceived effects of caregiving were determined by measuring the stability of the caregiving dyad (PCFUS), the caregivers' difficulties and the level of stress they caused (CADI), and the caregivers' satisfaction (CASI).

\section{Stability of the caregiving dyad}

The stability of the caregiving dyad was determined using the Patient Care Functional Unit Scale (PCFUS). Caregivers answered questions related to the ability of the care receiver to perform fourteen ADLs/IADLs tasks without help, with some help or unable to perform the task.

Excepting use of the telephone, care receivers required more assistance with IADLs than with ADLs. Shopping, traveling, and housework were the tasks with which most care receivers required at least some help. Fifteen (50.0\%) required some help with shopping, and the other $15(50.0 \%)$ were completely unable to do any shopping. Twentyseven $(90.0 \%)$ required some help with traveling, and $2(6.7 \%)$ were unable to travel without special arrangements. Similarly, $9(30.0 \%)$ care receivers needed some help with housework, and $19(63.3 \%)$ were completely unable to do any housework.

Of all the ADLs, bathing was the task care receivers required most help with. Eight (26.7\%) needed some help, and $12(40 \%)$ were completely unable to bathe by themselves. Need of at least some help for all other ADLs ranged from 30 to $53.3 \%$. Dependency of the care receiver can also be estimated by the number of tasks for which they needed assistance. Care receivers needed help on an average with 9.0 out of 14 tasks $(\mathrm{SD}=3.6)$. A summary of these results can be found in Table 10 . 
Table 10

Degree of Help that Care Receivers Need to Perform ADLs and IADLs Tasks Determined by the PCFUS $(n=30)$

\begin{tabular}{|c|c|c|c|c|c|c|c|}
\hline & \multirow[b]{3}{*}{ Tasks } & \multicolumn{6}{|c|}{ Ability of care receiver to do the task } \\
\hline & & \multicolumn{2}{|c|}{ Without help } & \multicolumn{2}{|c|}{ With some help } & \multicolumn{2}{|c|}{ Unable to do } \\
\hline & & $n$ & $\%$ & $\mathrm{n}$ & $\%$ & $\mathrm{n}$ & $\%$ \\
\hline \multirow[t]{7}{*}{ IADLs } & Telephone & 15 & 50.0 & 12 & 40.0 & 3 & 10.0 \\
\hline & Travel & 1 & 3.3 & 27 & 90.0 & 2 & 6.7 \\
\hline & Shop & 0 & 0 & 15 & 50.0 & 15 & 50.0 \\
\hline & Meal & 7 & 23.3 & 8 & 26.7 & 15 & 50.0 \\
\hline & Housework & 2 & 6.7 & 9 & 30.0 & 19 & 63.3 \\
\hline & Medicines & 6 & 20.0 & 21 & 70.0 & 3 & 10.0 \\
\hline & Finances & 7 & 23.3 & 10 & 33.3 & 13 & 43.3 \\
\hline \multirow[t]{7}{*}{ ADLs } & Feed & 17 & 56.7 & 8 & 26.7 & 5 & 16.7 \\
\hline & Dress & 14 & 46.7 & 9 & 30.0 & 7 & 23.3 \\
\hline & Groom & 17 & 56.7 & 6 & 20.0 & 7 & 23.3 \\
\hline & Walk & 14 & 46.7 & 8 & 26.7 & 8 & 26.7 \\
\hline & Transfer & 21 & 70.0 & 3 & 10.0 & 6 & 20.0 \\
\hline & Bathe & 10 & 33.3 & 8 & 26.7 & 12 & 40.0 \\
\hline & Toilet & 18 & 60.0 & 11 & 36.7 & 1 & 3.3 \\
\hline
\end{tabular}


When caregivers were asked if they helped with the previous 14 tasks, 28 (93.3\%) said they helped with shopping, $27(90.0 \%)$ with traveling, $26(86.7 \%)$ with housework. Only $9(30.0 \%)$ helped with transfers and $10(33.3 \%)$ with toileting (Table 11$)$.

Table 11

ADLs and IADLs' Tasks that Caregivers Help with as Determined by the PCFUS( $n=30)$

Caregivers that help the care receiver

\begin{tabular}{llrr} 
& Tasks & $\mathrm{n}$ & $\%$ \\
\hline IADLs & Telephone & 13 & 43.3 \\
& Travel & 27 & 90.0 \\
& Shop & 28 & 93.3 \\
& Meal & 23 & 76.7 \\
& Housework & 26 & 86.7 \\
& Medicines & 24 & 80.0 \\
& Finances & 20 & 66.7 \\
\hline \multirow{2}{*}{ FDLs } & Feed & 13 & 43.3 \\
& Dress & 14 & 46.7 \\
& Groom & 13 & 43.3 \\
& Walk & 11 & 36.7 \\
& Transfer & 9 & 30.0 \\
Bathe & 15 & 50.0 \\
& Toilet & 10 & 33.3 \\
\hline
\end{tabular}


The PCFUS also evaluated the difficulty the caregivers had (or would have) in helping the care receivers with the different tasks. Tasks were rated as not difficult, physically difficult, emotionally difficult, or both (Table 12).

Table 12

Difficulties Caregivers Had (or Would Have) in Helping the Care Receiver $(n=30)$

\begin{tabular}{|c|c|c|c|c|c|c|c|c|c|}
\hline & \multirow[b]{2}{*}{ Tasks } & \multicolumn{5}{|c|}{ Type of difficulty } & Both & \multicolumn{2}{|c|}{$\begin{array}{c}\text { Total } \\
\text { caregivers } \\
\text { with } \\
\text { difficulties }\end{array}$} \\
\hline & & $\mathrm{n}$ & $\%$ & $\mathrm{n}$ & $\%$ & $\mathrm{n}$ & $\%$ & $\mathrm{n}$ & $\%$ \\
\hline \multirow[t]{7}{*}{ IADLs } & Telephone & 1 & 3.3 & 2 & 6.7 & 2 & 6.7 & 5 & 16.7 \\
\hline & Travel & 2 & 6.7 & 4 & 13.3 & 4 & 13.3 & 10 & 33.3 \\
\hline & Shop & 3 & 10.0 & 2 & 6.7 & 3 & 10.0 & 8 & 26.7 \\
\hline & Meal & 2 & 6.7 & 0 & 0 & 3 & 10.0 & 5 & 16.7 \\
\hline & Housework & 2 & 6.7 & 0 & 0 & 6 & 20.0 & 8 & 26.7 \\
\hline & Medicines & 1 & 3.3 & 2 & 6.7 & 1 & 3.3 & 4 & 13.3 \\
\hline & Finances & 1 & 3.3 & 2 & 6.7 & 1 & 3.3 & 4 & 13.3 \\
\hline \multirow[t]{7}{*}{ ADLs } & Feed & 0 & 0 & 3 & 10.0 & 4 & 13.3 & 7 & 23.3 \\
\hline & Dress & 4 & 13.3 & 4 & 13.3 & 3 & 10.0 & 11 & 36.7 \\
\hline & Groom & 0 & 0 & 4 & 13.3 & 4 & 13.3 & 8 & 26.7 \\
\hline & Walk & 5 & 16.7 & 0 & 0 & 4 & 13.3 & 9 & 20.0 \\
\hline & Transfer & 12 & 40.0 & 2 & 6.7 & 7 & 23.3 & 21 & 70.0 \\
\hline & Bathe & 5 & 16.7 & 5 & 16.7 & 5 & 16.7 & 15 & 50.0 \\
\hline & Toilet & 3 & 10.0 & 6 & 20.0 & 5 & 16.7 & 14 & 46.7 \\
\hline
\end{tabular}




\section{Caregivers' difficulty}

To determine difficulties in caregiving, subjects answered section III of the interview, which consisted of the Carers' Assessment of Difficulties Index (CADI). Caregivers were presented with thirty statements regarding difficulties associated with caregiving and for each of these statements, subjects answered if they applied to their situation or not. Statements answered as not applying to the caregiver situation were scored as " 0 ". If they applied, caregivers rated the level of stress each difficulty caused. Difficulties were rated as not stressful (1), stressful (2), and very stressful (3). Total mean score for CADI was $1.83(\underline{S D}=0.43)$ and ranged from 1 to 2.56 .

The most common difficulties as measured by the percentage of caregivers who responded stressful or very stressful are shown in Table 13. To the statement "I don't have enough private time for myself," 21 answered that it applied to them. Of these 21,15 (71.4\%) found it stressful, and $3(14.3 \%)$ found it very stressful. The statement "It restricts my social life/outside interests was answered by $21(70.0 \%)$ caregivers as applicable to them. Fourteen (66.7\%) found it stressful, and $2(9.5 \%)$ found it very stressful. To the statement "My emotional well-being suffers," 20 found that it applied to them, and of these, $10(50.0 \%)$ considered it stressful, and $7(35.0 \%)$ considered very stressful. The other common difficulty was finding caregiving physically tiring. Nineteen caregivers thought this applied to them, $14(73.7 \%)$ found this to be stressful, and 3 (15.8\%) very stressful. Caregivers answers for all CADI items appear on Appendix G. 
Table 13

Most Common Difficulties in Caregiving measured by CADI $(n=28)$

\begin{tabular}{|c|c|c|c|c|c|c|c|}
\hline \multirow{3}{*}{ Item } & \multirow{3}{*}{$\mathrm{n}$} & \multicolumn{6}{|c|}{ Level of stress } \\
\hline & & \multicolumn{2}{|c|}{ Not stressful } & \multicolumn{2}{|c|}{ Stressful } & \multicolumn{2}{|c|}{ Very stressful } \\
\hline & & $\mathrm{n}$ & $\%$ & $\mathrm{n}$ & $\%$ & $\mathrm{n}$ & $\%$ \\
\hline $\begin{array}{l}\text { I don't have enough } \\
\text { private time for myself }\end{array}$ & 21 & 3 & 14.3 & 15 & 71.4 & 3 & 14.3 \\
\hline $\begin{array}{l}\text { It restricts my social } \\
\text { life/outside interests }\end{array}$ & 21 & 5 & 23.8 & 14 & 66.7 & 2 & 9.5 \\
\hline $\begin{array}{l}\text { My emotional well-being } \\
\text { suffers }\end{array}$ & 20 & 3 & 15.0 & 10 & 50.0 & 7 & 35.0 \\
\hline It is physically tiring & 19 & 2 & 10.5 & 14 & 73.7 & 3 & 15.8 \\
\hline
\end{tabular}

Note. Two caregivers did not consider any of the 30 items applicable to them.

Caregivers were also permitted to add other difficulties that they felt were not included in the statements. These difficulties related to the added role of caring for a relative in addition to other roles $(\mathrm{n}=3)$, having to deal with a care receiver unable to handle the role change $(n=3)$, added tasks the caregiver had to do which were stressful such as handling finances for the first time $(n=1)$, tolerating otherwise unacceptable behavior of paid caretakers $(n=1)$, caring for more than one disabled relative $(n=1)$, creating more tension at home $(n=1)$. One caregiver who was herself disabled worried that her own daughter was not going to be able to take care of her when needed or care for her grandmother if she got sicker.

\section{Caregivers' satisfaction}

To determine satisfaction in caregiving, subjects answered section IV of the interview which consisted of the Carers' Assessment of Satisfaction Index (CASI). Caregivers were presented with thirty statements regarding satisfaction associated with 
caregiving. Statements could be not applicable to the caregivers situation (0) or applicable.

If they applied, caregivers rated the level of satisfaction each caused. Statements were rated as providing no real satisfaction (1), quite a lot of satisfaction (2), and a great deal of satisfaction (3). Total mean score for CASI was $2.52(\mathrm{SD}=0.33)$ and scores ranged from 1.73 to 3.00 .

The most common sources of satisfaction as measured by the percentage of caregivers responding with a lot or great deal of satisfaction are shown in Table 14. Of the seven listed, three were related to obtaining satisfaction from situations that generated a direct physical or emotional benefit to the care receiver. To the statement "I get pleasure from seeing the person I care for happy," 8 caregivers $(26.7 \%)$ described it as a source of quite a lot of satisfaction and $22(73.3 \%)$ as a source of a great deal of satisfaction. The statement "I am able to ensure that the person I care for has his/her needs tended to" had $13(43.3 \%)$ and $17(56.7 \%)$ caregivers receiving quite a lot of satisfaction and a great deal of satisfaction respectively from it. To the statement "Maintaining the dignity of the person I care for is important to me," $9(31.0 \%)$ caregivers answered that they received quite a lot of satisfaction, and $19(65.6 \%)$ a great deal of satisfaction. 
Table 14

Most Common Satisfactions in Caregiving Measured by CASI $(n=30)$

Level of satisfaction

Item $\mathrm{n}$ None Quite a lot A great deal

\begin{tabular}{lllllllr} 
& & $\mathrm{n}$ & $\%$ & $\mathrm{n}$ & $\%$ & $\mathrm{n}$ & $\%$ \\
\hline $\begin{array}{l}\text { I get pleasure from seeing the } \\
\text { person I care for happy }\end{array}$ & 30 & 0 & 0 & 8 & 26.7 & 22 & 73.3 \\
$\begin{array}{l}\text { I am able to ensure that the } \\
\text { person I care for has their }\end{array}$ & 30 & 0 & 0 & 13 & 43.3 & 17 & 56.7 \\
needs tended to & & & & & & & \\
$\begin{array}{l}\text { Maintaining the dignity of the } \\
\text { person I care for is important } \\
\text { to me }\end{array}$ & 29 & 1 & 3.4 & 9 & 31.0 & 19 & 65.6 \\
$\begin{array}{l}\text { I am able to keep the person I } \\
\text { care for out of an institution }\end{array}$ & 30 & 0 & 0 & 6 & 20.0 & 24 & 80.0 \\
$\begin{array}{l}\text { I am the sort of person who } \\
\text { enjoys helping people }\end{array}$ & 30 & 1 & 3.3 & 11 & 36.7 & 18 & 60.0 \\
$\begin{array}{l}\text { Caring is one way of } \\
\text { expressing my love for the } \\
\text { person I care for }\end{array}$ & 29 & 0 & 0 & 7 & 24.1 & 22 & 75.9 \\
$\begin{array}{l}\text { Caring enables me to fulfill my } \\
\text { sense of duty }\end{array}$ & 29 & 2 & 6.9 & 7 & 24.1 & 20 & 69.0 \\
\hline
\end{tabular}


Other statements were related with what may be considered moral issues. Six caregivers (20.0\%) derived quite a lot of satisfaction from being able to keep their relative out of an institution, while $24(80.0 \%)$ derived a great deal of satisfaction. To the statement "I am the sort of person who enjoys helping people," $11(36.7 \%)$ caregivers answered that they received quite a lot of satisfaction, and $18(60.0 \%)$ received a great deal of satisfaction from this.

Twenty-nine caregivers received satisfaction from caregiving as a way of expressing love for their relative. Of these caregivers, 7 (24.1\%) received quite a lot of satisfaction, and $22(75.9 \%)$ a great deal of satisfaction from this. Finally, caring enabled caregivers to fulfill their sense of duty. Seven caregivers reported $(24.1 \%)$ quite a lot of satisfaction, and $20(69.0 \%)$ a great deal of satisfaction respectively. Caregivers responses to all CASI statements are summarized Appendix $\mathrm{H}$.

Caregivers were also permitted to add other sources of satisfactions that they felt were not included in the statements. Three caregivers derived satisfaction from caring for their parents because they could maintain close ties with grandchildren, other relatives and friends, or because they could keep the parents together. Two caregivers received satisfaction from maintaining the household the same way their parents did. Other sources of satisfaction were companionship and having more control over the caregiving situation.

\section{Acculturation}

Acculturation was measured using the Short Acculturation Scale for Hispanics (SASH). Twelve statements grouped in three factors were answered using a Likert scale. Language preference and electronic media preference questions are answered on a scale ranging from "Only Spanish" (1) to "Only English"(5). Social relations questions are 
answered on a scale ranging from "All Latinos/Hispanics" (1) to "All Americans (5).

Lower scores indicate less acculturized or more Hispanic, higher scores indicate more acculturized or closer to American mainstream culture. Average scores for all three factors are shown on Table 15. The highest average was for the electronic media preference $\underline{\mathrm{M}}=2.56, \underline{\mathrm{SD}}=1.43)$. Total mean score for $\mathrm{SASH}$ was $1.94(\underline{\mathrm{SD}}=0.68)$. Mean scores for all items are presented in Table 16.

Table 15

Means and Standard Deviations for Acculturation on the Three Factors of the SASH $\underline{(n=30)}$

\begin{tabular}{lcccc}
\hline \multicolumn{1}{c}{ Variables } & Mean & SD & $\begin{array}{c}\text { Minimum } \\
\text { value }\end{array}$ & $\begin{array}{c}\text { Maximum } \\
\text { value }\end{array}$ \\
\hline Language & 1.52 & 0.61 & 1.00 & 5.00 \\
Electronic Media & 2.56 & 1.43 & 1.00 & 5.00 \\
Social Relations & 2.02 & 0.55 & 1.00 & 3.00 \\
Acculturation Total & 1.94 & 0.68 & 1.17 & 3.58 \\
\hline Note. Values ranged from 1= Less acculturated (more Hispanic) to 5= More acculturated \\
(More mainstream American).
\end{tabular}


Table 16

Means and Standard Deviation for Items in the Three Factors of the SASH $(n=30)$

\begin{tabular}{llcc}
\hline \multicolumn{1}{c}{ Factors } & \multicolumn{1}{c}{ Items } & Mean & SD \\
\hline Language $^{\mathrm{a}}$ & Language generally used for reading and speaking & 1.97 & 0.85 \\
& Language used as a child & 1.17 & 0.53 \\
& Language usually spoken at home & 1.30 & 0.79 \\
& Language usually used when thinking & 1.50 & 0.90 \\
& Usually spoken with friends & 1.67 & 0.99 \\
\hline Media $^{\text {a }}$ & Language of T.V. programs watched & 2.90 & 1.49 \\
& Language of radio programs listened & 2.20 & 1.69 \\
& Language preferred for electronic media & 2.57 & 1.74 \\
\hline \multirow{2}{*}{ Social Relations } & bthnicity of close friends & 1.70 & 0.75 \\
& Preferred ethnicity of social gatherings/parties & 1.90 & 0.88 \\
& Ethnicity of visitors or persons that subjects visit & 1.63 & 0.72 \\
& Preferred ethnicity of children's friends & 2.83 & 0.53 \\
\hline
\end{tabular}

${ }^{\mathrm{a}}$ Scale ranges from $1=$ Spanish only to $5=$ English only. ${ }^{\mathrm{b}}$ Scale ranges from $1=$ Only Hispanics to $5=$ Only English. 
Statistical analysis

A Cronbach's alpha coefficient for the acculturation measure (SASH) of 0.87 indicated high reliability. Cronbach's alpha for the three factors were 0.79 for language, 0.84 for electronic media, and 0.74 for social relations. In other studies (Marin et al., 1987; Marin \& Gamba, 1996; Norris, Ford \& Bova, 1996; Szapocznik, et al., 1978), validity of acculturation scales have been determined by correlating the scale with other indicators of acculturation such as English proficiency, age of arrival to the U.S., length of residence in the U.S., and generation or place of birth. In the present study total acculturation score and the three factors (language, electronic media and social relations) were correlated with the subject's choice of language for the interview as a measure of English proficiency, age of arrival to the U.S., and the residence index. Following the criteria of other authors (Marin, Sabogal, Marin, Otero-Sabogal, \& Perez-Stable 1987; Szapocznik, Scopetta, Kurtines, \& Arnalde, 1978; Triandis, Kashima, Hui, Lisansky, \& Marin, 1982), this index was made up of the caregiver's length of stay in the U.S. divided by their current age. The basis for this construct is that the length of stay varies as a function of the age. Generation was not used as a validation of acculturation because all participants in this study were born in Cuba. The subject's choice of language for the interview was considered a measure of English proficiency. Thirty percent of the caregivers chose to be interviewed in English. Results are shown in Table 17 
Table 17

Pearson Correlations between Scores on Total and Each Factor of the SASH and Other

Indicators of Acculturation ( $\mathrm{n}=30$ )

\begin{tabular}{lccccccc}
\hline \multicolumn{1}{c}{ Variables } & \multicolumn{2}{c}{ Language of choice $^{\mathrm{c}}$} & \multicolumn{2}{c}{ Age of arrival } & \multicolumn{3}{c}{ Residence index } \\
& $\mathrm{r}$ & $\mathrm{p}$ & $\mathrm{r}$ & $\mathrm{p}$ & $\mathrm{r}$ & $\mathrm{p}$ \\
\hline $\begin{array}{l}\text { SASH } \\
\text { Total }\end{array}$ & -0.727 & $<.001^{* * *}$ & -0.683 & $<.001^{* * *}$ & 0.559 & $.001 * *$ \\
Language $^{\mathrm{a}}$ & -0.665 & $<.001^{* * *}$ & -0.781 & $<.001^{* * *}$ & 0.741 & $<.001^{* * *}$ \\
& & & & & & & \\
$\begin{array}{l}\text { Electronic } \\
\text { Media }^{\mathrm{a}}\end{array}$ & -0.636 & $<.001^{* * *}$ & -0.433 & $.017^{*}$ & 0.311 & .095 \\
$\begin{array}{l}\text { Ethnic/Social } \\
\text { Relations }\end{array}$ & -0.519 & $.003^{* *}$ & -0.592 & $.001^{* *}$ & 0.428 & $.018^{*}$ \\
\hline
\end{tabular}

${ }^{\mathrm{a}}$ Scale ranges from $1=$ Only Spanish to $5=$ Only English. ${ }^{\mathrm{b}}$ Scales ranges from $1=$ All Hispanics to $5=$ All Americans; ${ }^{c} 1=$ English, $2=$ Spanish .

$* \mathrm{p}<.05{ }^{* *} \mathrm{p}<.01{ }^{* * *} \mathrm{p}<.001$

Statistically significant negative correlations were found between total acculturation score and language of choice $(r=-0.727, p<.001)$ and age of arrival to the U. S. $(r=-0.683, p<.001)$. The three factors also correlated negatively with the language of choice for the interview and the age of arrival to the U. S. Except for the correlation between the media factor and the age of arrival $(r=-0.433, p=.017)$, all these correlations were highly significant $(p<.001)$. Highly significant positive correlations were found between total acculturation score and residence index $(r=0.559, p=.001)$. The language factor also had a highly significant correlation with the index $(r=0.741, p<.001)$. Social relations and the residence index had a significant positive correlation $(r=0.428, p=.018)$. These results indicated that caregivers who arrived at a younger age to the U. S., had a larger residence index either by having lived 
longer in the U.S. and/or being younger at the time of the study, and chose English as the language to be interviewed in are more acculturated or less Hispanic.

Relationship between acculturation and the effects of caregiving

Correlations were calculated between all variables to determine the pairwise relationship between acculturation (SASH), caregiver-care receiver stability (PCFUS), perceived caregivers' difficulties (CADI), and satisfaction (CASI) (Table 18). 
Table 18

Pearson Correlations between Total Each Acculturation Factor (SASH), Caregiving

Stability (PCFUS), Caregivers' Difficulties (CADI), and Caregivers' Satisfaction (CASI)

\begin{tabular}{|c|c|c|c|c|c|c|}
\hline & \multicolumn{6}{|c|}{ Pearson correlations of variables } \\
\hline & \multicolumn{2}{|c|}{$\begin{array}{l}\text { Caregiving } \\
\text { stability }^{\mathrm{f}}\end{array}$} & \multicolumn{2}{|c|}{$\begin{array}{l}\text { Caregivers' } \\
\text { difficulties }\end{array}$} & \multicolumn{2}{|c|}{$\begin{array}{l}\text { Caregivers' } \\
\text { satisfaction }\end{array}$} \\
\hline & r & $\mathrm{p}$ & $r$ & $\mathrm{p}$ & $r$ & $\mathrm{p}$ \\
\hline $\begin{array}{l}\text { Total } \\
\text { acculturation }\end{array}$ & -0.163 & .047 & 0.319 & .872 & -0.369 & .053 \\
\hline $\begin{array}{l}\text { Language } \\
\text { factor }^{b}\end{array}$ & -0.277 & .154 & 0.294 & .129 & -0.275 & .156 \\
\hline $\begin{array}{l}\text { Media } \\
\text { factor }^{b}\end{array}$ & -0.194 & .129 & -0.390 & .844 & -0.329 & .087 \\
\hline $\begin{array}{l}\text { Social relation } \\
\text { factor }{ }^{\circ}\end{array}$ & 0.152 & .441 & -0.187 & .341 & -0.355 & .064 \\
\hline $\begin{array}{l}\text { Caregivers' } \\
\text { difficulties }\end{array}$ & -0.642 & $<.001 * * *$ & & & & \\
\hline $\begin{array}{l}\text { Caregivers' } \\
\text { satisfaction }\end{array}$ & 0.222 & .255 & 0.302 & .118 & & \\
\hline
\end{tabular}

${ }^{a}$ SASH scores range from 1 (not acculturized) to 5 (completely acculturized). ${ }^{b}$ Scale ranges from $1=$ Only Spanish to $5=$ Only English. ${ }^{\circ}$ ranges from $1=$ All Hispanics to $5=$ All Americans. ${ }^{d}$ CADI scores range from $1=$ Not stressful to $3=$ Very stressful. ${ }^{e}$ CASI scores range from $1=$ No real satisfaction to $3=$ A great deal of satisfaction. ${ }^{\mathrm{f}}$ PCFUS scores range from - 28 (unstable relationship) to 28 (stable relationship).

$* * * p<.001$ 
The strongest association found was between caregivers' difficulties and stability of the caregiving dyad. The more unstable the situation was, the higher the level of stress associated with caregivers' difficulties was $(r=-0.642, p<.001)$.

To evaluate the perceived effects of caregiving two multiple regression analyses were performed with caregivers' difficulties (CADI) and then caregivers' satisfaction (CASI) as the dependent variables and acculturation (SASH) as the independent variable. However, since the stability of the caregiving relationship (PCFUS) may influence difficulties and satisfaction, it was added as a predictor to the equations with acculturation. Two regression equations were calculated for each dependent variable to measure the effects of the total acculturation score and also to measure the effects of the three factors separately.

The results of the regression analysis on CADI indicated that $42 \%$ of the variability of caregivers' difficulties can be explained by total acculturation and caregiver-care recipient stability $\left(\mathrm{R}^{2}=42 \%, \mathrm{~F}(2,25)=8.95, \mathrm{p}<.001\right)$. Total acculturation was not a predictor of caregiver's difficulties $(p=.634)$. However caregiving stability was a statistically significant predictor $(\mathrm{p}<.001)$. Caregivers involved in a more unstable caregiver - care receiver relationship perceived higher levels of stress associated with caregivers' difficulties (Table 19) 
Table 19

Multiple Regression of Level of Stress of Caregivers' Difficulties (CADI) on Total Acculturation (SASH) and Stability of the Caregiving Dyad (PCFUS) $(n=30)$

\begin{tabular}{lcccc}
\hline Predictor Variable & $\begin{array}{c}\text { Regression } \\
\text { coefficient } \\
(\mathrm{B})\end{array}$ & $\begin{array}{c}\text { Standard } \\
\text { error } \\
\text { (SE B })\end{array}$ & $\begin{array}{c}\text { Standardized } \\
\text { coefficient } \\
(\beta)\end{array}$ & $\mathrm{p}$ \\
\hline SASH Total & -0.05 & 0.10 & -0.07 & .634 \\
PCFUS & -0.03 & 0.07 & -0.64 & $<.001^{*}$ \\
\hline Note $\mathrm{R}^{2}=42 \%$, Adjusted $\mathrm{R}^{2}=37 \%, \mathrm{~F}(2,25)=8.94, \mathrm{p}<.001$ & &
\end{tabular}

Incorporating the three acculturation factors to the multiple regression equation provided a better prediction for the caregiver's perception of difficulties (Table 20). All together, language, electronic media, social relations and caregiving stability accounted for $54 \%$ of the variation of caregivers' difficulties $\left(R^{2}=54 \%, F(4,23)=6.70, p<.001\right)$.

Language $(p=.037)$ and caregiver-care recipient stability $(p=.002)$ were statistically significant predictors. Caregivers who use more English, and are involved in more unstable caregiver- care receiver relationships perceived higher levels of stress associated with difficulties. 
Table 20

Multiple regression of Level of Stress of Caregiver Difficulties (CADI) on Acculturation

Factors and Stability of the Caregiving Dyad (PCFUS) $(\mathrm{n}=30)$

\begin{tabular}{lcccc}
\hline Predictor Variable & $\begin{array}{c}\text { Regression } \\
\text { coefficient } \\
(\mathrm{B})\end{array}$ & $\begin{array}{c}\text { Standard } \\
\text { error } \\
(\text { SE B })\end{array}$ & $\begin{array}{c}\text { Standardized } \\
\text { coefficient } \\
(\beta)\end{array}$ & $\mathrm{p}$ \\
\hline Language & 0.35 & 0.16 & 0.46 & $.037^{*}$ \\
Electronic Media & -0.11 & 0.06 & -0.36 & .082 \\
Ethnic/Social Relations & -0.12 & 0.16 & -0.15 & .449 \\
PCFUS & -0.25 & 0.01 & -0.56 & $.002^{*}$ \\
\hline
\end{tabular}

Note $R^{2}=54 \%$, Adjusted $R^{2}=46 \%, F(4,23)=6.70, p<.001$

To see if the order of the predictors made a difference, additional multiple regressions were determined. First the total acculturation was entered as the first predictor of caregivers' difficulties and the caregiving dyad stability was added to measure its effects above acculturation. The change in $R^{2}$ was $41.6 \%$ and was highly significant $(p<.001)$. Then the order was reversed to measure the effect of total acculturation above caregiving dyad stability. The change in $R^{2}$ was not significant $(p=.634)$. Therefore, total acculturation did not help predict caregivers' difficulties after caregiving dyad stability was controlled.

The same procedures were used for the three acculturation factors. The change in $\mathrm{R}^{2}$ of caregiving dyad stability above the three factors was $24.3 \%$ and was highly significant $(p<.002)$. The change in $R^{2}$ of the three acculturation factors above the caregiving dyad stability was $12.7 \%$ and not statistically significant $(p=.128)$.

Multiple regression equations were calculated in order to establish how well acculturation can predict caregivers' perception of satisfaction (CASI) (Table 21). The 
results indicated that PCFUS and total SASH explain only $16 \%$ of the variation in caregivers' satisfaction $\left(\mathrm{R}^{2}=16 \%, \mathrm{~F}(2,25)=2.44, \mathrm{p}=.108\right)$.

Table 21

Multiple Regression of Caregivers' Satisfaction (CASI) on Total Acculturation (SASH) and Stability of the Caregiving Dyad (PCFUS) $(n=30)$

\begin{tabular}{lcccc}
\hline Predictor Variable & $\begin{array}{c}\text { Regression } \\
\text { coefficient } \\
(\mathrm{B})\end{array}$ & $\begin{array}{c}\text { Standard } \\
\text { error } \\
(\mathrm{SE} \mathrm{B})\end{array}$ & $\begin{array}{c}\text { Standardized } \\
\text { coefficient } \\
(\beta)\end{array}$ & $\mathrm{p}$ \\
\hline SASH Total & -0.17 & 0.09 & -0.34 & .077 \\
PCFUS & -0.01 & 0.01 & 0.17 & .377 \\
\hline Note $\mathrm{R}^{2}=16 \%$, Adjusted $\mathrm{R}^{2}=10 \%, \mathrm{~F}(2,25)=2.44, \mathrm{p}=.108$ &
\end{tabular}

Multiple regression calculated by adding the three acculturation factors and PCFUS explained $21 \%$ of the variation of the caregivers' satisfaction $\left(\mathrm{R}^{2}=21 \%, F(4,23)=1.55, \mathrm{p}=.221\right)($ Table 22$)$

Table 22

Multiple Regression of Caregiver Satisfaction (CASI) on Acculturation Factors and Stability of the Caregiving Dyad (PCFUS) $(n=30)$

\begin{tabular}{lcccc}
\hline Predictor Variable & $\begin{array}{c}\text { Regression } \\
\text { coefficient } \\
(\mathrm{B})\end{array}$ & $\begin{array}{c}\text { Standard } \\
\text { error } \\
(\mathrm{SE} \mathrm{B})\end{array}$ & $\begin{array}{c}\text { Standardized } \\
\text { coefficient } \\
(\beta)\end{array}$ & $\mathrm{p}$ \\
\hline Language & 0.06 & 0.16 & 0.09 & .735 \\
Electronic Media & -0.03 & 0.06 & -0.12 & .648 \\
Ethnic/Social Relations & -0.24 & 0.16 & -0.38 & .150 \\
PCFUS & 0.01 & 0.01 & 0.28 & .194 \\
\hline
\end{tabular}

Note $\mathrm{R}^{2}=21 \%$, Adjusted $\mathrm{R}^{2}=7 \%, \mathrm{~F}(4,23)=1.55, \mathrm{p}=.221$ 


\section{Additional findings}

$\underline{\text { Relationship between acculturation and other caregiving and demographic variables }}$

Acculturation was found to be correlated with other demographic and caregiving variables. Total acculturation was associated with the availability of another relative to share with caregiving $(r=0.391, p=.033)$, and the need to move to the same household in order to provide care $(r=0.493, p=.006)$. These results indicated that more acculturated caregivers are more likely to have other relatives sharing with the care, and more likely to have moved or have their relative move to the same household. All correlations are shown on Table 23.

Table 23

Pearson Correlations between Caregiving Situation Variables (Length of Care, Availability of a Relative to Share with Caregiving, and the Need to Move) and Total Acculturation $(\mathrm{SASH})$ and each SASH Factor $(\mathrm{n}=30)$

\begin{tabular}{|c|c|c|c|c|c|c|}
\hline \multirow[t]{2}{*}{ Variables } & \multicolumn{2}{|c|}{ Length of care ${ }^{c}$} & \multicolumn{2}{|c|}{ Share of care ${ }^{d}$} & \multicolumn{2}{|c|}{ Need to move } \\
\hline & $r$ & $\mathrm{p}$ & $r$ & $\mathrm{p}$ & $r$ & $\mathrm{p}$ \\
\hline SASH Total & -0.316 & .089 & 0.391 & $.033^{*}$ & 0.493 & $.006 * *$ \\
\hline Language $^{a}$ & -0.396 & $.030 *$ & 0.299 & .109 & 0.334 & .072 \\
\hline Electronic Media & -0.199 & .291 & 0.344 & .063 & 0.402 & $.028 *$ \\
\hline Social Relations ${ }^{b}$ & -0.226 & .229 & 0.357 & .053 & 0.573 & $.001 * *$ \\
\hline
\end{tabular}


Statistically significant relationships were also found between total acculturation

and age of the caregiver $(r=0.543, p=.002)$, educational level $(r=0.538, p=.002)$, and household income $(r=0.470, p=.012)$. These results indicated that more acculturized caregivers are younger and have a higher educational level, and household income. Similar results were obtained when these variables were correlated with the three SASH factors. The exceptions were the correlation between the social relations factor and educational level which was not significant $(r=0.292, p=.117)$, and the correlation with household income which was not significant, but in the desired direction $(r=0.353, p=.066)$ (Table 24).

\section{Table 24}

Pearson Correlations between Demographic Variables (Age, Educational Level and Household Income of the Caregiver) and Total Acculturation (SASH) and each SASH Factor $(n=30)$

\begin{tabular}{lccccccc}
\hline \multicolumn{1}{c}{ Variables } & \multicolumn{2}{c}{ Age } & \multicolumn{2}{c}{$\begin{array}{c}\text { Educational } \\
\text { level }\end{array}$} & & \multicolumn{3}{c}{$\begin{array}{c}\text { Household } \\
\text { income }\end{array}$} \\
& $\mathrm{r}$ & $\mathrm{p}$ & $\mathrm{r}$ & $\mathrm{p}$ & $\mathrm{r}$ & $\mathrm{p}$ \\
\hline SASH Total $^{*}$ & -0.543 & $.002 * *$ & 0.538 & $.002 * *$ & 0.470 & $.012 *$ \\
Language $^{\mathrm{a}}$ & -0.455 & $.011^{*}$ & 0.581 & $.001 * *$ & 0.452 & $.016^{*}$ \\
Electronic Media $^{\mathrm{a}}$ & -0.436 & $.016^{*}$ & 0.454 & $.012 *$ & 0.394 & $.038^{*}$ \\
Social Relations $^{\mathrm{b}}$ & -0.543 & $.003 * *$ & 0.292 & .117 & 0.353 & .066 \\
\hline
\end{tabular}

Note. $\mathrm{n}=28$ for household income. ${ }^{\mathrm{a}}$ Scale ranges from $1=$ Only Spanish to $5=$ Only English. ${ }^{\mathrm{b}}$ Scales ranges from $1=$ All Hispanics to $5=$ All Americans; ${ }^{\circ}$ Scale ranges from $1=$ Less than 4 years to $8=$ Post graduate college.

$* \mathrm{p}<.05 * * \mathrm{p}<.01$ 
$\underline{\text { Relationship between caregivers' difficulties and other demographic and caregiving }}$ variables

Caregivers' levels of stress associated with difficulties was found to be associated with the gender of the caregiver $(r=0.385, p=.043)$, the length of stay of the caregiver in the U.S. $(r=0.407, p=.031)$, and the need to move to the same household $(r=-0.464$, $p=.013$ ). Higher levels of stress caused by caregivers' difficulties were associated with female caregivers, living in the U. S. for a longer time and less likely to have moved (Table 25).

Table 25

Pearson Correlations between Caregivers' Difficulties (CADI) and Gender of the

Caregiver, Length of Stay in the U.S. and the Need to Move $(n=30)$

\begin{tabular}{lcc}
\hline \multicolumn{1}{c}{ Variables } & CADI & p - value \\
\hline Gender $^{\text {a }}$ & 0.385 & $.043^{*}$ \\
Length of stay (years) Need to move $^{b}$ & 0.407 & $.031^{*}$ \\
\hline
\end{tabular}

Note. CADI scores range from $1=$ Not stressful to $3=$ Very stressful. ${ }^{a} 1=$ Male, $2=$ Female $^{\mathrm{b}} 0=$ No, $1=$ Yes

$* p<.05$. 
Other caregivers' feelings associated with caregiving

Caregivers were able to add concerns or feelings about their caregiving situation.

Caregivers were given the opportunity to give more than one answer. Consequently, percentages may add to more than one hundred. To the question concerning the best thing about caring for their relative, 20 caregivers $(66.7 \%)$ gave answers related with maintaining the physical and/or emotional well-being of their relatives, 5 caregivers $(16.7 \%)$ expressed the importance of fulfillment of family or religious obligations with emphasis in setting an example for the children. The other answers were related to providing companionship, reciprocating previous actions, and acquiring new understanding of life situations.

To the question asking about the most important thing the caregivers do for their relatives, 21 caregivers $(70.0 \%)$ thought it was attending to their relatives emotional or spiritual needs, and $12(40.0 \%)$ gave answers relating to taking care of physical needs. Finally to the question concerning the possibility of changing anything about the care of their relative, 12 caregivers (40.0\%) stated they did not want to change anything, 6 $(20.0 \%)$ would like to change things related with the care receiver's personality and/or behavior, $5(16.7 \%)$ wanted some type of respite or sharing of care. Other answers were related to the desire to change the degree of the care receiver's disabilities and to obtain better conditions for caregiving. 


\section{CHAPTER V}

\section{Discussion}

Most of the research on elderly caregivers' burden and satisfaction has been on White non-Hispanic caregivers and many of the limited studies about Hispanic caregivers have grouped together participants from different ethnic groups (Cox \& Monk, 1990, 1993; Polich \& Gallagher- Thompson, 1997; Talamantes, Lawler \& Espino, 1995; Tirrito \& Nathason, 1994). Hispanic is a broad term used to refer to Spanish-speaking individuals originating from a variety of Latin American countries (Talamantes, Lawler \& Espino, 1995) and includes individuals from different cultural backgrounds (Talamantes, Lawler \& Espino, 1995; Vargas, 1992), language acculturations (Krause \& Goldenhar, 1992), economical statuses (Krause \& Goldenhar, 1992; Wallace \& Lew-Ting, 1992), and educational levels (Del Pinal, 1996; Krause \& Goldenhar, 1992). Therefore, differences in caregiving could be expected among the different Hispanic ethnic subgroups. Recently, some authors have looked at specific Hispanic groups, such as Mexican Americans (Clark \& Huttlinger, 1998; John, Resendiz, \& De Vargas, 1997; Luna et al. , 1996), Puerto Ricans (Davis, 1994; Delgado \& Tennstedt, 1997a, 1997b), and Cuban Americans (Mintzer, et al., 1992).

To answer the first research question concerning the effects of caregiving among Cuban Americans, this study provides descriptive information on caregiving situation characteristics, caregiving dyad stability, perceived stress of caregivers' difficulties, and caregivers' satisfaction among individuals of Cuban origin. A second research question investigated the relationship between acculturation and the different caregiving variables. 


\section{Caregiver characteristics}

Most of the caregivers were women (93.3\%) caring for a parent $(63.3 \%)$, or a husband (16.7\%). This result is similar to findings in other studies. Cox and Monk (1990, 1993) reported a majority of women caregivers of relatives with Alzheimer's or dementia, mostly daughters and daughters in law. In the Polich and Gallagher-Thompson (1997) study of Hispanic caregivers, $61.9 \%$ were daughters and $21.4 \%$ were wives. In a study of 194 Puerto Rican caregivers similar results were reported, $45.9 \%$ were daughters and 26.3\% were spouses (Delgado and Tennstedt, 1997a).

Caregivers in this study reported a variety of family members able to share with caregiving. Seventy percent of caregivers felt that they had relatives sharing with the care and $66.7 \%$ of caregivers thought that relatives were available to take over if needed.

These results differ from the findings of Cox and Monk (1993) in which more than half the caregivers did not have anyone who could provide care if the primary caregiver was unavailable.

In a much larger study of the elderly in Miami-Dade county, Golstin (1998) found the family caregivers of the Cuban Hispanic elderly were predominantly daughters but included other family members while the non Cuban Hispanic elderly were cared for almost exclusively by daughters. Caution must be used in such comparisons because of the considerable presence of the Cuban culture and environment in the Miami Dade area, compared with the much smaller non Cuban Hispanic population.

South Florida, in particular Miami, has been categorized as a true Cuban ethnic enclave drawing Cubans not only from Cuba but from other cities in the U.S. (Perez, 1994). Portes and Jensen (1989) defined the Cuban experience as unique. With the 
establishment of ethnic enclaves, Cuban Americans benefit not only economically, but more importantly by the provision of a source for effective support for the elderly. Family networks may have been established with the reunification of the families in the Miami area, therefore increasing the number of relatives readily available to care for the elderly.

In this study, the average age of the caregivers was 59.2 years. Most of the caregivers were Catholic ( $80.0 \%)$ with at least a high school education (76.7\%). Fifty percent of the caregivers were employed full time and thirteen out of twenty-eight caregivers had household incomes of $\$ 30,000$ a year or higher.

Higher levels of education and income of Cuban Hispanics in the general population have been previously documented by other researchers (Angel \& Angel, 1992; Krause \& Goldenhar, 1992; Perez, 1994). Overall caregivers in this study had a higher level of education and income than found in a previous study in the Miami Dade area. These results differed from data derived from the Dade County Needs Assessment conducted in 1994 and reported by Goltsin (1998). More than half of the 271 elderly Cubans interviewed for the earlier study had only a grade school education, and almost three quarters of them had an income of less than $\$ 10,000$ a year. These differences in education and household income could be because this was a small convenience sample. Another reason for obtaining a higher average income in the present study could be that the question was phrased as "household income." Therefore, the income of the spouse and/ or caregiver, and any other persons living in the same household were included.

Cox and Monk (1990) reported a median education of 11 years and median income between $\$ 6,000$ and $\$ 10,000$ a year among Hispanics, mostly Puerto Ricans, in New York City and Baltimore. In a more recent study (Cox \& Monk, 1993), these same 
authors found that $41.8 \%$ of Hispanic caregivers had only an elementary school education and $67.4 \%$ had incomes below $\$ 15,000$ a year. Among thirteen Cuban-American caregivers of mothers with Alzheimer's disease, Mintzer and collaborators (1992) found that the average education level was 13.69 years $(\underline{S D}=3.50)$. Although these caregivers were mostly employed in non-skilled worker categories, their incomes were not statistically different from the ones found for White non-Hispanic caregivers that participated in the study.

\section{Acculturation}

This sample was characterized by its homogeneity regarding acculturation. All SASH item mean scores were lower than 3 out of $5(1.17-2.90)$ suggesting a more traditional Hispanic orientation within the acculturation continuum.

Other researchers have established the validity of acculturation scales by calculating how they correlate with other indicators of acculturation such as age of arrival, length of stay in the U.S., and country of birth (Marin, Sabogal, Marin, Otero-Sabogal, \& Perez-Stable 1987; Szapocznik, Scopetta, Kurtines, \& Arnalde, 1978; Triandis, Kashima, Hui, Lisansky, \& Marin, 1982).

All participants were Cuban born and the majority arrived to the U.S. after their 20 's. Seventy percent of this sample chose Spanish as the language for the interview, which was highly associated with total acculturation scores and the three acculturation factors in the SASH.

The age of arrival was also found to be associated with the total SASH score, the language factor, the ethnic/social relations factor, and to a lesser degree with the electronic media factor. Therefore, Cubans in this study who arrived at a younger age 
were more acculturized than those who arrived at an older age. Marin and collaborators (1987) obtained similar results in a study of 363 Hispanics, mostly Mexican and Central Americans. The total SASH score and the three acculturation factors were highly associated with the age of arrival.

The residence index, calculated as the length of stay in the U.S. divided by current age (Marin, Sabogal, Marin, Otero-Sabogal, \& Perez-Stable 1987; Szapocznik, Scopetta, Kurtines, \& Arnalde, 1978; Triandis, Kashima, Hui, Lisansky, \& Marin, 1982) was found to be associated with the total SASH score $(p<.01)$, the language factor $(p<.001)$, and the ethnic/social relations factor $(\mathrm{p}<.05)$. Marin and collaborators (1987) found highly significant associations $(p<.001)$ between the residence index and all acculturation factors including the total SASH score. A larger residence index results from the combination of having lived longer in the U.S. and/or being younger at the time of the study. Rodriguez and Kolosky (1998) used SASH to measure acculturation among 182 Puerto Rican Americans. These authors examined the association between length of stay, which is one of the components of the residence index and acculturation. Length of stay correlated with the language and the ethnic/social relations factor, but not with the electronic media factor. Polich and Gallager-Thompson (1997) also found that acculturation, measured with a scale developed by Cuellar, Harris, and Jasso (1980), correlated with caregivers who had lived longer in the U.S. From these results, it can be concluded that the SASH was a valid measure of acculturation for Cuban Americans in this study. In addition, similarly to other Hispanic ethnic subgroups, younger Cuban immigrants who arrived at a younger age and have lived longer in the U.S. were more acculturated. 


\section{Caregiving situation}

The most common reason for becoming a caregiver was the availability to help, either because no other relative was willing, or because no other daughters were available. This result was similar to a study of Puerto Rican caregivers where half the subjects gave availability as the initial reason for providing help (Delgado \& Tennstedt, 1997a). Previous studies by Cox and Monk $(1990,1993)$ reported that most Hispanics agree that children have a duty to assist their parents, parents should expect assistance from their children, and married children should live close to the parents to provide care. Other authors have also reported similar expectations (Clark \& Hutlinger, 1998; Davis, 1994; Hernandez, 1992; John, Resendiz \& De Vargas, 1997). Therefore, even though the caregivers initially reported availability as the reason for assuming the caregiving role, the reason why they continue to sustain the role could be due to ethnic attitudes toward caregiving.

Caregivers provided help with a variety of IADL and ADL tasks. The average number of tasks the caregivers helped with was nine out of a possible fourteen tasks included in the PCFUS. This value is within the same range reported in a study of caregivers from a comprehensive geriatric assessment program ( 7.1 tasks) and from a social service agency (12 tasks) (Fredman \& Daly, 1998). Diverse measurements of carereceivers' impairment have been used in caregiver studies making comparison of results difficult. Polich and Gallager-Thompson (1997) reported care receivers needing help with an average of seventeen out of twenty-seven possible ADLs and IADLs tasks. Delgado and Tennstedt (1997a) reported an average of $6.8(\underline{\mathrm{SD}}=3.2)$ out of thirteen possible ADLs, IADLS, and mobility disabilities. Cox and Monk (1990) used the Memory Behavior Checklist to score ADL dependency. From a possible score of 0 to 27 , the 
average score was 10.9 .

Several authors have reported that the majority of the elderly need help primarily with IADLs (Branch, Horowitz, \& Carr, 1989; Matthews, 1988; Wallhagen, 1992). Most elders who receive help with ADLs receive help with IADLs. However, caregivers may need to provide elders with help for IADLs but the elderly person may continue to be relatively independent for ADLs (Walker, Pratt, \& Eddy, 1995). In addition, women caregivers helping with IADLs may have these tasks organized around their daily homemaking activities (Barer \& Johnson, 1990; Sankar, 1993; Schulz, 1990).

As expected from previous research, caregivers mostly assisted with IADL tasks. However, more difficulties were associated with helping with ADLs when compared with IADLs. Transfers, bathing, and toileting were the tasks caregivers thought as more difficult. These activities are physically challenging and therefore elderly caregivers would have more difficulties with them. Seventy five percent or more of the care receivers required at least some help with all IADL tasks except with the telephone. These results are reinforced by the caregivers' answers to the open- ended question "What are the things that you do that make you the person responsible for taking care of your relative?" More than a third of the caregivers responded that assisting with the administration of medication and transportation to shops, medical appointments, and to visit friends and relatives were the tasks that defined the caregiving role. Comparable results were obtained by Delgado and Tennsdedt (1997a) on Puerto Rican caregivers. These caregivers provided help most frequently with shopping, housekeeping, meal provision, transportation, and financial management. The same authors, when comparing daughter and son caregivers found that daughters were more likely to provide help with self-care while sons more 
frequently provided financial help and transportation (Delgado and Tennsdedt, 1997b).

\section{Perceived effects of caregiving}

The most common difficulties, as measured by the percent of caregivers who responded to them as stressful or very stressful, were related to perceptions of emotional or physical demands. All these difficulties were related to perceived effects on the caregiver. The difficulties were lack of private time ( 21 out of 30 ), restriction of social life (21), decreased emotional well-being (20), and being tired (19) and they fall into the category of subjective variables (Biegel, Song \& Chakravarthy, 1994). Delgado and Tennstedt (1997b) also reported personal and leisure time as the primary negative impact of caregiving among Puerto Rican caregivers, but in their study, only 23.4 percent of the sons and 25.8 percent of the daughters reported this effect. Other negative effects reported by Delgado and Tennstedt (1997b), but not found in this study, were effects on sleep ( $23.5 \%$ for sons, $24.7 \%$ for daughters), employment ( $18.8 \%$ for sons, $23.1 \%$ for daughters), health ( $11.8 \%$ for sons, $23.6 \%$ for daughters), and managing the household ( $17.6 \%$ for sons, $20.2 \%$ for daughters).

Most common sources of satisfaction among the caregivers that participated in the study were related to satisfaction derived from situations generating a physical and/or emotional benefit to the care receiver, such as seeing the elder happy, his/hers needs tended to, and maintaining the dignity of the elder. Keeping a parent out of an institution, showing love for the care receiver, fulfilling a sense of duty, and enjoying helping people were other common sources of satisfaction.

Caregiving is an important and expected role for the Hispanic woman (Davis, 1994; Hernandez, 1992; Horowitz, 1985). Hernandez (1992) reported that caregiving 
constitutes an extraordinary source of pride and status for Cuban women and for elderly Cuban women in particular; the role of caregiver is a way of being in control of her individual destiny and that of her spouse's. John, Resendiz and De Vargas (1997) reported that among Mexican-Americans caregivers, a sense of duty, feelings of desire, gladness, and privilege were also feelings derived from caring for a family member.

According to the Model of Human Occupation (MOHO) (Kielhofner, 1995a), roles are assumed when the individual is motivated by a sense of mastery or the awareness of his/her capabilities to perform the tasks associated with the role. Family members, and daughters in particular, may assume the role of caregiver because they have the convictions and sense of obligation to do so, and they have the belief that they are capable of performing the role adequately. However, an increase in role conflict for Cuban American more acculturized daughters is to be expected. Other authors have previously reported that adult children caring for their parents and their own children present role conflicts (Kahana et al., 1994). Daughters caregivers provide more personal care, report more stress, and have more competing demands from other roles than sons (Horowitz, 1985; Kahana \& Young, 1990). Differences between the cultural expectations of less acculturized parents and more acculturized daughters may be added to these conflicts creating more environmental press.

Results from this study offer preliminary information on how Cuban-American caregivers may perceive satisfaction during the caregiving process. Fourteen of the thirty satisfaction statements related with caregiving were answered as applicable by 90 percent of the caregivers. This is corroborated by the findings of several authors who have stated that ethnic values and familism among Hispanics play an important role in the expectation 
for care and caregiving for their elderly (Davis, 1994; Henderson, 1996; Henderson \& Gutierrez-Mayka, 1992; Hernandez, 1992; Horowitz, 1985; John, Resendiz \& De Vargas, 1997). However, most caregivers expressed that caregiving was a source of a number of difficulties and stresses. This is an important finding considering that Hispanics have a tendency to give socially desirable responses, and to exhibit a low level of self-disclosure (Marin \& Marin, 1991).

In this sample the CADI and PCFUS used together appear to be useful instruments for measuring the type of difficulty associated with helping perform a task and the difficulties associated with caregiving respectively. Items from both the English and the translated Spanish version of CADI, CASI, and PCFUS, were found relevant to the subjects.

\section{$\underline{\text { Relationship between variables }}$}

A strong relationship was found between caregivers' difficulties and stability of the caregiving dyad $(r=-0.642, \mathrm{p}<.001)$. Unstable caregiving dyads are characterized by a high number of mismatches between the care receiver needs and the emotional and/or physical difficulties perceived by the caregiver (Daly \& Fredman, 1998). Caregivers involved in more unstable caregiver-care recipient relationships perceived higher levels of stress associated with the difficulties of caregiving.

One of the research questions of this study was to determine if there was a relationship between acculturation and the perceived effects of caregiving assuming that acculturation was a valid measurement of cultural change. Kielhofner (1995c) stated that culture shapes how the world is organized and viewed by humans. Therefore, it could be expected that acculturized individuals would perceive caregiving differently than 
traditional Hispanic individuals. However, the results from this study did not provide strong evidence that acculturation by itself can predict the perceived effects of caregiving. Therefore, more research needs to be done in this area because these findings may be a result of the low dispersion of acculturation scores along the acculturation continuum in this sample. This could be due to several reasons: studying a convenient sample, having caregiver and care receiver living in the same home, or even that more acculturized Hispanics may not have the care receiver living in the same household. In addition, Cubans living in the Miami Dade area can get along without knowing English and are probably less acculturized than Cubans or Cuban Americans living in other areas where knowing English becomes more important. Further studies are needed to clarify this situation.

Regression analysis results suggested that acculturation by itself was not a predictor of caregivers' difficulties and satisfactions. However, total acculturation and stability of the caregiving dyad predicted $42 \%$ of caregivers' difficulties. These results suggest that the stability of the caregiving dyad influences how acculturation affects the perception of the stress associated with caregiving difficulties. Substituting the three acculturation factors for the total acculturation scores increased the explained percentage of the variation in caregivers' difficulties to $54 \%$. Of the three factors, language was a significant predictor of caregivers' difficulties $(p=.037)$. Marin and collaborators (1987) have reported that the language factor accounts for almost $55 \%$ of the variance of acculturation while the media preference factor and the ethnic/social relations factor explained $7 \%$ and $6 \%$ respectively. For the sample of Cubans in this study the language factor was also the most relevant predictor.

No relationship was found between acculturation and caregivers' satisfaction. 
Consequently, neither acculturation, nor stability of the caregiving dyad were predictors of perceived satisfaction with caregiving. A possible explanation for this result could be that there was a difference in the degree of disclosure of negative feelings between more acculturated and more Hispanic caregivers. It may be that more acculturated caregivers were able to accept more difficulties associated with caregiving than traditional Hispanics.

More acculturated caregivers were also more likely to have a relative sharing with the care. Perhaps these caregivers were more assertive than the more traditional Hispanic caregivers in expecting and accepting other relatives to share in the caregiving.

Results also suggested that caregivers who were more acculturated had been taking care of their relatives for a shorter period of time, and were more likely to have moved, or had the care receiver moved to facilitate care. Presumably, less acculturated (more Hispanic) caregivers may have been more likely to be living with the elder or had lived in the same household prior to the caregiver role. Therefore moving would not be an issue since they all lived together, and the beginning of care would be estimated to have started at the first indications of illness and/or dependency of the care receiver.

Living within the same household may also be important because caregivers may be more willing to maintain their elderly relatives at home for a longer period of time before admitting them to an institution. This was also suggested by Mintzer and collaborators (1992) who found that more Cuban-American daughters cared for their mothers with Alzheimer's disease for a longer time at home compared with White nonHispanic. They suggested the reason for this could be that Hispanic daughters and mothers were more likely to share the same household prior to the mothers' illnesses making it more difficult for the daughter to send the mother to a nursing home. 
Similar to other studies, less acculturation was associated with older age (Marin,

Sabogal, Marin, Otero-Sabogal, \& Perez-Stable, 1987, Rodriguez \& Kosloski, 1998), and lower household income (Negy \& Woods, 1992).

\section{$\underline{\text { Recommendations }}$}

Although the results of this study cannot be generalized to the general population, this study offers some very important preliminary data on Cuban-American caregivers and the relationship between caregiving variables and acculturation. The translated and original version of the instruments used to measure stability of the caregiving dyad (PCFUS), caregiving difficulties (CADI), and acculturation (SASH) appeared to be valid measures for this population. However, the measure for caregiving satisfaction (CASI) may need to be modified for it to be more sensitive to variations of this variable. The limitations derived by using instruments written in English and translated into Spanish can be minimized by further studies to standardize these instruments for various Hispanic populations.

Similar studies of these same variables should be conducted in larger randomized Cuban-American samples to try to reproduce these results. However, Cuban-Americans born in the U.S. who are more fluent in English or equally able to use both languages must be included in the studies. In order to include more acculturated Cuban-Americans it may be necessary to include caregivers not sharing the same household as the care receivers. All future studies in this population should include a scale measuring positive effects of caregiving. Because of the involvement of other relatives in the care of the Cuban elders, future studies should always include questions addressing the type of help provided by other family members in tasks in which the primary caregivers are not involved. 
This type of research may contribute to much needed information for all health professionals, and in particular for occupational therapists dealing with the current health care changes where family caregivers are expected to provide more of the care for the elderly. For South Florida's Cuban-American population, research in this area could help provide better assistance to the elderly and their family caregivers. Finally, future research is needed to find acceptable solutions for younger Cuban-American daughters who will experience multiple cultural press.

\section{$\underline{\text { Summary }}$}

Hispanic individuals are a heterogeneous group with the Spanish language as the most common bond. Cuban-Americans constitute the largest Hispanic group in South Florida with their own unique cultural characteristics. The way caregiving is perceived is modulated by cultural values, habits, and roles. Therefore, acculturation or the assimilation of values from the mainstream culture, could be expected to influence the way family members assume the caregiving role. This study was a first attempt to find a relationship between acculturation and caregiving and to measure satisfactions and difficulties due to caregiving in Cuban-Americans. Three instruments assessing caregiving difficulties, satisfaction, and stability of the caregiving dyad were translated into Spanish and used for the first time with Cuban-Americans in Miami Dade county.

Difficulties associated with caregiving were related to how caregivers perceived the effects on themselves. These difficulties were mostly due to restriction in personal time or activities and effects on the emotional or physical well-being of the caregiver. A strong association was found between caregiving dyad stability and stress caused by caregiving difficulties. Caregivers involved in more unstable caregiving dyads, that is those with a 
higher level of discrepancy between the care receiver's needs and the caregiver's difficulties in providing help, perceived higher levels of stress. Fifty-four percent of the stress associated with caregiving difficulties could be predicted by the stability of the caregiving dyad and the three acculturation factors (language, electronic media, and ethnic/social relations). Caregiving satisfaction was associated with assuring the well-being of the care receiver and fulfilling a sense of duty. All these variables could be important when implementing support and education programs for Cuban-Americans elders and their caregivers. 
Ailinger, R. L. (1989). Functional capacity of Hispanic elderly immigrants. The Journal of Applied Gerontology, 8, 97-109.

Aldous, J. (1994). Someone to watch over me: Family responsibilities and their realization across family lives. In E. Kahana, D. E. Biegel \& M. L. Wykle (Eds.) Family caregiving across the lifespan (pp. 41-68). Thousand Oaks, CA: Sage Publications.

Angel, J. L., Angel, R. J. (1992). Age at migration, social connections, and wellbeing among elderly Hispanics. Journal of Aging and Health, $4,480-499$.

Barer, B. M. \& Johnson, C. I. (1990). A critique of the caregiver literature. The Gerontologist, 30, 26-29.

Barush, A. S., \& Spaid, W. M. (1996). Spouse caregivers and the caregiving experience: Does cognitive impairment make a difference? Journal of Gerontological Social Work, 25, 93-105.

Biegel, D. E., \& Blum, A. (1990). Introduction In. D. E. Biegel \& A. Blum (Eds.), Aging and caregiving: theory, research and policy (pp. 9-24). Newsbury Park, CA: Sage Publications.

Biegel, D. E., Song, L. Y., \& Chakravarthy, V. (1994). Predictors of caregiver burden among support group members of persons with chronic mental illness. In $\mathrm{E}$. Kahana, D. E.

Biegel \& M. L. Wykle (Eds.) Family caregiving across the lifespan (pp. 178-215). Thousand Oaks, CA: Sage Publications.

Borell, L., Burke, J., Helfrich, C., Kielhofner, G.,\& Nygard, L. (1995). Volition subsystem. In G. Kielhofner (Ed.), A Model of Human Occupation: Theory and Occupation (pp. 39-62). Maryland: Williams \& Wilkins.

Branch, L. G., Horowitz, A., \& Carr, C. (1989). The implications for everyday life of incident self-reported visual decline among people over 65 living in the community. The Gerontologist, 29,' 350-365.

Brislin, R. W. (1970). Back translation for cross-cultural research. Journal of Cross-Cultural Psychology, 1, 185-216.

Brody, E. (1985). Parent care as a normative stress. The Gerontologist, 25, 19-29.

Burnam, M. A., Telles, C. A., Karno, M., Hough, R. L., \& Escobar, J.I. (1987). Measurement of acculturation in a community population of Mexican Americans. Hispanic 
Campbell, P. R. (1996). Population projections for states by age, sex, race, and Hispanic origin: 1995 to 2025. (U. S. Bureau of the Census, Population Division, PPL47). [On-line]. Available: Internet, htpp://www.census.gov./population/www/projections/pp 147.html.

Cantor, M. (1983). Strain among caregivers: a study of the experience in the United States. The Gerontologist, 24, 597-604.

Caserta, M. S., Lund, D. A., \& Wright, S. D. (1996). Exploring the Caregiver Burden Inventory (CBI): Further evidence for a multidimensional view of burden. International Journal of Aging and Human Development, 43, 21-34.

Clark, M., \& Huttlinger, K. (1998). Elder care among Mexicam American families. Clinical Nursing Research, 7 64-81.

Caudle, P. (1993). Providing culturally sensitive health care to Hispanic clients. Nurse Practitioner, 18, 40, 43-44, 46, 50-51.

Chiriboga, D,A., Weiler, P. G., Nielsen, K. (1990). The stress of caregivers. In. D. E. Biegel \& A. Blum (Eds.), Aging and caregiving: theory, research and policy (pp. 121-138). Newsbury Park, CA: Sage Publications.

Cicirelli, V. G. (1983). Adult children's attachment and helping behavior to elderly parents: a path model. Journal of Marriage and the Family, 45, 815-825.

Clark, M., Huttlinger, K. (1998). Elder care among Mexican American families. Clinical Nursing Research, 7, 64-81.

Cox, C., \& Gelfand, D. E. (1987). Familial assistance, exchange and satisfaction among Hispanic, Portuguese, and Vietnamese ethnic elderly. Journal of Cross-Cultural Gerontology, 2, 241-255.

Cox, C., \& Monk, A. (1990). Minority caregivers of dementia victims: a comparison of Black and Hispanic families. The Journal of Applied Gerontology, 9,340 354.

Cox, C., \& Monk, A. (1993). Hispanic culture and family care of Alzheimer's patients. Health and Social Work, 18, 92-100.

Critchfield, T. S., Tucker, J. A., \& Vuchinich, R. E. (1998). Self-report methods. In K. A. Lattal \& M. Perone (Eds.) Handbook of research methods in human operant behavior (pp. 435-470). New York: Plenum Press.

Cuellar, I., Arnold, B., \& Maldonado, R. (1995). Acculturation Rating Scale for 
Mexican Americans-II: a revision of the original ARSMA scale. Hispanic Journal of Behavioral Sciences, 17, 275-304.

Cuellar, I., Harris, L. C., \& Jasso, R. (1980). An acculturation scale for Mexican American normal and clinical populations. Hispanic Journal of Behavioral Sciences, 2 197-217.

Daly, M. P., Fredman, L. (1998). A simole function-based scale for practitioners to assess the patient-caregiver dyad. Topics in Geriatric Rehabilitation, 14, 45-53.

Dana, R. H. (1996). Assessment of acculturation in Hispanic populations. Hispanic Journal of Behavioral Sciences, 18, 317-328.

Davis, K. , \& Shoen, C. (1996). Health services research and the changing health care system. [On-line]. Available: Internet, htpp://www.cmwf.org.

Davis, L. L. (1992). Building a science of caring for caregivers. Community Health, $15,1-9$.

Davis, R. E. (1994). The heart and soul of Puerto Rican community: caring and caregivers. The Journal of Multicultural Nursing, 1, 21-27.

Deimling, G. T. (1994). Caregiver functioning. Annual Review of Gerontology and Geriatrics, 14, 257-280.

Delgado, M., Tennstedt, S. (1997a). Making the case for culturally appropriate community services: Puerto Rican elders and their caregivers. Health and Social Work 22, 246-255.

Delgado, M., Tennstedt, S. (1997b). Puerto Rican sons as primary caregivers of elderly parents. Social Work, 42, 125-134.

Del Pinal, J. (1996). The Hispanic population. [On-line]. Available: Internet, htpp://www.census.gov/population/www.pop-profile/hisppop.html.

Economics and Statistics Administration, U.S. Department of Commerce. (1995). Sixty-five plus in the United States. [On-line]. Available: Internet, htpp://www.census.gov/ socdemo/www.agebrief.html.

Fisher, A., \& Kielhofner, G. (1995). Mind-brain-body performance subsystem. In G. Kielhofner (Ed.), A Model of Human Occupation: Theory and Occupation (pp. 8390). Maryland: Williams \& Wilkins.

Fredman. L., \& Daly, M. P. (1998). Enhancing practitioner ability to recognize and treat caregiver physical and mental consequences. Topics in Geriatric Research, 14, 36-44. 
Fulton Picot, S. J., Youngblut, J., \& Zeller, R. (1997). Development and testing of a measure of perceived caregiver rewards in adults. Journal of Nursing Measurement, 5 , 33-52.

Gallager-Thompson, D., Moorehead, R. S., Polich, T. M., Arguello, D., Jonhson, C., Rodriguez, V., \& Meyer, M. (1992). A comparison of outreach strategies for Hispanic caregivers of Alzheimer's victims. Clinical Gerontologist, 15, 57-62.

Gelfand, D. E. (1994). Ethnicity, gerontological theory, and research. In D. E. Gelfand Aging and ethnicity: knowledge and services. Springer Publishing Company, Inc: New York.

George, L. K. (1990). Caregiver stress studies: there really is more to learn. The Gerontologist, 30, 580-581.

George, L. K., Gwyther, L. P. (1986). Caregiver well-being: a multidimensional examination of family caregivers of demented adults. The Gerontologist, 26, 253-259.

Given, B. A., Given, B., Stommel, M., Collins, C., King, S., \& Franklin, S. (1992). The Caregiver Reaction Assessment (CRA) for caregivers to persons with chronic physical and mental impairments. Research in Nursing and Health, 15, 271-283.

Golstin, R. (1998). A comparison of the sources of assistance for White nonHispanic and Hispanic elderly who have difficulties in performance of daily activities. Unpublished master's thesis, Florida International University, Miami, Florida.

Grant, G., Ramcharan, P., McGrath, M., Nolan, M., \& Keady, J. (1998). Rewards and gratifications among family caregivers.: towards a refined method of caring and coping. Journal of Intellectual Disability Research, 42, 58-71.

Guarnaccia, P. J., Parra, P., Deschamps, A., Milstein, G., \& Argiles, N. (1992). Si Dios quiere: Hispanic families' experiences of caring for a seriously mentally ill family member. Culture, Medicine and Psychiatry, 16, 187-215.

Hasselkus, R. (1989). The meaning of daily activity in family caregiving of the elderly. home. The American Journal of Occupational Therapy, 43, 649-656.

Heard, C. (1977). Occupational role acquisition: a perspective on the chronically disabled. The American Journal of Occupational Therapy, 41, 243-247.

Hernandez, G. G. (1992). The family and its aged members: the Cuban experience. Clinical Gerontologist. 12, 45-57.

Hills Maguire, G. (1996). Activities of daily living. In C. Bernstein Lewis (Ed.), Aging, the health care challenge: an interdisciplinary approach to assessment and rehabilitative management of the elderly (3rd ed., pp.47-78). Philadelphia: F. A. Davis 
Company.

Hobbs, F. B. (1996). The elderly population. [On-line]. Available: Internet, htpp:// www.census.gov/population/www/pop-profile/elderpop.html.

Holzberg, C. S. (1982). Ethnicity and aging: Anthropological perspectives on more than just the minority elderly. The Gerontologist, 22, 249-257.

Hooyman, N. R. (1990). Women as caregivers of the elderly. In. D. E. Biegel \& A. Blum (Eds.), Aging and caregiving: theory, research and policy (pp. 221-241). Newsbury Park, CA: Sage Publications.

Horowitz, A. (1985). Family caregiving to the frail elderly. In C. Eisdorfer, M. P. Lawton, \& G. L. Maddox (Eds.), Annual Review of Gerontology and Geriatrics, Vol 5. The social lifestyles of older people. New York: Springer Publishing Company.

John, R., Resendiz, R., \& De Vargas, L. W. (1997). Beyond familism: Familism as explicit motive for eldercare among Mexican American caregivers. Journal of CrossCultural Gerontology, 12, 145-162.

Johnson, C. L. (1983). Dyadic family relations and social support. The Gerontologist, 23, 612-618.

Jutras, S., Lavoie, J. P. (1995). Living with an impaired elderly person: the informal caregiver's physical and mental health. Journal of Aging and Health, 7, 46-73.

Kahana, E., Kahana, B., Johnson, J. R., Hammond, R. J., \& Kercher, K. (1994). Developmental challenges and family caregiving: bridging concepts and research. In $\mathrm{E}$. Kahana, D. E. Biegel \& M. L. Wykle (Eds.) Family caregiving across the lifespan (pp. 3-41). Thousand Oaks, CA: Sage Publications.

Kahana, E., Young, R. (1990). Clarifying the caregiving paradigm. In. D. E. Biegel \& A. Blum (Eds.), Aging and caregiving: theory, research and policy (pp. 76-97). Newsbury Park, CA: Sage Publications.

Katz, S., Ford, A. B., Moskowitz, R. W., Jackson, B. A., \& Jaffe, M. W. (1963). Studies of illness in the aged. The index of ADL: A standardized measure of biological and psychosocial function. Journal of the American Medical Association, 185, 914-919.

Kielhofner, G. (Ed.) (1995a). A model of human occupation: theory and application. Maryland: Williams \& Wilkins.

Kielhofner, G. (1995b). Habituation subsystem. In G. Kielhofner (Ed.), A Model of Human Occupation: Theory and Occupation (pp. 63- 81). Maryland: Williams \& Wilkins. 
Kielhofner, G. (1995c). Environmental influences on occupational therapy. In G. Kielhofner (Ed.), A Model of Human Occupation: Theory and Occupation (pp. 91-110). Maryland: Williams \& Wilkins.

Killeen, M. (1990). The influence of stress and coping on family caregivers' perceptions of health. International Journal of Aging and Human Development, 30, 197 211.

Kinney, J. M., \& Stephens, M. A. (1989). Hassles and uplifts of giving care to a family member with dementia. Psychology and Aging, 4, 402-408.

Kosberg, J. I., \& Cairl, R. E. (1986). The Cost of Care Index: a case management tool for screening informal care providers. The Gerontologist, 26, 273-278.

Kosberg, J. I., Cairl, R. E., \& Keller, D. M. (1990). Components of burden: interventive implications. The Gerontologist, 30, 236-242.

Krause, N., Goldenhar, L. M. (1992). Acculturation and psychological distress in three groups of elderly Hispanics. Journals of Gerontology 47, S279-S288.

Krefting, L. (1991). The culture concept in the everyday practice of occupational and physical therapy. Physical and Occupational Therapy in Pediatrics, 11, 1-16.

Lawton, M. P., Kleban, M. H., Moss, M., Rovine, M., \& Glicksman, A. (1989). Measuring caregiver appraisal. Journal of Gerontology, 44, P61-P67.

Litterst, T. A. E. (1985). A reappraisal of anthropological fieldwork methods and the concept of culture in occupational therapy research. The American Journal of Occupational Therapy, 39, 602-604.

Livingston, M. G., Manela, M., \& Katona, C. (1996). Depression and other psychiatric morbidity in carers of elderly people living at home. BMJ, 312, 163-156.

Lockery, S. A. (1991). Caregiving among racial \& ethnic minority elders: Family \& social supports. Generations, 15, 58-62

Luna, I., Torres de Ardon, E., Lim, Y. m., Cromwell, S. L., Phillips, L. R., \& Russell, C. K. (1996). The relevance of familism in cross-cultural studies of family caregiving. Western Journal of Nursing Research, 18, 267-283.

Marin, G., \& Gamba, R. J. (1996). A new measurement of acculturation for Hispanics: The Bimensional Acculturation Scale for Hispanics. Hispanic Journal of Behavioral Sciences, 18, 297-316.

Marin, G. ; Marin. B. V. (1991). Translation of data collection instruments. In G. Marin \& B. V. Marin Research with Hispanic populations. 123pp Newbury Park, CA: 
Sage Publications.

Marin, G., Sabogal, F., VanOss Marin, B., Otero-Sabogal, R., \& Perez-Stable, E.J. (1987). Development of a short acculturation scale for Hispanics. Hispanic Journal of Behavioral Sciences, 9, 183-205.

Matsutsuyu, J. (1971). Occupational behavior: a perspective on work and play. The American Journal of Occupational Therapy, 25, 291-294.

Matthews, A. (1993). Issues in the examination of the caregiving relationship. . In S. H. Zarit, L. I. Pearlin, \& K. W. Schaie (Eds.), Caregiving systems: informal and formal helpers (pp. 107-118). Hillsdale, NJ: Lawrence Erlbaum Associates, Publishers.

Matthews, S. H. (1988). The burdens of parent care: A critical evaluation of recent findings. Journal of Aging Studies, 2, 157-165.

McNaughton, M. E., Patterson, T. L., Smith, T. L., \& Grant, I. (1995). The relationship among stress, depression, locus of control, irrational beliefs, social support, and health in Alzheimer's disease caregivers. The Journal of Nervous and Mental Diseases, 183, 78-85.

Medalie, J. H. (1994). The caregiver as the hidden patient: challenges for medical practice. In E. Kahana, D. E. Biegel \& M. L. Wykle (Eds.) Family caregiving across the lifespan (pp. 312-330). Thousand Oaks, CA: Sage Publications.

Mena, F. J., Padilla, A. M., Maldonado, M. (1987). Acculturative stress and specific coping strategies among immigrant and later generation college students. Hispanic Journal of Behavioral Sciences, 9, 207-225.

Mintzer, J. E., Rubert, M. P., Loewenstein, D., Gamez, E., Millor, A., Quinteros, R., Flores, L., Miller, M., Rainerman, A., \& Eisdorfer, C. (1992). Daughters caregiving for Hispanic and non-Hispanic Alzheimer's patients: Does ethnicity make a difference? Community Mental Health Journal, 28, 293-303.

Mui, A, C. (1995). Perceived health and functional status among spouse caregivers of frail older persons. Journal of Aging and Health, 7, 283-300.

Negy, C., \& Woods, D.J. (1992). The importance of acculturation in understanding research with Hispanic-Americans. Hispanic Journal of Behavioral Sciences, 14, 224-247.

Nolan, M., \& Grant, G. (1992). Regular respite: an evaluation of a hospital ROTA bed scheme for elderly people ( 310 pp.).London: Age Concern England.

Nolan, M., Grant, G., \& Keady, J. (1996). Satisfactions of caring: the neglected dimension. In M. Nolan, G. Grant, \& J. Keady (Eds.), Understanding family care: a 
multidimensional model of caring and coping (pp. 82-106). Bristol, PA: Open University Press.

Novak, M., \& Guest, C. (1989). Application of a multidimensional Caregiver Burden Inventory. The Gerontologist, 6, 798-803.

Oakley, F., Kielhofner, G., Barris. R., \& Reicher, R. K. (1986), The Role Checklist: development and empirical assessment of reliability. Occupational therapy Journal of Research, 6 , 157-170.

O'Guinn, T. C., Imperia, G., MacAdams, E. A. (1987). Acculturation and perceived family decision-making input among Mexican-American wives. Journal of Cross-Cultural Psychology, 18, 78-92.

Orbell, S., \& Gillies, B. (1993). What's stressful about caring? Journal of Applied Psychology, 23, 272-290.

Pearlin, L. I., Mullan, J. T., Semple, S. J., \& Skaff, M. M. (1990). Caregiving and the stress process: an overview of concepts and their measures. The Gerontologist, 30 , 583-594.

Pearlin, L. I., \& Schooler, C. (1978). The structure of coping. Journal of Health and Social Behavior, 19, 2-21.

Pearlin, L. I., \& Zarit, S. H. (1993). Research into informal caregiving: current perspectives and future directions. In S. H. Zarit, L. I. Pearlin, \& K. W. Schaie (Eds.), Caregiving systems: informal and formal helpers (pp. 155-167). Hillsdale, NJ: Lawrence Erlbaum Associates, Publishers.

Perez, L. (1994). Cuban families in the United States In R. L. Taylor (Ed.) Minority families in the United States: a multicultural perspective (pp. 82-112). Englewood Cliffs, NJ: Prentice Hall, Inc.

Polich, T. M., Gallagher-Thompson, D. (1997). Preliminary study investigating psychological distress among female Hispanic caregiver. Journal of Clinical Geropsychology, 3, 1-15.

Poulshock, , S. W., \& Deimling, G. T. (1984). Families caring for elders in residence: Issues in the measurement of burden. Journal of Gerontology, 39, 230-239.

Portes, A., Jensen, L. (1989). The enclave and the entrants: Patterns of ethnic enterprise in Miami before and after Mariel. American Sociological Review, 54, 929-949.

Pruchno, R., \& Resch, N. L. (1989). Mental health of caregiving spouses: Coping as mediator, moderator, or main effect? Psychology and Aging 4 454-463. 
Queralt, M. (1984). Understanding Cuban immigrants: a cultural perspective. Social Work, 29, 115-121.

Raveis, V. H., Siegel, K., \& Sudit, M. (1990). Psychological impact of caregiving on the caregiver. In. D. E. Biegel \& A. Blum (Eds.), Aging and caregiving: theory, research and policy (pp. 53-75). Newsbury Park, CA: Sage Publications.

Reddy, M.A. (1993). Demographics In M. A. Reddy (Ed.) Statistical record of Hispanic Americans (pp. 1-193). Detroit, MI: Gale Research Inc.

Reinhard, S., Gubman, G., Horwitz, A., \& Minsky, S. (1994). Burden assessment scale for families of the seriously mentally ill. Evaluation and Program Planning, 17, 261269.

Reinhard, S. C. \& Horwitz, A. V. (1995). Caregiver burden: Differentiating the content and consequences of family caregiving. Journal of Marriage and the Family, 57. 741-750.

Sabogal, F., Marin, G., Otero-Sabogal, R., Marin, B., \& Perez-Stable, E. (1987). Hispanic familism: What changes and what doesn't? Hispanic Journal of Behavioral Sciences, 9, 397-412.

Sankar, A. (1993). Culture, research, and policy. The Gerontologist, 33, 437-438.

Schulz, R. (1990). Theoretical perspectives on caregiving: concepts, variables, and methods. In. D. E. Biegel \& A. Blum (Eds.), Aging and caregiving: theory, research and policy (pp. 27-52). Sage Publications: Newsbury Park, California.

Schulz., R., O'Brien, A. T.,Bookwala, J., \& Fleissner, K. (1995). Psychiatric and physical morbidity effects of dementia caregiving: prevalence, correlates, and causes. The Gerontologist, 35, 771-791.

Schulz. R., Williamson, G. M., Morycz, R., \& Biegel, D. E. (1993). Changes in depression among men and women caring for an Alzheimer's patient. In S. H. Zarit, L. I. Pearlin, \& K. W. Schaie (Eds.), Caregiving systems: informal and formal helpers (pp. 119140). Hillsdale, NJ: Lawrence Erlbaum Associates, Publishers.

Schur, C. L., , Bernstein, A. B., \& Berk. M. L. (1987). The importance of distinguishing Hispanic subpopulations in the use of medical care. Medical Care, 25, 627641 .

Sokolovsky, J. (1990). Bringing culture back home: aging, ethnicity, and family support. In J. Sokolovsky (Ed.), The cultural context of aging: worldwide perspectives (pp. 201-211). Bergin \& Garvey: New York.

Stoll, D. E. (1996). The Multidimensional Caregiver Strain Index (MCSI): its 
measurement and structure. Journal of Clinical Geropsychology, 2, 175-196.

Stommel, M., Given, C. W., \& Given, B. (1990). Depression as an overriding variable explaining caregiver burdens. Journal of Aging and Health, 2, 81-102.

Szapocznik, J., Kurtines, W. M., \& Fernandez, T. (1980). Bicultural involvement and adjustment in Hispanic-American youths. International Journal of Intercultural Relations, 4, 353-365.

Szapocznik, J., Scopetta, M., Kurtines, W., \& Arnalde, M. A. (1978) Theory and measurement of acculturation. Interamerican Journal of Psychology, 12, 113-130.

Tacher, R. D. (1987). Traditional vs. culturally sensitive family therapy sessions: comparison of ratings by Cuban immigrants. Ph. D. dissertation. University of Texas, Austin, Texas.

Talamantes, M. A., Ross Lawler, W., \& Espino, D. V. (1995). Hispanic American elders: Caregiving norms surrounding dying and the use of hospice services. The Hospice Journal, 10, 35-49.

Taylor Seeman, B. (1997, March 10). A little help: More minority elders enter homes. The Miami Herald pp. 1B, 6B.

Taylor, R. L. (1994). Minority families in America: an introduction. In R. L. Taylor (Ed.), Minority families in the United States (pp. 1-16). Englewood Cliffs, NJ: Prentice-Hall Inc.

Tirrito, T., \& Nathason, I. (1994). Ethnic differences in caregiving: adult daughters and elderly mothers. Affilia, $9,71-84$.

Tran, T. V. (1997). Ethnicity, gender and social stress among three groups of elderly Hispanics. Journal of Cross-Cultural Gerontology, 12, 341-356.

Tran, T. V., \& Dhooper, S. S. (1996). Ethnic and gender differences in perceived needs for social services among three elderly Hispanic groups. Journal of Gerontological Social Work, 25, 121-147.

Triandis, H. C., Kashima, Y., Hui, H., Lisansky, J., Marin, G. (1982) Acculturation and biculturism indices among relatively acculturated Hispanic young adults. Interamerican Journal of Psychology, 16, 140-149.

Vargas, L. A. (1992). Diversity of aging experience in Latin America and the Caribbean. Clinical Gerontologist, 12, 5-19.

Vitaliano, P. P., Russo, J.,Young, H. M., Becker, J., \& Maiuro, R. D. (1991). The Screen for Caregiver Burden. The Gerontologist, 31 76-83. 
Vitaliano, P. P., Young, H. M., \& Russo, J. (1991). Burden: A review of measures used among caregivers of individuals with dementia. The Gerontologist, 31, 67-75.

Walker, A. J., Pratt, C. P., \& Eddy, L. (1995). Informal caregiving to aging family members: a critical review. Family Relations, 44, 402-411.

Wallace, S.P., \& Lew-Ting, C. Y. (1992). Getting by at home-community-based long-term care of Latino elders. The Western Journal of Medicine, 157 337-344.

Wallhagen, M. I. (1992). Caregiving demands: their difficulty and effects on the well-being of elderly caregivers. Scholarly Inquiry for Nursing Practice, 6, 111-127.

Webster Dictionary [Computer software]. (1995). Infopedia CD-ROM: Future Vision Multimedia.

Zanetti, O., Frisone, G. B., Bianchetti, A., Tamanza, G., Cigoli, V., \& trabucchi, M. (1998). Depressive symptoms of Alzheimer caregivers are, mainly due to personal rather than patient factors. International Journal of Geriatric Psychiatry, 13, 358-367.

Zarit, S. H., Pearlin, L. I., \& Schaie, K. W. (Eds.). (1993). Caregiving systems: informal and formal helpers. Hillsdale, NJ: Lawrence Erlbaum Associates, Publishers.

Zarit, S. H., Reever, K. E., \& Bach-Peterson, J. (1980). Relatives of the impaired elderly: correlates of feelings of burden. The Gerontologist, 20, 649-655.

Zarit, S. H., Todd, P. A., \& Zarit, J. M. (1986). Subjective burden of husbands and wives as caregivers: a longitudinal study. The Gerontologist, 26, 260-266.

Zsembik, B. A. (1992). Determinants of living alone among older Hispanics. Research on Aging, 15, 449-464. 
APPENDICES 
Appendix A

\section{Subject's eligibility criteria}

This is a study about family members taking care of elderly relatives. In particular we are interested in Cuban-American caregivers because there is little information about these issues among different Hispanic cultures. Thank-you for agreeing to participate in this study. Please consider if these statement apply to your situation.

1. Do you consider yourself of Cuban origin?

YES No

2. Are you caring for an elderly relative?

YES

No

3. Is the relative you care for 65 years or older?

YES

No

4. Does your relative consider him or herself of Cuban origin?

YES

No

5. Do you and your relative live in the same house?

YES

No

6. Has your relative been diagnosed with dementia?

Yes

NO

7. Has your relative been hospitalized with some serious illness

(such as: stroke, heart attack, cancer or severe trauma) during the last month?

Yes

No

If the caregiver answered YES to questions 1 to 5 and NO to questions 6 or 7: You qualify to participate in this study. If you would like to participate we can set a date, time, and place convenient for the interview.

If the caregiver answered NO to any question from 1 to 5 or YES to either 6 or 7: This study does not apply to your particular situation. However I appreciate your help in answering these questions. Thank you for your cooperation. 
Criterio para seleccionar a las personas que califican para esta investidación Este es un estudio sobre las personas que cuidan a un familiar anciano. Estamos interesados particularmente en cubano-americanos porque no hay suficiente información sobre las personas que cuidan a sus familiares dentro de los diferentes grupos de Hispanos. Muchas gracias por su participación en este estudio. Sus respuestas a estas preguntas nos permitirá determinar si Ud. califica para participar en este estudio. Por favor escoja la respuesta que describe mejor su situación.

1. ¿Se considera Ud. de origen cubano?

Sí No

2. ¿Está Ud. cuidando a un familiar anciano?

Sí

No

3. ¿Tiene el familiar que Ud. cuida 65 años de edad o más?

Sí

No

4. ¿Se considera su familiar de origen cubano?

Sí

No

5. ¿Viven Ud. y su familiar en la misma casa?

Sİ

No

6. ¿Ha sido su familiar diagnosticado con demencia?

Sí

No

7. ¿Ha estado su familiar hospitalizado por alguna enfermedad

seria (tal como un derrame cerebral, ataque del corazón,

cáncer o trauma serio) durante el mes pasado?

Sí

No

Si la persona que cuida el familiar contestó $\mathrm{SI}$ a las preguntas de la 1 al 5 y NO a las preguntas 6 ó 7: Usted califica para participar en este estudio. Si desea participar podemos fijar una fecha, hora y lugar para la entrevista.

Si la persona que cuida el familiar contestó NO a cualquiera de las preguntas de la 1 a la 5 o SI a la preguntas 6 ó 7: Este estudio no se aplica a su situación particular, pero le agradezco su ayuda en contestar estas preguntas. Gracias por su cooperación 


\section{Invitation to participate in the study}

My name is Georgia de las Pozas and I am a graduate student in occupational therapy at Florida International University. Occupational therapists work with other health professionals in the rehabilitation of persons after illnesses or accidents.

The purpose of this research project is to learn about Cuban-Americans living in our community who take care of their loved ones after they have suffered an illness, accident or are just frail. A lot of information is known about American caregivers, but Cuban-Americans have their own customs and ways of doing things. Anything we learn will be useful for health care professionals treating elderly Cuban-Americans.

This study involves answering a questionnaire with questions related to yourself and about taking care of your elderly relative, in particular about your feelings about caregiving. Some questions will be specific to your Cuban origin.

Your identity and answers to the questions will be kept anonymous as your name will not be placed anywhere on this questionnaire. The results will only be reported as a group.

No side effects have been noted in association with answering this type of questionnaire. However, some people may feel tired or some questions may cause stress and anxiety. There are no risks anticipated by participating in this study.

Your participation is voluntary. You are free to stop your participation anytime during the study. If you have any questions please contact:

Georgia de las Pozas, Principal Investigator at (305) 388-6464, or Dr. Gail A. Hills, Faculty Advisor in FIU at (305) 348-3104

Again, let me thank you for your help. Without the participation of people like you I would not be able to finish this study and valuable information would not obtained. 


\section{Invitación para participar en este estudio}

Mi nombre es Georgia de las Pozas y soy una estudiante de la Universidad Internacional de la Florida (FIU) haciendo una Maestría en Terapia Ocupacional. Terapistas ocupacionales, junto con otros profesionales de salud, trabajan en la rehabilitación de las personas después de un accidente o una enfermedad.

El propósito de este proyecto de investigación es obtener información sobre los cubanos-americanos que viven en nuestra comunidad y que se ocupan del cuidado de sus seres queridos que han sufrido alguna enfermedad, accidente o que simplemente son frágiles dado su edad. Se conoce mucho sobre personas americanas que cuidan sus familiares, pero los cubanos-americanos tienen sus costumbres y sus formas de hacer las cosas. Cualquier cosa que aprendamos será de utilidad para los profesionales de la salud que tratan cubanos-americanos de edad mayor.

Este estudio consiste en contestar un cuestionario con preguntas sobre usted, sobre el cuidado de su familiar mayor de edad y en particular sobre sus sentimientos sobre el proveer este cuidado. Algunas preguntas se refieren a su origen cubano.

Su identidad y sus respuestas serán mantenidas anónimas y su nombre no aparecerá en ninguna parte del cuestionario. Los resultados se reportarán como parte del grupo.

El contestar este tipo de cuestionario no ha estado asociado a efectos secundarios. Sin embargo, algunas personas pueden sentirse cansadas o algunas preguntas pueden causar estrés y ansiedad. No hay riesgos asociados con la participación en este estudio.

Su participación es voluntaria. Usted es libre de parar su participación en este estudio en cualquier momento. Si usted tiene alguna pregunta por favor contacte a:

Georgia de las Pozas, Investigadora Principal al (305) 388-6464, ó Dra. Gail A. Hills, Asesora de la Facultad en FIU al (305) 348-3104

Otra vez le agradezco por su ayuda. Sin la participación de personas como usted yo no podría finalizar este estudio y no se obtendría información de gran importancia. 
Appendix E

\section{Caregiver questionnaire}

Thank you for participating in this study.

AGREEING TO ANSWER THIS QUESTIONNAIRE MEANS YOU HAVE AGREED TO PARTICIPATE IN THE STUDY.

We will be asking you questions about you, the person you care for, your family, and about how you feel about caring for your relative. There are no right or wrong answers. It is important to answer all the questions. If a question does not have an answer that applies exactly to you, you may pick the best answer. This information is only used to describe the group of people who have completed the survey. This information is STRICTLY ANONYMOUS and you will NOT be identified in any way. Please listen carefully and choose the answers which best apply to you. It should take approximately 40 minutes to respond to all of the questions.

\section{Let's start Section I.}


$\mathrm{D} \#$

\section{Section I}

To begin, we would like to know about you, your relative, and your caregiving situation. First we will like some information about you and your family member. Please listen carefully to all questions and choose the answer which most closely describes your situation.

Sex: $\mathrm{M}(1)$

1. How old are you? years old.

2. Where were you born?

1. Cuba

2. U.S.

3. Other, please specify:

3. If you were not born in the U. S., what year did you arrive? In 19

4. If you were not born in the U.S., how old were you when you arrived in the U.S.?

_ _ years old

5. How far did you go in school?

1. Less than 4 years

2. 4 years but less than 8 years

3. 8 to 12 years (without a high school diploma) [IN SOME CASES HIGH SCHOOL MAY INCLUDE A YEAR 13]

4. High school diploma

5. Post high school, business, or trade/vocational. (Graduated from high school Yes No)

6. Some college

7. College degree (not including medicine or law)

8. Post graduate college (including medicine, law, Ph.D., "candidatura", doctorate) 
6. What is your religious affiliation?

1. Catholic

2. Protestant

3. Jewish

4. None

5. Other, please specify:

7. With which racial group do you identify?

8. Are you presently:

1. Employed full time

2. Employed part time

3. Unemployed (not receiving retirement benefits)

4. Retired (with benefits) but still working some

5. Retired (with benefits) but not working

6. Retired (without benefits)

7. Housewife (never regularly employed outside of home)

9. What is your relationship to the elderly relative you care for? I am his/her:

1. Wife

2. Husband

3. Daughter

4. Son

5. Son-in-law

6. Daughter-in-law

7. Other, please specify:

10. How long have you been providing care for your elderly family member?

1. Less than one month

2. One month but less than six months

3. Six months to one year

4. More than one year

11. What is the sex of your elderly family member?

1. Male

2. Female

12. How old is your elderly relative? years old. 
ID\#

13. What are the things that you do that make you the person responsible for taking care of your relative?

There are a lot of different ways that families handle the care for elderly relatives. The following questions are about how your family manages and some of the changes you may have done to accommodate caring for your relative.

14. We would like to know how each person became a caretaker. How did this happen with you?

15. Do you feel you give a major part of the care for your elderly relative?

0 . No

1. Yes

If No: What kind of care do you give?

16. Does anyone else share the responsibility of helping with your elderly relative?

0 . No

1. Yes

\section{If Yes:}

A. What is the relationship of this person to your elderly relative? (spouse, son, daughter, brother, sister, etc).

B. How does the other person share the caregiving? 
ID\#

17. If you were unavailable, is there someone else who could take over care of your family member?

0 . No

1. Yes

If Yes:

A. What is the relationship of this person to your elderly relative?

IF THERE IS NO PERSON SHARING THE CAREGIVING (QUESTION

16) THE FOLLOWING QUESTION 17 B IS NOT PERTINENT. SKIP TO QUESTION 18

B. Is this the same person you mentioned shares in the caregiving?

0 . No

1. Yes

18. Have you or your relative moved so that you could take care of him or her?

0 . No

1. Yes

19. Have you made changes in your home (such as ramps, shower bars, more lights, switch bedrooms, etc) to accommodate your elderly relative?

0. No

1. Yes 
Some people are uncomfortable answering questions regarding household income. We only use this information to learn whether or not people feel they have adequate resources to be a caregiver.

20. Approximately, what is your household income? Please choose the answer which best apply to you.

Yearly

0. Less than $\$ 4,999$

1. $\$ 5,000-\$ 6,999$

2. $\$ 7,000-\$ 9,999$

3. $\$ 10,000-\$ 14,999$

4. $\$ 15,000-\$ 19,999$

5. $\$ 20,000-\$ 29,999$

6. $\$ 30,000-\$ 39,999$

7. $\$ 40,000-\$ 49,999$

8. $\$ 50,000$ or more

9. NO ANSWER
OR

Less than $\$ 416$

$\$ 417-\$ 583$

$\$ 584-\$ 833$

$\$ 834-\$ 1249$

$\$ 1250-\$ 1666$

$\$ 1667-\$ 2499$

$\$ 2500-\$ 3333$

$\$ 3334-\$ 4166$

$\$ 4167$ or more

You have completed section I of the questionnaire. We will go now to section II. 


\section{Section II}

The following questions are about your elderly relative's ability to perform daily activities, the type of assistance needed, and your feelings as caregiver. Please listen carefully and choose the answer which best describes your situation.

21. Can your elderly relative use the telephone...

$0=\quad$ without help (including looking up numbers and dialing)

$1=\quad$ with some help (can answer phone or dial operator in an emergency, but needs a special phone or help in getting the number of dialing),

$2=\quad$ or is he/she completely unable to use the telephone

$9=\quad$ NOT ANSWERED

21 a. Do you currently help your elderly relative use the telephone?

$0=$ No

$1=$ Yes

$21 \mathrm{~b}$. Is it or would it be emotionally or physically difficult for you to help your elderly relative to use the telephone?

$0=$ No

$1=$ Physically difficult only

2=Emotionally difficult only

$3=$ Both physically and emotionally difficult

22. Can your elderly relative get to places of walking distance...

$0=\quad$ without help (can travel alone on buses, taxis, or drive your own car),

$1=\quad$ with some help (need someone to help him/her or go with him/her when traveling) or

$2=\quad$ or is he/she completely unable to travel unless emergency arrangements are made for a specialized vehicle like an ambulance?

$9=\quad$ NOT ANSWERED

22 a. Do you currently help your elderly relative to get places?

$0=$ No

$1=$ Yes 
ID\#

$22 \mathrm{~b}$. Is it/would it be emotionally or physically difficult for you to help your elderly relative to get places?

$0=$ No

$1=$ Physically difficult only

$2=$ Emotionally difficult only

$3=$ Both physically and emotionally difficult

23. Can your elderly relative go shopping for groceries or clothes [ASSUMING YOUR ELDERLY RELATIVE HAS TRANSPORTATION]...

$0=\quad$ without help (taking care of all shopping needs him/herself, assuming he/she had transportation),

$1=\quad$ with some help (need someone to go with him/her on all shopping trips), or

$2=\quad$ is he/she completely unable to do any shopping?

$9=\quad$ NOT ANSWERED

23 a. Do you currently help your elderly relative to go shopping?

$0=$ No

$1=$ Yes

$23 \mathrm{~b}$. Is it/would it be emotionally or physically difficult for you to help your elderly relative to go shopping?

$0=$ No

$1=$ Physically difficult only

$2=$ Emotionally difficult only

$3=$ Both physically and emotionally difficult

24. Can your elderly relative prepare his/her own meals...

$0=\quad$ without help (plan and cook full meals him/herself)

$1=\quad$ with some help (can prepare some things but unable to cook full meals for him/herself),

$2=\quad$ or is he/she completely unable to prepare any meals?

$9=$ NOT ANSWERED

24 a. Do you currently help your elderly relative to prepare his/her meals?

$0=$ No

$1=$ Yes 
$24 \mathrm{~b}$. Is it/would it be emotionally or physically difficult for you to help your elderly relative to prepare his/her meals?

$0=$ No

$1=$ Physically difficult only

$2=$ Emotionally difficult only

$3=$ Both physically and emotionally difficult

25. Can your elderly relative do his/her housework...

$0=\quad$ without help (can scrub floors, etc.)

$1=\quad$ with some help (can do light housework but need help with heavy work),

$2=\quad$ or is he/she completely unable to do any housework?

$9=\quad$ NOT ANSWERED

25 a. Do you currently help your elderly relative to do housework?

$$
\begin{aligned}
& 0=\text { No } \\
& 1=\text { Yes }
\end{aligned}
$$

$25 \mathrm{~b}$. Is it/would it be emotionally or physically difficult for you to help your elderly relative to do housework?

$$
\begin{aligned}
& 0=\text { No } \\
& 1=\text { Physically difficult only } \\
& 2=\text { Emotionally difficult only } \\
& 3=\text { Both physically and emotionally difficult }
\end{aligned}
$$

26. Can your elderly relative take his/her own medicine...

$0=\quad$ without help (in the right dose at the right time)

$1=\quad$ with some help (able to take medicine if someone prepares it for him/her and/or reminds him/her to take it),

$2=\quad$ or is he/she completely unable to take his/her own medicine?

$9=\quad$ NOT ANSWERED

26 a. Do you currently help your elderly relative to take his/her medicine?

$$
\begin{aligned}
& 0=\text { No } \\
& 1=\text { Yes }
\end{aligned}
$$


IDH

$26 \mathrm{~b}$. Is it/would it be emotionally or physically difficult for you to help your elderly relative to take his/her medicine?

$0=$ No

$1=$ Physically difficult only

$2=$ Emotionally difficult only

$3=$ Both physically and emotionally difficult

27. Can your elderly relative manage his/her own money...

$0=\quad$ without help (write checks, pay bills, etc.)

$1=\quad$ with some help (manage day-to-day buying but need help with managing his/her checkbook and paying his/her bills).

$2=\quad$ Or is he/she completely unable to handle his/her own money?

$9=\quad$ NOT ANSWERED

27 a. Do you currently help your elderly relative with his/her finances?

$0=$ No

$1=$ Yes

$27 \mathrm{~b}$. Is it/would it be emotionally or physically difficult for you to help your elderly relative to help with his/her finances?

$0=$ No

$1=$ Physically difficult only

$2=$ Emotionally difficult only

$3=$ Both physically and emotionally difficult

28. Can your elderly relative eat...

$0=\quad$ without help (able to feed him/herself completely)

$1=\quad$ with some help (need help with cutting, etc.)

$2=$ or is he/she completely unable to feed him/herself?

$9=\quad$ NOT ANSWERED

28 a. Do you currently help your elderly relative to eat?

$0=$ No

$1=$ Yes 
IDH

$28 \mathrm{~b}$. Is it/would it be emotionally or physically difficult for you to help your elderly relative to eat?

$0=$ No

$1=$ Physically difficult only

$2=$ Emotionally difficult only

$3=$ Both physically and emotionally difficult

29. Can your elderly relative dress and undress him/herself...

$0=\quad$ without help (able to pick out clothes, dress and undress him/herself)

$1=\quad$ with some help

$2=\quad$ or is he/she completely unable to dress and undress him/herself?

$9=\quad$ NOT ANSWERED

29 a. Do you currently help your elderly relative with dressing?

$0=$ No

$1=$ Yes

$29 \mathrm{~b}$. Is it/would it be emotionally or physically difficult for you to help your elderly relative with dressing?

$0=$ No

$1=$ Physically difficult only

2= Emotionally difficult only

$3=$ Both physically and emotionally difficult

30. Can your elderly relative take care of his/her own appearance, for example, combing his/her hair...

$0=\quad$ without help

$1=\quad$ with some help

$2=\quad$ or is he/she completely unable to maintain his/her appearance him/herself?

$9=\quad$ NOT ANSWERED

30 a. Do you currently help your elderly relative with grooming?

$0=$ No

$1=$ Yes 
ID\#

$30 \mathrm{~b}$. Is it/would it be emotionally or physically difficult for you to help your elderly relative with grooming?

$0=$ No

$1=$ Physically difficult only

$2=$ Emotionally difficult only

$3=$ Both physically and emotionally difficult

31. Can your elderly relative walk...

$0=\quad$ without help (except from a cane)

$1=\quad$ with some help from a person or with the use of a walker, or crutches, etc.

$2=\quad$ or is he/she completely unable to walk?

$9=\quad$ NOT ANSWERED

31 a. Do you currently help your elderly relative to walk/ [OR IF CANNOT WALK] to move?

$0=$ No

$1=$ Yes

$31 \mathrm{~b}$. Is it/would it be emotionally or physically difficult for you to help your elderly relative walk/ [OR IF CANNOT WALK] move?

$0=$ No

$1=$ Physically difficult only

$2=$ Emotionally difficult only

$3=$ Both physically and emotionally difficult

32. Can your elderly relative get in and out of bed...

$0=\quad$ without help or aids

$1=\quad$ with some help (from either a person or with the aid of some device),

$2=\quad$ or is he/she totally dependent on someone else to lift him/her?

$9=\quad$ NOT ANSWERED

32 a. Do you currently help your elderly relative get in and out of bed?

$0=$ No

$1=$ Yes 
$32 \mathrm{~b}$. Is it/would it be emotionally or physically difficult for you to help your elderly relative get in and out of bed?

$0=$ No

$1=$ Physically difficult only

$2=$ Emotionally difficult only

$3=$ Both physically and emotionally difficult

33. Can your elderly relative take a bath or shower...

$0=\quad$ without help

$1=\quad$ with some help (need help getting in and out of the tub, or need special attachments on the tub),

$2=$ or is he/she completely unable to bathe him/herself?

$9=\quad$ NOT ANSWERED

33 a. Do you currently help your patient with bathing?

$0=$ No

$1=$ Yes

$33 \mathrm{~b}$. Is it/would it be emotionally or physically difficult for you to help your elderly relative with bathing?

$0=$ No

$1=$ Physically difficult only

$2=$ Emotionally difficult only

$3=$ Both physically and emotionally difficult

34. Does your elderly relative ever have trouble getting to the bathroom on time or using the toilet...

$0=\quad$ No

$1=$ Yes

$2=\quad$ Have a catheter or colostomy

$9=\quad$ NOT ANSWERED

34 a. Do you currently help your elderly relative with toileting?

$$
\begin{aligned}
& 0=\text { No } \\
& 1=\text { Yes }
\end{aligned}
$$


$34 \mathrm{~b}$. Is it/would it be emotionally or physically difficult for you to help your elderly relative with toileting?

$0=$ No

$1=$ Physically difficult only

$2=$ Emotionally difficult only

$3=$ Both physically and emotionally difficult

You have completed section II of the questionnaire. We will go now to section III. 


\section{ID\#}

\section{Section III}

Now we are going to ask you some questions about why caregiving may be difficult for you. Please choose the answers which best apply to your situation.

\begin{tabular}{|c|c|c|c|c|c|}
\hline & & $\begin{array}{l}\text { This } \\
\text { does } \\
\text { not }\end{array}$ & $\begin{array}{l}\text { This state } \\
\text { Ind th: }\end{array}$ & entappies & o me and \\
\hline & ing ean bs dificut because: & $\begin{array}{l}\text { apply to } \\
\text { ne }\end{array}$ & Not: & Sursisturi & 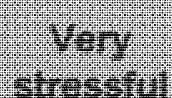 \\
\hline 35 & $\begin{array}{l}1 \text { don't have enough private time } \\
\text { for myself }\end{array}$ & & & & \\
\hline 36 & $\begin{array}{l}1 \text { can fel helpless/ not in control } \\
\text { of the situation }\end{array}$ & & & & \\
\hline 37 & $\begin{array}{l}\text { I can't devote enough time to } \\
\text { other family members }\end{array}$ & & & & \\
\hline 38 & It causes financial difficulties & & & & \\
\hline 39 & $\begin{array}{l}\text { The person I care for can } \\
\text { manipulate me }\end{array}$ & & & & \\
\hline 40 & $\begin{array}{l}\text { The person } 1 \text { care for is } \\
\text { immobilehas problems getting } \\
\text { about }\end{array}$ & & & & \\
\hline 41 & $\begin{array}{l}\text { Professional workers don't seem } \\
\text { to appreciate the problems carers } \\
\text { face }\end{array}$ & & & & \\
\hline 42 & $\begin{array}{l}\text { It restricts my social lifeloutside } \\
\text { interests }\end{array}$ & & & & \\
\hline 43 & $\begin{array}{l}\text { It can put a strain on family } \\
\text { relationships }\end{array}$ & & & & \\
\hline 44 & It is physically tring & & & & \\
\hline
\end{tabular}


IDH

\begin{tabular}{|c|c|c|c|c|c|}
\hline & & $\begin{array}{l}\text { This } \\
\text { does } \\
\text { not }\end{array}$ & $\begin{array}{l}\text { This stat: } \\
\text { I find it: }\end{array}$ & mi applit & me and: \\
\hline & ing can be diffcull because: & me & Not & Stregret & Ver: \\
\hline 46 & $\begin{array}{l}\text { I no longer have a meaningful } \\
\text { relationship with the person I care } \\
\text { for }\end{array}$ & & & & \\
\hline 47 & $\begin{array}{l}\text { The person } 1 \text { care for needs a lot } \\
\text { of help with personal care }\end{array}$ & & & & \\
\hline 48 & $\begin{array}{l}\text { The person I care for doesn't } \\
\text { always help as much as they } \\
\text { could }\end{array}$ & & & & \\
\hline 49 & $\begin{array}{l}\text { My slecping patterns have } \\
\text { changed }\end{array}$ & & & & \\
\hline 50 & $\begin{array}{l}\text { Relatives don't keep in touch as } \\
\text { often as Td like }\end{array}$ & & & & \\
\hline 51 & I feel angry about the situation & & & & \\
\hline 52 & $\begin{array}{l}\text { I can't see friends as often as I'd } \\
\text { like }\end{array}$ & & & & \\
\hline 53 & My emotional well-being suffers & & & & \\
\hline 54 & $\begin{array}{l}\text { I can't have a break or take a } \\
\text { holiday. }\end{array}$ & & & & \\
\hline 55 & My standard of living has fallen & & & & \\
\hline 56 & $\begin{array}{l}\text { The person I care for doesn't } \\
\text { always appreciate what I do }\end{array}$ & & & & \\
\hline 57 & My physical health has suffered & & & & $=$ \\
\hline 58 & $\begin{array}{l}\text { The person } 1 \text { care for is } \\
\text { incontinent }\end{array}$ & & & & \\
\hline 59 & $\begin{array}{l}\text { The behavior of the person } 1 \text { care } \\
\text { for is a problem }\end{array}$ & & & & \\
\hline 60 & $\begin{array}{l}\text { There is no satisfaction to be } \\
\text { gained from caring }\end{array}$ & & & & \\
\hline
\end{tabular}


IDH

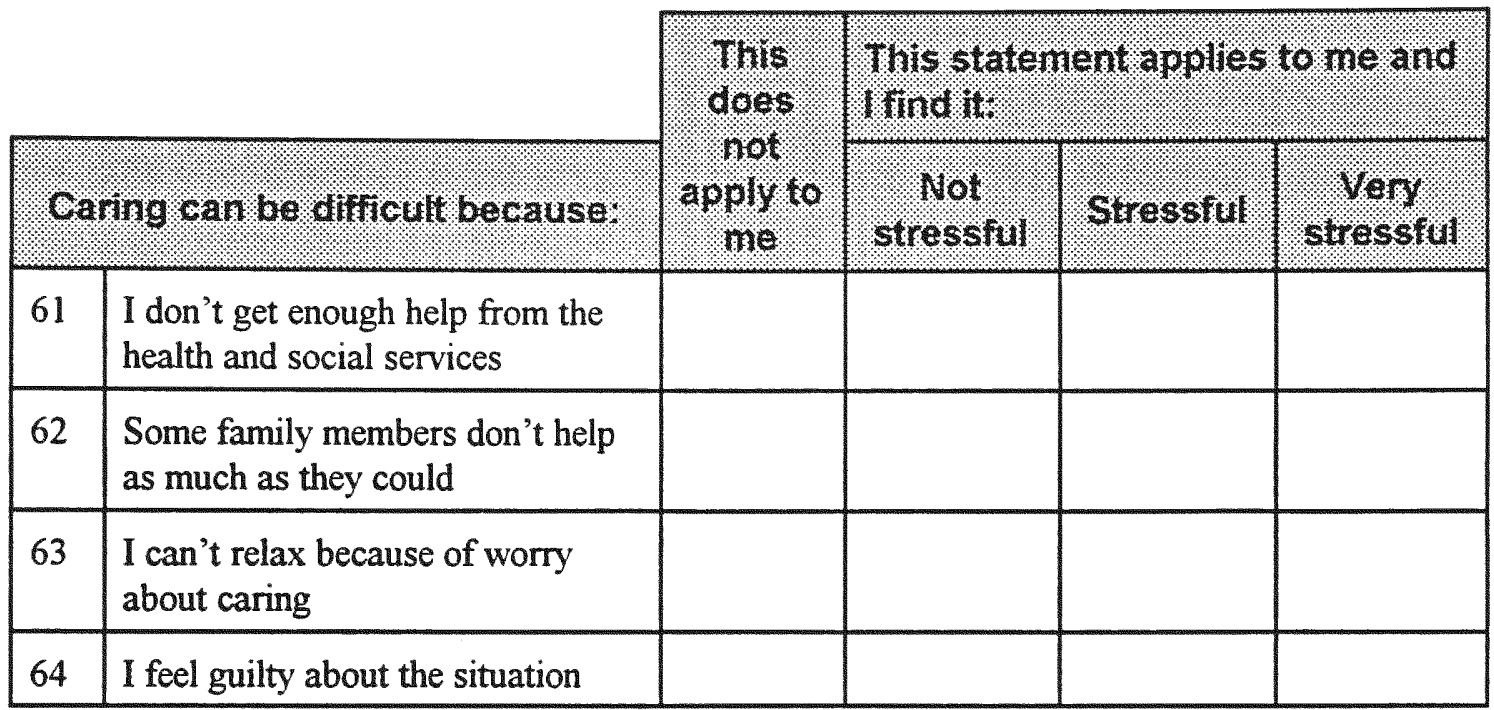
find them:

Please add below any further difficulties you face and indicate how stressful you



You have completed section III of the questionnaire. We will go now to section IV. 
IDH

\section{Section IV}

Now we are going to ask you some questions about why caregiving may be satisfying to you. Please choose the answers which best apply to you.

\begin{tabular}{|c|c|c|c|c|c|}
\hline & & $\begin{array}{l}\text { This } \\
\text { does }\end{array}$ & This applit & to ne and prot & les ne with: \\
\hline & If can bo satistying & $\begin{array}{c}\text { apply } \\
\text { to }\end{array}$ & $\begin{array}{l}\text { No real } \\
\text { sites }\end{array}$ & Qutem lot of & $\begin{array}{l}\text { A goreat deal } \\
\text { of }\end{array}$ \\
\hline 65 & $\begin{array}{l}\text { Caring has allowed me to } \\
\text { develop new skills and } \\
\text { abilities }\end{array}$ & & & & \\
\hline 66 & $\begin{array}{l}\text { The person } 1 \text { care for is } \\
\text { appreciative of what } 1 \text { do }\end{array}$ & & & & \\
\hline 67 & $\begin{array}{l}\text { Caring has brought me } \\
\text { closer to the person } 1 \text { care } \\
\text { for }\end{array}$ & & & & \\
\hline 68 & $\begin{array}{l}\text { It's good to see small } \\
\text { improvements in their } \\
\text { condition }\end{array}$ & & & & \\
\hline 69 & $\begin{array}{l}\text { I am able to help the person } \\
\text { I care for reach their full } \\
\text { potential }\end{array}$ & & & & \\
\hline 70 & $\begin{array}{l}\text { I am able to repay their past } \\
\text { acts of kindness }\end{array}$ & & & & \\
\hline 71 & Caring provides a challenge & & & & \\
\hline 72 & $\begin{array}{l}\text { Despite all their problems } \\
\text { the person I care for does } \\
\text { not grumble or moan }\end{array}$ & & & & \\
\hline 73 & $\begin{array}{l}\text { It is nice to see the person I } \\
\text { care for clean, comforable } \\
\text { and well tumed out }\end{array}$ & & & & \\
\hline 74 & $\begin{array}{l}\text { Caring enables me to fulfill } \\
\text { my sense of duty }\end{array}$ & & & & \\
\hline
\end{tabular}


ID\#

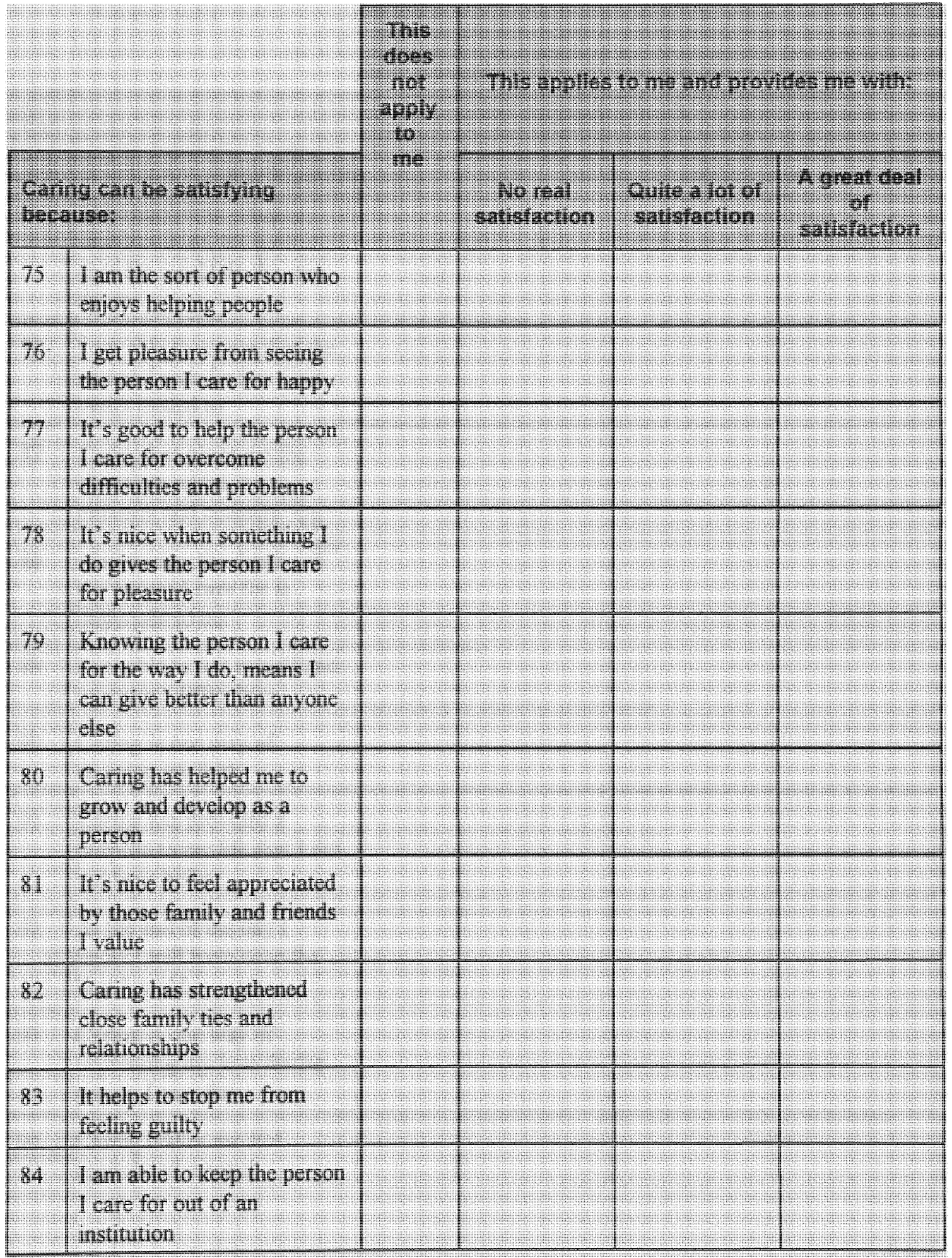


ID\#

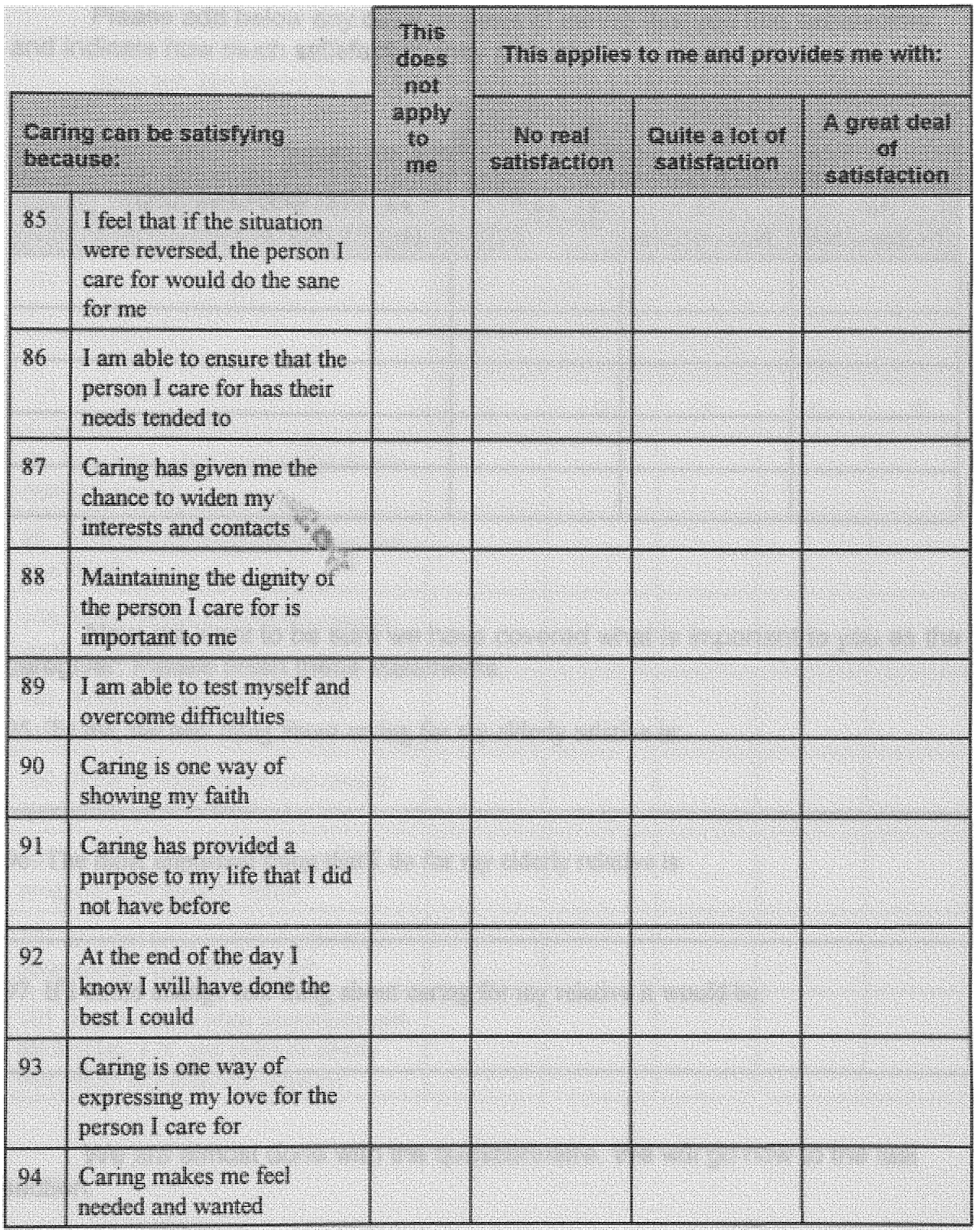


Please add below any other aspects of caring that you find satisfactory and indicate how much satisfaction they give you.

\begin{tabular}{|c|c|c|c|}
\hline 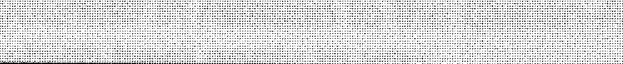 & \multicolumn{3}{|c|}{ This applies to me and provides me with: } \\
\hline Caring can be satistying because: & $\begin{array}{l}\text { No feal } \\
\text { satisfaction }\end{array}$ & $\begin{array}{l}\text { Ouite a lot } \\
\text { of } \\
\text { satisfaction }\end{array}$ & $\begin{array}{l}\text { A great deal } \\
\text { of } \\
\text { satistaction }\end{array}$ \\
\hline & & & \\
\hline & & & \\
\hline & & & 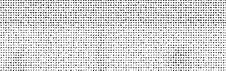 \\
\hline & & & \\
\hline & & & \\
\hline
\end{tabular}

Now, we want to be sure we have covered what is important to you as the caregiver: Please finish these statements.

95. To me, the best thing about caring for my elderly relative is:

96. The most important thing that I do for my elderly relative is:

97. If I could change one thing about caring for my relative it would be:

We are almost done with the questionnaire. We will go now to the last section. 
ID\#

\section{Section V}

Now we are going to ask you some questions about how you describe yourself in relation to the Cuban-American culture. Please choose the answers which best apply to you.

\begin{tabular}{|c|c|c|c|c|c|}
\hline & $\begin{array}{l}\text { Oniy } \\
\text { Spanish }\end{array}$ & $\begin{array}{l}\text { Spanlsh } \\
\text { betier } \\
\text { than } \\
\text { English }\end{array}$ & $\begin{array}{l}\text { Bent } \\
\text { egually }\end{array}$ & $\begin{array}{l}\text { Englsh } \\
\text { betiet } \\
\text { hant } \\
\text { Spanion }\end{array}$ & $\begin{array}{l}\text { Enty } \\
\text { enouls }\end{array}$ \\
\hline & 1 & $\underline{\underline{2}}$ & 3 & $\frac{A_{4}}{\xi}$ & $\bar{E}$ \\
\hline $\begin{array}{l}\text { 98. In general, what language(s) do you } \\
\text { read and speak? }\end{array}$ & & & & & \\
\hline $\begin{array}{l}\text { 99. What was the language(s) you used } \\
\text { as a clild? }\end{array}$ & & & & & \\
\hline $\begin{array}{l}\text { 100. What language(s) do you usually } \\
\text { speak at home? }\end{array}$ & & & & & \\
\hline $\begin{array}{l}\text { 101. In which language(s) do you } \\
\text { usually think? }\end{array}$ & & & & & \\
\hline $\begin{array}{l}\text { 102. What language(s) do you usually } \\
\text { speak with your friends? }\end{array}$ & & & & & \\
\hline $\begin{array}{l}\text { 103. In what language(s) are the T.V. } \\
\text { programs you usually watch? }\end{array}$ & & & & & \\
\hline $\begin{array}{l}\text { 104. In what language(s) are the radio } \\
\text { program you usually listen to? }\end{array}$ & & & & & \\
\hline $\begin{array}{l}\text { 105. In general, in what language(s) are } \\
\text { the movies, } \mathrm{V}, \mathrm{\text {and }} \text { radio programs } \\
\text { you prefer to wateh and listen to? }\end{array}$ & & & & & \\
\hline
\end{tabular}


ID\#

\begin{tabular}{|c|c|c|c|c|c|}
\hline & $\begin{array}{l}\text { Mit } \\
\text { teatinost } \\
\text { Hispanics }\end{array}$ & $\begin{array}{l}\text { More } \\
\text { Wuros } \\
\text { man } \\
\text { mancans }\end{array}$ & $\begin{array}{l}\text { Aboul } \\
\text { Hail } \\
\text { ard } \\
\text { Hall }\end{array}$ & 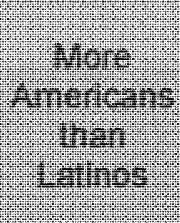 & $\begin{array}{l}\text { Mi } \\
\text { Arrertoans }\end{array}$ \\
\hline$=$ & 1 & 2 & 3 & 4 & 5 \\
\hline 106. Your close friends are & & & & & \\
\hline $\begin{array}{l}\text { 107. You prefer going to } \\
\text { social gatherings/parties at } \\
\text { which people are: }\end{array}$ & & & & & \\
\hline $\begin{array}{l}\text { 108. The persons you visit } \\
\text { or who visit you are: }\end{array}$ & & & & & \\
\hline $\begin{array}{l}\text { 109. If you could choose } \\
\text { your children's frends, you } \\
\text { would want them to be: }\end{array}$ & & & & & \\
\hline
\end{tabular}

We have finished the last section of the questionnaire and I want to thank you again for your participation. 
Cuestionario para personas que cuidan a un familiar mayor de edad

Gracias por su participación en este estudio.

El hecho de que Ud. está de acuerdo en contestar este cuestionario nos indica que Ud. está de acuerdo en participar en este estudio.

Vamos a preguntarle sobre Ud. , la persona que Ud. cuida, su familia, y sobre sus sentimientos con respecto al cuidado de su familiar. No hay repuestas correctas o incorrectas. Es muy importante que conteste todas las preguntas. Si alguna pregunta no se aplica a su situación exáctamente, escoja la respuesta que más se acerque. La información que obtengamos sólo será usada para describir el grupo de personas que completó esta encuesta. La información obtenida es estríctamente anónima y Ud. no será identificado de ninguna forma. Por favor, escuche aténtamente y escoja la respuesta que mejor se ajuste a su situación. El contestar todas las preguntas demorará apróximadamente 40 minutos.

Vamos a comenzar la sección I 
ID \#

\section{Sección I}

Para comenzar quisiéramos conocer aspectos sobre Ud., su familiar, y su situación con respecto al cuidado de su familiar. Primero, quisiéramos saber sobre Ud. y su familiar. Por favor, escuche aténtamente y escoja la respuesta que mejor represente su situación.

Sexo: $M(1)$

1. ¿Cuál es su edad? años de edad.

2. ¿Donde nació usted?

1. Cuba

2. Estados Unidos

3. Otro país, por favor especifique:

3. Si Ud. no nació en los Estados Unidos, ¿en que año llegó? En 19

4. Si Ud. no nació en los Estados Unidos, ¿qué edad tenía Ud. cuando llegó a los Estados Unidos? años de edad.

5. ¿Cúal es el grado de escolaridad más alto que Ud. ha alcanzado?

1. Menos de 4 años

2. 4 años per menos de 8 años

3.8 a 12 años ( pero sin haberse graduado de bachillerato o preuniversitario =high school) [EN ALGUNOS CASOS PUEDE INCLUIR GRADO 13]

4. Diploma de bachillerato o preuniversitario $=$ high-school

5. Escuela de comercio o técnico/vocacional (Graduado de bachillerato o preuniversitario $\mathrm{Si}$ No)

6. Algunos años de universidad pero no graduado

7. Graduado universitario (sin incluir medicina y leyes)

8. Educación post-graduada (include medicina, leyes, $\mathrm{PhD}$, candidatura, doctorado)

6. ¿Cúal es su afiliacion religiosa?

1. Católico

2. Protestante

3. Judío

4. Ninguna

5. Otra, por favor especifique 
ID \#

7. ¿Con qué grupo racial se identifica Ud?

8. ¿Está usted actualmente:

1. Empleado(a) tiempo completo

2. Empleado(a) medio tiempo

3. Desempleado(a) (no recibiendo beneficios de retiro)

4. Retirado(a) (con beneficios) pero trabaja algo

5- Retirado(a) (con beneficios) pero sin trabajar

6. Retirado(a) (sin beneficios)

7. Ama de casa (nunca trabajó regularmente fuera de la casa)

9. ¿Cúal es su parentesco con su familiar mayor de edad? Soy su:

1. Esposa

2. Esposo

3. Hija

4. Hijo

5. Yerno

6. Nuera

7. Otro: Si contesta "otro", por favor especifique:

10. ¿Cúanto tiempo lleva usted cuidando a su familiar mayor de edad?

1. Un mes o menos

2. Entre un mes pero menos de seis meses

3. Entre seis meses y un año

4. Más de un año

11. ¿Cúal es el sexo de su familiar mayor de edad?

1. Masculino

2. Femenino

12. ¿Cual es la edad de su familiar mayor de edad? años de edad

13. ¿Cúales son las cosas que Ud. hace que le hacen a Ud. la persona responsable del cuidado de su familiar? 
D \#

La familia tiene muchas maneras de manejar el cuidado de sus familiares mayor de edad. Las próximas preguntas se relacionan con la forma en que su familia se desenvuelve con el cuidado de su familiar y con los cambios que puedan haber hecho para acomodar a su familiar. COMO UD. ESTÁ CUIDANDO A SU FAMILIAR MAYOR DE EDAD LO LLAMAREMOS CUIDADOR o CUIDADORA

14. Quisiéramos conocer como es que cada persona se convierte en cuidador/cuidadora. ¿Cómo es que fue con Ud. ?

15. ¿Cree qué Ud. es el que provee la mayor parte del cuidado a su familiar?

0 . No

1. Sí

Si la respuesta es No: ¿Qué tipo de ayuda provee Ud.?

16. ¿Hay alguna otra persona que comparta la responsibilidad de ayudar con el cuidado de su familiar?

0 . No

1. Sí

Si la respuesta es Sí:

A. ¿Cúal es el parentesco entre esta persona y su familiar? (esposo(a), hijo(a), hermano(a), etc.)

B. ¿Cómo comparte esta persona el cuidado de su familiar? 
17. Si Ud. no estuviera disponible, ¿hay alguna otra persona disponible para ayudar a su familiar?

0 . No

1. Sí

Si la respuesta es sí:

A. ¿Cúal es el parentesco entre esta persona y su familiar?

SI NO HAY OTRA PERSONA COMPARTIENDO EL CUIDADO DE SU FAMILIAR MAYOR DE EDAD (PREGUNTA 16) LA PREGUNTA 17 B A CONTINUACIÓN NO ES PERTINENTE. SALTE A LA PREGUNTA 18

B. ¿Es esta persona la misma de la pregunta anterior?

0. No

1. Sí

18. ¿Se ha mudado Ud. o su familiar para que Ud. pudiera cuidarlo(a)?

0 . No

1. Sí

19. ¿Ha hecho cambios en su casa para acomodar a su familiar (tales como poner rampas, barras en el baño, más luces, intercambio de dormitorio, etc.) ?

0 . No

1. Sí

Algunas personas se sienten incómodos contestando preguntas con respecto al ingreso del hogar. Nosotros sólo usamos esta información para saber si a las personas le parecen que tienen o no los recursos adecuados para ser un (a) cuidador(a). 
ID\#

20. Apróximadamente, cúal es el ingreso de su hogar? Por favor escoja la respuesta que mejor representa su situación.
Anual
$\mathrm{O}$
Mensual

0. $\quad$ Menos que $\$ 4,999$

Menos que $\$ 416$

1. $\$ 5,000-\$ 6,999$

$\$ 417-\$ 583$

2. $\$ 7,000-\$ 9,999$

$\$ 584-\$ 833$

3. $\$ 10,000-\$ 14,999$

$\$ 834-\$ 1249$

4. $\$ 15,000-\$ 19,999$

$\$ 1250-\$ 1666$

5. $\$ 20,000-\$ 29,999$

$\$ 1667-\$ 2499$

6. $\$ 30,000-\$ 39,999$

$\$ 2500-\$ 3333$

7. $\$ 40,000-\$ 49,999$

$\$ 3334$ - \$4166

8. $\$ 50,000$ o más

$\$ 4167$ o más

9. NINGUNA RESPUESTA

Ud. ha completado la seccion I del cuestionario. Pasemos ahora a la seccion II. 
ID\#

\section{Sección II}

Las preguntas a continuación son sobre la habilidad de su familiar anciano de realizar sus actividades diarias, sobre el tipo de asistencia que necesita y sus sentimientos. Por favor, escuche cuidadosamente y escoja la respuesta que describe mejor su situación.

21. ¿Puede su familiar mayor de edad usar el teléfono?

$0=\quad$ sin ayuda (incluyendo buscar y marcar el número)

$1=\quad$ con alguna ayuda ( puede contestar el teléfono o discar la operadora en caso de emergencia, pero necesita un teléfono especial o ayuda obteniendo el número a discar).

$2=\quad$ o es completamente incapaz de usar el teléfono

$9=\quad$ NO HAY RESPUESTA

21 a. Actualmente, ¿ayuda usted a su familiar mayor de edad a usar el teléfono?

$$
\begin{aligned}
& 0=\mathrm{No} \\
& 1=\mathrm{Sí}
\end{aligned}
$$

21 b. ¿Es o sería dificil emocional o fisicamente para Ud. ayudar a su familiar mayor de edad a usar el teléfono?

$0=$ No

$1=$ Sólo dificil fisicamente

$2=$ Sólo dificil emocionalmente

$3=$ Dificil fisica y emocionalmente

22. ¿Puede su familiar mayor de edad ir a lugares que se encuentran a distancias cercanas (lugares a los que se puede ir caminando)?

$0=\quad$ sin ayuda ( puede viajar en ómnibus, taxis o manejar su propio carro)

$1=\quad$ con alguna ayuda ( necesita de alguien para que lo ayude o que viaje con él o ella),

$2=\quad$ o está completamente incapacitado para viajar a no ser que se establezcan medidas de emergencia para usar un vehículo especial tal como una ambulancia

$9=\quad$ NO HAY RESPUESTA

22 a. ¿Actualmente, ayuda usted a su familiar mayor de edad a llegar a los lugares?

$$
\begin{aligned}
& 0=\mathrm{No} \\
& 1=\mathrm{Sí}
\end{aligned}
$$


22 b. ¿Es o sería dificil emocional o fisicamente para Ud. ayudar a su familiar mayor de edad a llegar a los lugares?

$$
\begin{aligned}
& 0=\text { No } \\
& 1=\text { Sólo dificil fisicamente } \\
& 2=\text { Sólo dificil emocionalmente } \\
& 3=\text { Dificil fisica y emocionalmente }
\end{aligned}
$$

23. ¿Puede su familiar mayor de edad comprar sus alimentos o su ropa [ SI ASUMIMOS QUE SU FAMILIAR MAYOR DE EDAD TIENE TRANSPORTACIÓN]?

$0=\quad \sin$ ayuda (haciéndose cargo de todas sus compras, asumiendo que él/ella tuviera transportación)

$1=\quad$ con alguna ayuda ( necesita de alguien que lo acompane $\mathrm{a}$ ir de compras),

$2=\quad$ o está completamente incapacitado para ir de compras

$9=\quad$ NO HAY RESPUESTA

23 a ¿Actualmente, ayuda usted a su familiar mayor de edad a comprar sus alimentos o ropa?

$0=$ No

$1=$ Sí

23 b. ¿Es o sería dificil emocional o fisicamente para Ud. ayudar a su familiar mayor de edad a ir de compras?

$0=$ No

$1=$ Sólo dificil fisicamente

$2=$ Sólo dificil emocionalmente

$3=$ Dificil fisica y emocionalmente

24. ¿Puede su familiar mayor de edad preparar sus comidas?

$0=\quad$ sin ayuda $($ planifica y cocina sus comidas)

$1=\quad$ con alguna ayuda ( puede preparar algunas cosas pero es incapaz de cocinar comidas completas),

$2=\quad$ o es completamente incapaz de prepararse ninguna comida

$9=\quad$ NO HAY RESPUESTA 
24 a. ¿Actualmente, ayuda usted a su familiar mayor de edad a prepararse sus comidas?

$$
\begin{aligned}
& 0=\text { No } \\
& 1=S i ́
\end{aligned}
$$

24 b. ¿Es o sería dificil emocional o fisicamente para Ud. ayudar a su familiar mayor de edad a preparar sus comidas?

$0=$ No

$1=$ Sólo dificil fisicamente

$2=$ Sólo dificil emocionalmente

$3=$ Dificil fisica y emocionalmente

25. ¿ Puede su familiar mayor de edad hacer las tareas de la casa?

$0=\quad$ sin ayuda (limpiar pisos, etc)

$1=\quad$ con alguna ayuda (puede hacer trabajos ligeros pero necesita ayuda con las tareas pesadas),

$2=\quad$ o está completamenta incapacitado de hacer ninguna tarea de la casa.

$9=\quad$ NO HAY RESPUESTA

25 a. ¿Actualmente, ayuda usted a su familiar mayor de edad a realizar las tareas de la casa?

$0=$ No

$1=\mathrm{Si}$

25 b. ¿Es o sería dificil emocional o fisicamente para Ud. ayudar a su familiar mayor de edad a realizar las tareas de la casa?

$0=$ No

$1=$ Sólo dificil fisicamente

$2=$ Sólo dificil emocionalmente

$3=$ Dificil fisica y emocionalmente

26. ¿Puede su familiar mayor de edad tomar sus medicinas?

$0=\quad \sin$ ayuda ( la dosis corecta a la hora correcta)

$1=\quad$ con alguna ayuda ( puede tomar la medicina si alguien se la prepara o le recuerda tomarla),

$2=$ o es completamente incapaz de tomar su medicina

$9=\quad$ NO HAY RESPUESTA 
ID\#

26 a. ¿Actualmente, ayuda usted a su familiar mayor de edad a tomar sus medicinas?

$0=$ No

$1=$ Sí

26 b. ¿Es o sería difícil emocional o fisicamente para Ud. ayudar a su familiar mayor de edad a tomar sus medicinas?

$0=$ No

$1=$ Sólo dificil fisicamente

$2=$ Sólo dificil emocionalmente

$3=$ Dificil fisica y emocionalmente

27. ¿Puede su familiar mayor de edad manejar su propio dinero?

$0=\quad$ sin ayuda (hacer cheques, pagar sus cuentas, etc.)

$1=\quad$ con alguna ayuda ( maneja las compras diarias pero necesita ayuda manejando la chequera y pagando sus cuentas),

$2=$ o es completamente incapaz de manejar su propio dinero

$9=\quad$ NO HAY RESPUESTA

27 a. ¿Actualmente, ayuda usted a su familiar mayor de edad con el manejo de sus finanzas?

$0=$ No

$1=$ Sí

27 b. ¿Es o sería dificil emocional o fisicamente para Ud. ayudar a su familiar mayor de edad con el manejo de sus finanzas?

$0=$ No

$1=$ Sólo dificil fisicamente

$2=$ Sólo dificil emocionalmente

$3=$ Dificil fisica y emocionalmente

28. ¿Puede su familiar mayor de edad comer?

$0=\quad$ sin ayuda (puede comer completamente sin ayuda)

$1=\quad$ con alguna ayuda (necesita ayuda cortando, etc),

$2=\quad$ o es completamente incapaz de comer solo

$9=\quad$ NO HAY RESPUESTA 
28 a. ¿Actualmente, ayuda usted a su familiar mayor de edad a comer?

$$
\begin{aligned}
& 0=\text { No } \\
& 1=S i ́
\end{aligned}
$$

28 b. ¿Es o seria dificil emocional o fisicamente para Ud. ayudar a su familiar mayor de edad a comer?

$$
\begin{aligned}
& 0=\text { No } \\
& 1=\text { Sólo dificil fisicamente } \\
& 2=\text { Sólo dificil emocionalmente } \\
& 3=\text { Dificil fisica y emocionalmente }
\end{aligned}
$$

29. ¿Puede su familiar mayor de edad vestirse y desvestirse solo?

$0=\quad$ sin ayuda (capaz de escoger la ropa, vestirse y desvestirse)

$1=$ con alguna ayuda,

$2=\quad$ o es completamente incapaz de vestirse y desvestirse solo

$9=\quad$ NO HAY RESPUESTA

29 a. ¿Actualmente, ayuda usted a su familiar mayor de edad a vestirse?

$$
\begin{aligned}
& 0=\text { No } \\
& 1=S i ́
\end{aligned}
$$

29 b. ¿Es o sería dificil emocional o fisicamente para Ud. ayudar a su familiar mayor de edad a vestirse?

$$
\begin{aligned}
& 0=\text { No } \\
& 1=\text { Sólo dificil fisicamente } \\
& 2=\text { Sólo dificil emocionalmente } \\
& 3=\text { Dificil fisica y emocionalmente }
\end{aligned}
$$

30. ¿Puede su familiar mayor de edad mantener su cuidado personal, por ejemplo peinarse

$0=\quad$ sin ayuda

$1=$ con alguna ayuda,

$2=\quad$ o es completamente incapaz de realizar su cuidado personal

$9=\quad$ NO HAY RESPUESTA 
30 a. ¿Actualmente, ayuda usted a su familiar mayor de edad a mantener su apariencia personal adecuada?

$$
\begin{aligned}
& 0=\text { No } \\
& 1=S i ́
\end{aligned}
$$

30 b. ¿Es o sería dificil emocional o fisicamente para Ud. ayudar a su familiar mayor de edad a mantener su cuidado personal ( por ejemplo peinarse)?

$0=$ No

$1=$ Sólo dificil fisicamente

$2=$ Sólo dificil emocionalmente

$3=$ Dificil fisica y emocionalmente

31. ¿Puede su familiar mayor de edad caminar?

$0=\quad \sin$ ayuda (con la exception de un bastón)

$1=$ con alguna ayuda de una persona, andador, muletas, etc,

$2=\quad$ o está completamente incapacitado para caminar

$9=\quad$ NO HAY RESPUESTA

31 a. ¿Actualmente, ayuda usted a su familiar mayor de edad a caminar o moverse [SI NO PUEDE CAMINAR] ?

$$
\begin{aligned}
& 0=\text { No } \\
& 1=S i ́
\end{aligned}
$$

31 b. ¿Es o sería dificil emocional o fisicamente para Ud. ayudar a su familiar mayor de edad a caminar o moverse [SI NO PUEDE CAMINAR]?

$$
\begin{aligned}
& 0=\text { No } \\
& 1=\text { Sólo dificil fisicamente } \\
& 2=\text { Sólo dificil emocionalmente } \\
& 3=\text { Dificil fisica y emocionalmente }
\end{aligned}
$$

32. ¿Puede su familiar mayor de edad subir y bajar de la cama?

$0=\quad \sin$ ayuda 0 equipos

$1=$ con alguna ayuda ( sea de persona o de algun equipo),

$2=\quad$ o está totalmente dependiente de alguna persona que lo levante de la cama.

$9=\quad$ NO HAY RESPUESTA 
32 a. ¿Actualmente, ayuda usted a su familiar mayor de edad a subir y bajar de la cama?

$0=$ No

$1=\mathrm{Si}$

32 b. ¿Es o sería dificil emocional o fisicamente para Ud, ayudar a su familiar mayor de edad a subir y bajar de la cama?

$0=$ No

$1=$ Sólo dificil fisicamente

$2=$ Sólo dificil emocionalmente

$3=$ Dificil fisica y emocionalmente

33. ¿Puede su familiar mayor de edad darse un baño o una ducha?

$0=\quad$ sin ayuda

$1=\quad$ con alguna ayuda (necesita ayuda entrando y saliendo de la bañadera, 0 necesita agarraderas en la bañadera?,

$2=\quad$ o es completamente incapaz de bañarse por si solo

$9=\quad$ NO HAY RESPUESTA

33a. ¿Actualmente, ayuda usted a su familiar mayor de edad a bañarse?

$$
\begin{aligned}
& 0=\mathrm{No} \\
& 1=\mathrm{Si}
\end{aligned}
$$

33 b. ¿Es o sería dificil emocional o fisicamente para Ud. ayudar a su familiar mayor de edad con el baño?

$0=$ No

$1=$ Sólo dificil fisicamente

$2=$ Sólo dificil emocionalmente

$3=$ Dificil fisica y emocionalmente

34. ¿Tiene alguna vez su familiar mayor de edad problemas llegando a tiempo al baño para usar el inodoro?

$0=$ No

$1=$ Sí

$2=$ Tiene un cateter 0 colostomía

$9=$ NO HAY RESPUESTA 
34 a ¿Actualmente, ayuda Ud. a su familiar mayor de edad a ir al inodoro?

$$
\begin{aligned}
& 0=\text { No } \\
& 1=S^{\prime}
\end{aligned}
$$

34 b. ¿Es o sería dificil emocional o fisicamente para Ud. ayudar a su familiar mayor de edad a ir al inodoro?

$0=$ No

$1=$ Sólo dificil fisicamente

$2=$ Sólo dificil emocionalmente

$3=$ Dificil fisica y emocionalmente

Ud. ha completado la seccion II del cuestionario. Pasemos ahora a la seccion III 


\section{Sección III}

Ahora vamos a hacerle preguntas para conocer porqué el cuidar a un familiar puede ser difícil para Ud. Por favor escoja las respuestas que mejor correspondan a su situación.

\begin{tabular}{|c|c|c|c|c|c|}
\hline \multicolumn{2}{|c|}{ 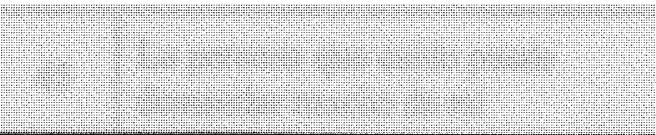 } & 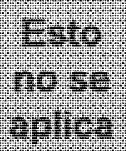 & \multicolumn{3}{|c|}{ 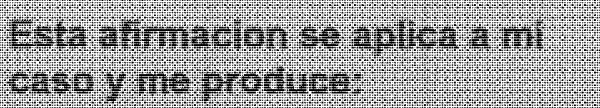 } \\
\hline \multicolumn{2}{|c|}{ 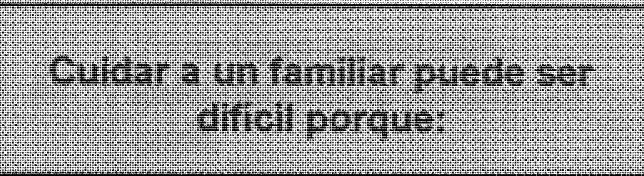 } & $\begin{array}{l}\text { pplica } \\
\text { sintit } \\
\text { pats }\end{array}$ & 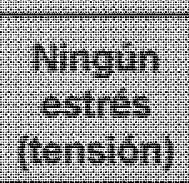 & 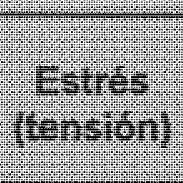 & 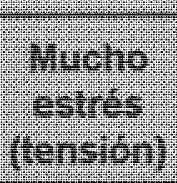 \\
\hline 35 & $\begin{array}{l}\text { No tengo suficiente tiempo } \\
\text { privado para mi }\end{array}$ & & & & \\
\hline 36 & $\begin{array}{l}\text { Me sicnto incapas/sin control do } \\
\text { la siuacion }\end{array}$ & & & & \\
\hline 37 & $\begin{array}{l}\text { No tengo sufiolente tiempo para } \\
\text { dedicarle a oros tamulares }\end{array}$ & & & & \\
\hline 38 & Me cause dificultades financieras & & & & \\
\hline 39 & $\begin{array}{l}\text { La persona que cuido me: } \\
\text { manipula }\end{array}$ & & & & \\
\hline 40 & $\begin{array}{l}\text { La persona que cuido está } \\
\text { inmovilticte problemas para } \\
\text { moverse }\end{array}$ & & & & \\
\hline $4 !$ & $\begin{array}{l}\text { Los trabajadores profesionales no } \\
\text { parccen darse cuenta los } \\
\text { problemas que cnfrentamos los } \\
\text { que cuidamos familiares }\end{array}$ & & & $=$ & \\
\hline 42 & $\begin{array}{l}\text { Me restringe mi vida sociall } \\
\text { interests ruera del hogar }\end{array}$ & & & & \\
\hline 43 & $\begin{array}{l}\text { Puede imponer tension th las } \\
\text { relaciones familiares }\end{array}$ & & & & \\
\hline 44 & Da cansancio fisiog & & & & \\
\hline
\end{tabular}


ID\#

\begin{tabular}{|c|c|c|c|c|c|}
\hline & & $\begin{array}{l}\text { Esto } \\
\text { no se }\end{array}$ & $\begin{array}{l}\text { Esta afirm } \\
\text { caso y me }\end{array}$ & ion se ap & Fa a ml \\
\hline & $\begin{array}{l}\text { dar a un familar puede ser } \\
\text { dilicil porgue: }\end{array}$ & $\operatorname{can}$ & $\begin{array}{l}\text { No estres } \\
\text { (tension) }\end{array}$ & $\begin{array}{l}\text { Estros } \\
\text { (cension) }\end{array}$ & $\begin{array}{l}\text { Mucho } \\
\text { estros } \\
\text { (tension) }\end{array}$ \\
\hline 45 & $\begin{array}{l}\text { La persona que cuido puede } \\
\text { demandar mucho de mí }\end{array}$ & & & & \\
\hline 46 & $\begin{array}{l}\text { Ya no tengo una relacion } \\
\text { importante con la persona que } \\
\text { cuido. }\end{array}$ & & & & \\
\hline 47 & $\begin{array}{l}\text { La persona que cuido necesita } \\
\text { mucha ayuda con su cuidado } \\
\text { personal. }\end{array}$ & & & & \\
\hline 48 & $\begin{array}{l}\text { La persona que cuido no siempre } \\
\text { me ayuda tanto como pudiera. }\end{array}$ & & & & \\
\hline 49 & $\begin{array}{l}\text { Mi patron de domir ha cambiado } \\
\text { (incluye cambios en número de } \\
\text { horas de suento, horanos, etc) }\end{array}$ & & & & \\
\hline 50 & $\begin{array}{l}\text { Los familiares no se mantienen en } \\
\text { contacto tanto como yo quisiera }\end{array}$ & & & & \\
\hline 51 & $\begin{array}{l}\text { Me siento molesto(a) sobre la } \\
\text { situación }\end{array}$ & & & & \\
\hline 52 & $\begin{array}{l}\text { No puedo ver a los amigos tanto } \\
\text { como quisiera }\end{array}$ & & & & \\
\hline 53 & Mi estado emocional sufre & & & & \\
\hline 54 & $\begin{array}{l}\text { No puedo tener un descanso o } \\
\text { tomar un dia de fiesta }\end{array}$ & & & & \\
\hline 55 & Mi nivel de vida ha declinado & & & & \\
\hline 56 & $\begin{array}{l}\text { La persona que cuido no siempre } \\
\text { aprecia lo que hago }\end{array}$ & & & & \\
\hline 57 & $\begin{array}{l}\text { Mi estado de salud fisico ha } \\
\text { sufrido }\end{array}$ & & & & \\
\hline
\end{tabular}


ID\#

\begin{tabular}{|c|c|c|c|c|c|}
\hline & & $\begin{array}{l}\text { Esto } \\
\text { no sio }\end{array}$ & $\begin{array}{l}\text { Esta atim } \\
\text { caso y me }\end{array}$ & sion se ap & Fa a mi \\
\hline & $\begin{array}{l}\text { dar a un tamiliar puede ser } \\
\text { diricil porgue. }\end{array}$ & $\begin{array}{c}\text { e mil } \\
\text { caso }\end{array}$ & $\begin{array}{l}\text { No estrés } \\
\text { (tension) }\end{array}$ & $\begin{array}{l}\text { Estros } \\
\text { (tensior) }\end{array}$ & $\begin{array}{l}\text { Wuicho } \\
\text { estres } \\
\text { (tension) }\end{array}$ \\
\hline 58 & $\begin{array}{l}\text { La persona que cuido está } \\
\text { incontinente }\end{array}$ & & & & \\
\hline 59 & $\begin{array}{l}\text { El comportamiento de la persoma } \\
\text { que cuido es un problema }\end{array}$ & & & & \\
\hline 60 & $\begin{array}{l}\text { No se obtiene satisfaccion por } \\
\text { cuidar a un familiar }\end{array}$ & & & & \\
\hline 61 & $\begin{array}{l}\text { No obtengo suficiente ayuda de } \\
\text { los servicios de salud y sociales }\end{array}$ & & & & \\
\hline 62 & $\begin{array}{l}\text { Algunos mombros de la familia } \\
\text { no ayudan tanto cono pudieran }\end{array}$ & & & & \\
\hline 63 & $\begin{array}{l}\text { La preocupación por cuidar (a un } \\
\text { familiar) no me deja relajame }\end{array}$ & & & & \\
\hline 64 & $\begin{array}{l}\text { Me siento culpable por la } \\
\text { simación }\end{array}$ & & & & \\
\hline
\end{tabular}

Por favor añada a continuación cualquier otra dificultad que UD. enfrenta $e$ indique cuanto estrés le proporcionan.

\begin{tabular}{|c|c|c|c|}
\hline 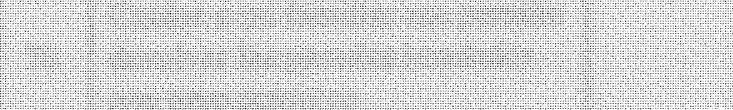 & \multicolumn{3}{|c|}{$\begin{array}{l}\text { Esta afirmacion se aplica a mi } \\
\text { caso y me da: }\end{array}$} \\
\hline $\begin{array}{l}\text { Ouldar a un famillar puede ser dificil } \\
\text { porquo: }\end{array}$ & $\begin{array}{l}\text { No estres } \\
\text { (terision) }\end{array}$ & $\begin{array}{l}\text { Estres } \\
\text { (tension) }\end{array}$ & 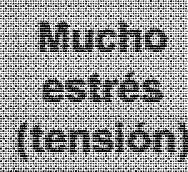 \\
\hline 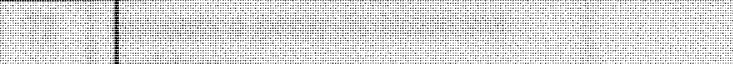 & & & \\
\hline & & & \\
\hline & & & \\
\hline & & & \\
\hline
\end{tabular}

Ud. ha completado la seccion III del cuestionario. Pasemos ahora a la seccion IV 
ID\#

\section{Sección IV}

Ahora vamos a hacerle preguntas para averiguar porqué cuidar a un familiar le brinda satisfacción a Ud. Por favor escoja las respuestas que mejor se ajusten a su situación.

\begin{tabular}{|c|c|c|c|c|c|}
\hline & 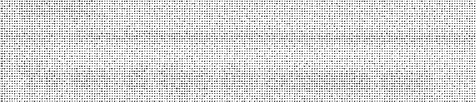 & $\begin{array}{l}\text { Esto } \\
\text { no se }\end{array}$ & $\begin{array}{l}\text { Esta afima } \\
\text { me provee: }\end{array}$ & on se aplies & micasosy \\
\hline & 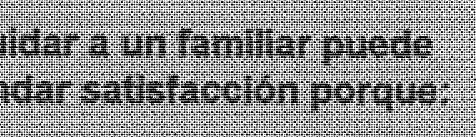 & an & $\begin{array}{l}\text { Wingune } \\
\text { satisfaccion } \\
\text { red }\end{array}$ & $\begin{array}{l}\text { Bastante } \\
\text { satistaccion }\end{array}$ & $\begin{array}{l}\text { Crem } \\
\text { satistaction }\end{array}$ \\
\hline 65 & $\begin{array}{l}\text { Cuidar (a un familiar) me ha } \\
\text { permitido desarrollar nuevas } \\
\text { habilidades y aptitudes. }\end{array}$ & & & & \\
\hline 66 & $\begin{array}{l}\text { La persona que yo cuido aprecia } \\
\text { lo que yo hago. }\end{array}$ & & & & \\
\hline 67 & $\begin{array}{l}\text { Cuidar (a un farniliar) me ha } \\
\text { acercado a ellella. }\end{array}$ & & & & \\
\hline 68 & $\begin{array}{l}\text { Es bueno ver las pequenlas } \\
\text { mejorias de su condicion. }\end{array}$ & & & & \\
\hline 69 & $\begin{array}{l}\text { Yo soy capaz de ayudar a la } \\
\text { persona que cuido a gue alcanze } \\
\text { su mávino potencial. }\end{array}$ & & & & \\
\hline 70 & $\begin{array}{l}\text { Cuidar a mi familiar ne permite } \\
\text { devolver las pasadas bondades } \\
\text { que tuvo conmigo }\end{array}$ & & & & \\
\hline 71 & $\begin{array}{l}\text { Cuidar (a un familiar) me } \\
\text { provee un reto. }\end{array}$ & & & & \\
\hline 72 & $\begin{array}{l}\text { Mi familiar no se queja ni se } \\
\text { lamenta a pesar de todos sus } \\
\text { problemas. }\end{array}$ & & & & \\
\hline 73 & $\begin{array}{l}\text { Es agradable ver que la persona } \\
\text { que cuido esta limpio(a). } \\
\text { comodo(a) y bien cuidado(a). }\end{array}$ & & & & \\
\hline
\end{tabular}


ID\#

\begin{tabular}{|c|c|c|c|c|c|}
\hline \multirow{2}{*}{\multicolumn{2}{|c|}{ Guibar a unfianiliar puede }} & \multirow{2}{*}{$\begin{array}{l}\text { Esto } \\
\text { no se } \\
\text { apllat } \\
\text { anm } \\
\text { caso }\end{array}$} & \multicolumn{3}{|c|}{ 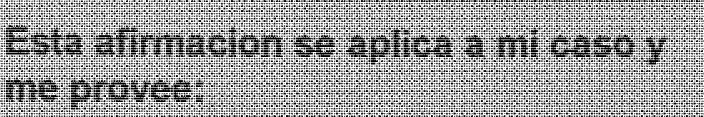 } \\
\hline & & & 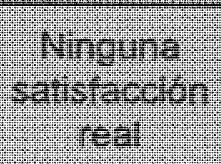 & 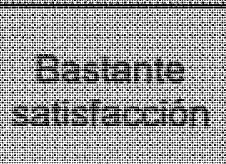 & 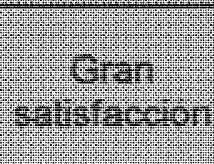 \\
\hline 74 & $\begin{array}{l}\text { Cudiar (a un familian) me } \\
\text { permite satisfacer mi sentido de } \\
\text { deber. }\end{array}$ & & & $=$ & \\
\hline 75 & $\begin{array}{l}\text { Yo soy el tpo de persona que } \\
\text { disfiua aydando a los denits. }\end{array}$ & & & & \\
\hline 76 & $\begin{array}{l}\text { Me produce placer al ver alegre } \\
\text { a la persona gue cuido }\end{array}$ & & & & \\
\hline 77 & $\begin{array}{l}\text { Es bueno ayular a la persma } \\
\text { gue cuido a sobreponerse a las } \\
\text { dificultades y problemas. }\end{array}$ & & & & \\
\hline 78 & $\begin{array}{l}\text { Es agratible cuando algo que } \\
\text { jo hago le da placer a la } \\
\text { persorib que yo cardo. }\end{array}$ & & & & \\
\hline 79 & $\begin{array}{l}\text { Debido a que conozco a mi } \\
\text { farrititar de la ruancta que is } \\
\text { conozco lo puedo cuidar mejor } \\
\text { que nadie. }\end{array}$ & & & $=0$ & \\
\hline 80 & $\begin{array}{l}\text { Cuidar (a un familiar) me ha } \\
\text { ayudado a crecer y } \\
\text { desarnollarne como persona. }\end{array}$ & & & & \\
\hline 81 & $\begin{array}{l}\text { Es agradable sentirse apreciado } \\
\text { por aguellos faminares y amigos } \\
\text { que yo valoro. }\end{array}$ & & & & \\
\hline 82 & $\begin{array}{l}\text { Cuidar (a un fariliar) ha } \\
\text { fortalezido laros de familiares } \\
\text { cercanos y demas relaciones: }\end{array}$ & & & $=$ & \\
\hline 83 & $\begin{array}{l}\text { Cuidar a ni tamiliar cvita gue } \\
\text { ne sienta cuipule. }\end{array}$ & & & & \\
\hline 84 & $\begin{array}{l}\text { Yo puedo mantener a la persona } \\
\text { gue cuido fuera de una } \\
\text { instivion (astlo) }\end{array}$ & & & & \\
\hline
\end{tabular}


ID\#

\begin{tabular}{|c|c|c|c|c|c|}
\hline \multirow{2}{*}{\multicolumn{2}{|c|}{$\begin{array}{l}\text { Culdar a un tamiliar puede } \\
\text { brindar satisfacción porcue: }\end{array}$}} & \multirow{2}{*}{$\begin{array}{l}\text { Esto } \\
\text { ro se } \\
\text { aplica } \\
\text { a } \mathrm{mi} \\
\text { caso }\end{array}$} & \multicolumn{3}{|c|}{$\begin{array}{l}\text { Esta afirmacion so aplica a mi casoy } \\
\text { me provee: }\end{array}$} \\
\hline & & & \multirow[t]{2}{*}{$\begin{array}{l}\text { Ninguna } \\
\text { satisfaccion } \\
\text { real }\end{array}$} & \multirow[t]{2}{*}{$\begin{array}{l}\text { Bastante } \\
\text { satistacción }\end{array}$} & $\begin{array}{l}\text { Gran } \\
\text { sustaccion }\end{array}$ \\
\hline 85 & $\begin{array}{l}\text { Yo siento que si la situacion } \\
\text { fuera a la inversa, la persona } \\
\text { que jo cuido haria lo mismo por } \\
\text { mi. }\end{array}$ & & & & \\
\hline 86 & $\begin{array}{l}\text { Yo puedo asegurar que la } \\
\text { persona que cuido tenga sus } \\
\text { necesidades atendidas. }\end{array}$ & & & & \\
\hline 87 & $\begin{array}{l}\text { Cuidar (a un familiar) me ha } \\
\text { dado el chance de ampliar mis } \\
\text { intereses y contactos. }\end{array}$ & & & & \\
\hline 88 & $\begin{array}{l}\text { Mantener la dignidad de la } \\
\text { persona que cuido es importante } \\
\text { para mi. }\end{array}$ & & & & \\
\hline 89 & $\begin{array}{l}\text { Soy capaz de ponerne a prueba } \\
\text { a mi nisno(a) y sobreponeme } \\
\text { a las dificulades. }\end{array}$ & & & & \\
\hline 90 & $\begin{array}{l}\text { Cuidar (a un familiar) es una } \\
\text { forma de mostrar (demostrar)mi } \\
\text { fé. }\end{array}$ & & & & \\
\hline 91 & $\begin{array}{l}\text { Cuidar (a un familiar) ha dado } \\
\text { un propósito a mi vida que no } \\
\text { tenia antes. }\end{array}$ & & & & \\
\hline 92 & $\begin{array}{l}\text { Al final del dia se que habré } \\
\text { hecho lo mejor que pude. }\end{array}$ & & & & \\
\hline 93 & $\begin{array}{l}\text { Cuidar (a un familiar) es una } \\
\text { forma de expresar mi amot por } \\
\text { elvella. }\end{array}$ & & & & \\
\hline 94 & $\begin{array}{l}\text { Cuidar a mi familiar me hace } \\
\text { sentir necesitado(a) y } \\
\text { deseado(a). }\end{array}$ & & & & \\
\hline
\end{tabular}


ID\#

Por favor añada a continuación cualquier otro aspecto de cuidar a su familiar que le brinde satisfacción e indique cuanta satisfacción le proporcionan.

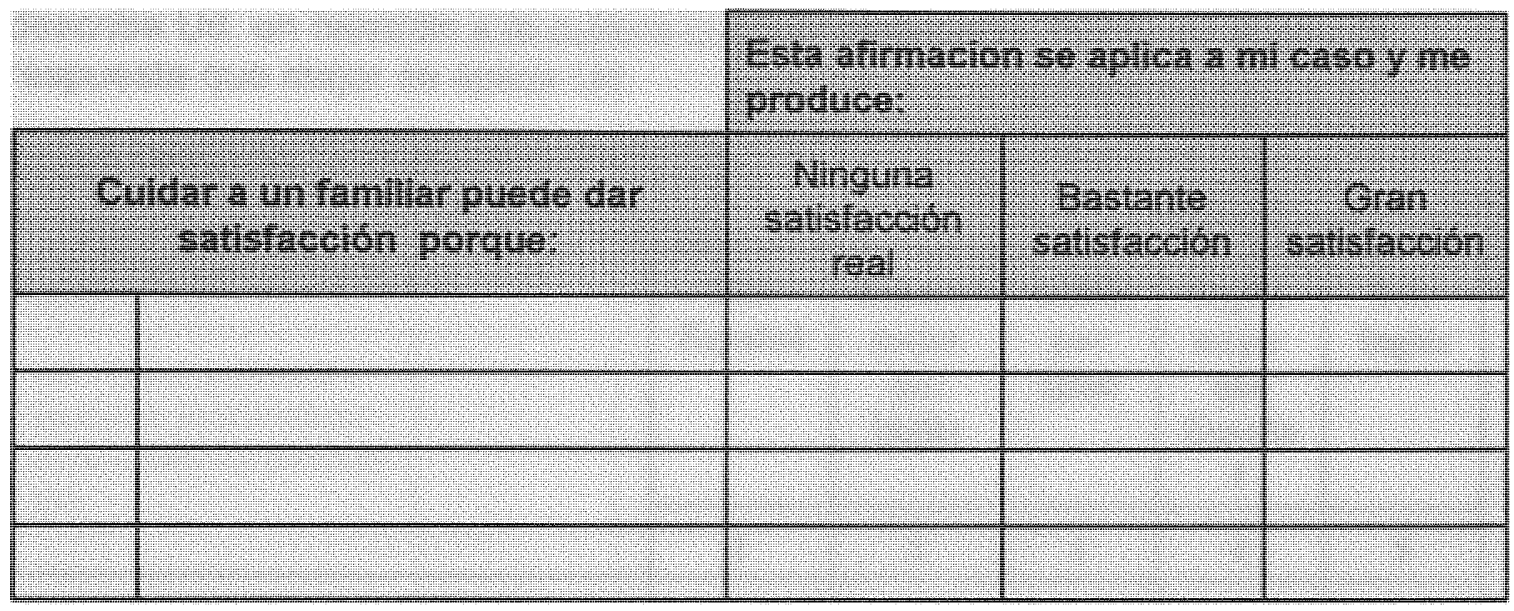

Ahora queremos estar seguros que hemos cubierto todo lo que es importante para Ud. como persona que cuida a su familiar: Por favor complete estas expresiones.

95. Para mí, lo mejor de cuidar a mi familiar mayor de edad es:

96. Lo más importante que yo hago para mi familiar mayor de edad es:

97. Si yo pudiera cambiar algo sobre el cuidado de mi familiar mayor de edad sería esto:

Casi hemos terminado el cuestionario. Pasemos ahora a la última sección 
ID\#

\section{Sección V}

Ahora vamos a hacerle algunas preguntas con respecto a como se describe Ud. en relación a la cultura cubano-americana. Por favor escoja la respuesta que mejor se aplica Ud.

\begin{tabular}{|l|c|c|c|c|c|}
\cline { 2 - 6 } \multicolumn{1}{l|}{} & $\begin{array}{c}\text { Sólo } \\
\text { Español }\end{array}$ & $\begin{array}{c}\text { Español } \\
\text { mejor } \\
\text { que } \\
\text { Inglés }\end{array}$ & $\begin{array}{c}\text { Ambos } \\
\text { por } \\
\text { igual }\end{array}$ & $\begin{array}{c}\text { Inglés } \\
\text { mejor } \\
\text { que } \\
\text { Españo } \\
\text { Inolés }\end{array}$ & $\begin{array}{c}\text { Solo } \\
\text { Inglés }\end{array}$ \\
\cline { 2 - 6 } & 1 & 2 & 3 & 4 & 5 \\
\hline $\begin{array}{l}\text { 98. Por lo general, que idioma(s) lee y } \\
\text { habla usted? }\end{array}$ & & & & & \\
\hline $\begin{array}{l}\text { 99. Cual fue el idioma(s) que hablo cuando } \\
\text { era niño(a)? }\end{array}$ & & & & & \\
\hline $\begin{array}{l}\text { 100. Por lo general, en que idioma(s) habla } \\
\text { en su casa? }\end{array}$ & & & & & \\
\hline $\begin{array}{l}\text { 101. Por lo general, en que idioma(s) } \\
\text { piensa? }\end{array}$ & & & & & \\
\hline $\begin{array}{l}\text { 102. Por lo general, en que idioma(s) habla } \\
\text { con sus amigos(as)? }\end{array}$ & & & & & \\
\hline $\begin{array}{l}\text { 103. Por lo general, en que idioma(s) son } \\
\text { los programas de televisión que usted ve? }\end{array}$ & & & & & \\
\hline $\begin{array}{l}\text { 104. Por lo general, en que idioma(s) son } \\
\text { los programas de radio que usted escucha? }\end{array}$ & & & & & \\
\hline $\begin{array}{l}\text { 105.Por lo general, en que idioma(s) } \\
\text { prefiere oir y ver películas, y programas } \\
\text { de radio y televisión? }\end{array}$ & & & & & \\
\hline
\end{tabular}


ID\#

\begin{tabular}{|l|c|c|c|c|c|}
\cline { 2 - 5 } \multicolumn{1}{l|}{} & $\begin{array}{c}\text { Latinos } \\
\text { (as) }\end{array}$ & $\begin{array}{c}\text { Más Latinos } \\
\text { (as) que } \\
\text { Americanos } \\
\text { (as) }\end{array}$ & $\begin{array}{c}\text { Casi mitad } \\
\text { y mitad }\end{array}$ & $\begin{array}{c}\text { Más } \\
\text { Americanos } \\
\text { (as) que } \\
\text { Latinos (as) }\end{array}$ & $\begin{array}{c}\text { Americanos } \\
\text { (as) }\end{array}$ \\
\cline { 2 - 6 } & 1 & 2 & 3 & 4 & 5 \\
\hline $\begin{array}{l}\text { 106 Sus amigos y amigas } \\
\text { cercanos son: }\end{array}$ & & & & & \\
\hline $\begin{array}{l}\text { 107. Usted prefiere ir a } \\
\text { reuniones sociales/fiesta } \\
\text { en las cuales las personas } \\
\text { son: }\end{array}$ & & & & & \\
\hline $\begin{array}{l}\text { 108. Las personas que } \\
\text { usted visita o que le } \\
\text { visitan a usted son: }\end{array}$ & & & & & \\
\hline $\begin{array}{l}\text { 109. Si usted pudiera } \\
\text { escoger los amigos(as) de } \\
\text { sus hijos(as), quisiera que } \\
\text { ellos fueran: }\end{array}$ & & & & & \\
\hline
\end{tabular}

Hemos finalizado de contestar el cuestionario y deseo darle las gracias de nuevo por su participación. 
Appendix G

Table 1. Caregiver Responses on Each Item of the CADI ( $n=30$ )

\begin{tabular}{|c|c|c|c|c|c|c|c|c|}
\hline \multirow[b]{3}{*}{ Item } & \multirow{2}{*}{\multicolumn{2}{|c|}{$\begin{array}{l}\text { Does not } \\
\text { apply }\end{array}$}} & \multicolumn{6}{|c|}{ Level of stress } \\
\hline & & & \multicolumn{2}{|c|}{$\begin{array}{c}\text { Not } \\
\text { stressful }\end{array}$} & \multicolumn{2}{|c|}{ Stressful } & \multicolumn{2}{|c|}{$\begin{array}{c}\text { Very } \\
\text { stressful }\end{array}$} \\
\hline & $\mathrm{n}$ & $\%$ & $\mathrm{n}$ & $\%$ & $\mathrm{n}$ & $\%$ & $\mathrm{n}$ & $\%$ \\
\hline $\begin{array}{l}\text { I don't have enough private } \\
\text { time for myself }\end{array}$ & 9 & 30.0 & 3 & 10.0 & 15 & 50.0 & 3 & 10.0 \\
\hline $\begin{array}{l}\text { I can feel helpless/ not in } \\
\text { control of the situation }\end{array}$ & 19 & 63.3 & 0 & 0 & 8 & 26.7 & 3 & 10.0 \\
\hline $\begin{array}{l}\text { I can't devote enough time to } \\
\text { other family members }\end{array}$ & 17 & 56.7 & 4 & 13.3 & 8 & 26.7 & 1 & 3.3 \\
\hline It causes financial difficulties & 18 & 60.0 & 5 & 16.7 & 4 & 13.3 & 3 & 10.0 \\
\hline $\begin{array}{l}\text { The person I care for can play } \\
\text { me up }\end{array}$ & 18 & 60.0 & 4 & 13.3 & 4 & 13.3 & 4 & 13.3 \\
\hline $\begin{array}{l}\text { The person I care for is } \\
\text { immobile/has problems getting } \\
\text { about }\end{array}$ & 17 & 56.7 & 6 & 20.0 & 4 & 13.3 & 3 & 10.0 \\
\hline $\begin{array}{l}\text { Professional workers don't } \\
\text { seem to appreciate the } \\
\text { problems caregivers face }\end{array}$ & 20 & 66.7 & 2 & 6.7 & 6 & 20.0 & 2 & 6.7 \\
\hline $\begin{array}{l}\text { It restricts my social } \\
\text { life/outside interests }\end{array}$ & 9 & 30.0 & 5 & 16.7 & 14 & 46.7 & 2 & 6.7 \\
\hline $\begin{array}{l}\text { It can put a strain on family } \\
\text { relationships }\end{array}$ & 15 & 50.0 & 1 & 3.3 & 10 & 33.3 & 4 & 13.3 \\
\hline It is physically tiring & 11 & 36.7 & 2 & 6.7 & 14 & 46.7 & 3 & 10.0 \\
\hline $\begin{array}{l}\text { The person I care for can } \\
\text { demand too much of me }\end{array}$ & 13 & 43.3 & 5 & 16.7 & 11 & 36.7 & 1 & 3.3 \\
\hline
\end{tabular}


Table 1. (continued)

\begin{tabular}{|c|c|c|c|c|c|c|c|c|}
\hline \multirow[b]{3}{*}{ Item } & \multirow{2}{*}{\multicolumn{2}{|c|}{$\begin{array}{l}\text { Does not } \\
\text { apply }\end{array}$}} & \multicolumn{6}{|c|}{ Level of stress } \\
\hline & & & \multicolumn{2}{|c|}{$\begin{array}{c}\text { Not } \\
\text { stressful }\end{array}$} & \multicolumn{2}{|c|}{ Stressful } & \multicolumn{2}{|c|}{$\begin{array}{c}\text { Very } \\
\text { stressful }\end{array}$} \\
\hline & $\mathrm{n}$ & $\%$ & $\mathrm{n}$ & $\%$ & $\mathrm{n}$ & $\%$ & $\mathrm{n}$ & $\%$ \\
\hline $\begin{array}{l}\text { I no longer have a meaningful } \\
\text { relationship with the person I } \\
\text { care for }\end{array}$ & 27 & 90.0 & 0 & 0 & 2 & 6.7 & 1 & 3.3 \\
\hline $\begin{array}{l}\text { The person I care for needs a } \\
\text { lot of help with personal care }\end{array}$ & 13 & 43.3 & 9 & 30.0 & 7 & 23.3 & 1 & 3.3 \\
\hline $\begin{array}{l}\text { The person I care for doesn't } \\
\text { always help as much as they } \\
\text { could }\end{array}$ & 24 & 80.0 & 1 & 3.3 & 5 & 16.7 & 0 & 0 \\
\hline My sleep is affected & 19 & 63.3 & 2 & 6.7 & 6 & 20.0 & 3 & 10.0 \\
\hline $\begin{array}{l}\text { Relatives don't keep in touch } \\
\text { as often as I'd like }\end{array}$ & 17 & 56.7 & 6 & 20.0 & 6 & 20.0 & 1 & 3.3 \\
\hline I feel angry about the situation & 20 & 66.7 & 0 & 0 & 8 & 26.7 & 2 & 6.7 \\
\hline $\begin{array}{l}\text { I can't see friends as often as } \\
\text { I'd like }\end{array}$ & 15 & 50.0 & 6 & 20.0 & 7 & 23.3 & 2 & 6.7 \\
\hline $\begin{array}{l}\text { My emotional well-being } \\
\text { suffers }\end{array}$ & 10 & 33.3 & 3 & 10.0 & 10 & 33.3 & 7 & 23.3 \\
\hline $\begin{array}{l}\text { I can't have a break or take a } \\
\text { holiday }\end{array}$ & 15 & 50.0 & 7 & 23.3 & 5 & 16.7 & 3 & 10.0 \\
\hline My standard of living has fallen & 20 & 66.7 & 3 & 10.0 & 6 & 20.0 & 1 & 3.3 \\
\hline $\begin{array}{l}\text { The person I care for doesn't } \\
\text { always appreciate what I do }\end{array}$ & 21 & 70.0 & 2 & 6.7 & 4 & 13.3 & 3 & 10.0 \\
\hline My physical health has suffered & 19 & 63.3 & 1 & 3.3 & 5 & 16.7 & 5 & 16.7 \\
\hline
\end{tabular}


Table 1. (continued)

\begin{tabular}{|c|c|c|c|c|c|c|c|c|}
\hline \multirow[b]{2}{*}{ Item } & \multicolumn{2}{|c|}{$\begin{array}{l}\text { Does not } \\
\text { apply }\end{array}$} & \multicolumn{2}{|c|}{$\begin{array}{l}\text { Not } \\
\text { stressful }\end{array}$} & \multicolumn{2}{|c|}{ Stressful } & \multicolumn{2}{|c|}{$\begin{array}{c}\text { Very } \\
\text { stressful }\end{array}$} \\
\hline & $\mathrm{n}$ & $\%$ & $\mathrm{n}$ & $\%$ & $\mathrm{n}$ & $\%$ & $\mathrm{n}$ & $\%$ \\
\hline $\begin{array}{l}\text { The person I care for is } \\
\text { incontinent }\end{array}$ & 23 & 76.7 & 3 & 10.0 & 4 & 13.3 & 0 & 0 \\
\hline $\begin{array}{l}\text { The behavior of the person I } \\
\text { care for is a problem }\end{array}$ & 24 & 80.0 & 0 & 0 & 3 & 10.0 & 3 & 10.0 \\
\hline $\begin{array}{l}\text { There is no satisfaction to be } \\
\text { gained from caring }\end{array}$ & 26 & 86.7 & 0 & 0 & 2 & 6.7 & 2 & 6.7 \\
\hline $\begin{array}{l}\text { I don't get enough help from } \\
\text { the health and social services }\end{array}$ & 23 & 76.7 & 1 & 3.3 & 2 & 6.7 & 4 & 13.3 \\
\hline $\begin{array}{l}\text { Some family members don't } \\
\text { help as much as they could }\end{array}$ & 19 & 63.3 & 3 & 10.0 & 6 & 20.0 & 2 & 6.7 \\
\hline $\begin{array}{l}\text { I can't relax because of worry } \\
\text { about caring }\end{array}$ & 16 & 53.3 & 0 & 0 & 9 & 30.0 & 5 & 16.7 \\
\hline I feel guilty about the situation & 24 & 80.0 & 0 & 0 & 2 & 6.7 & 4 & 13.3 \\
\hline
\end{tabular}


Appendix $\mathrm{H}$

Table 2. Caregiver Responses on Each Item of the CASI $(n=30)$

\section{Level of satisfaction}

$\begin{gathered}\text { Does not } \\ \text { apply }\end{gathered}$
None Quite a lot $\begin{gathered}\text { A great } \\ \text { deal }\end{gathered}$

\begin{tabular}{|c|c|c|c|c|c|c|c|c|}
\hline Item & $\mathrm{n}$ & $\%$ & $\mathrm{n}$ & $\%$ & $\mathrm{n}$ & $\%$ & $\mathrm{n}$ & $\%$ \\
\hline $\begin{array}{l}\text { Caring has allowed me to } \\
\text { develop new skills and abilities }\end{array}$ & 10 & 33.3 & 1 & 3.3 & 13 & 43.3 & 6 & 20.0 \\
\hline $\begin{array}{l}\text { The person I care for is } \\
\text { appreciative of what I do }\end{array}$ & 7 & 23.3 & 0 & 0 & 14 & 46.7 & 9 & 30.0 \\
\hline $\begin{array}{l}\text { Caring has brought me closer } \\
\text { to the person I care for }\end{array}$ & 12 & 40.0 & 0 & 0 & 9 & 30.0 & 9 & 30.0 \\
\hline $\begin{array}{l}\text { It's good to see small } \\
\text { improvements in their } \\
\text { condition }\end{array}$ & 10 & 33.3 & 0 & 0 & 10 & 33.3 & 10 & 33.3 \\
\hline $\begin{array}{l}\text { I am able to help the person I } \\
\text { care for reach their full } \\
\text { potential }\end{array}$ & 11 & 36.7 & 1 & 3.3 & 9 & 30.0 & 9 & 30.0 \\
\hline $\begin{array}{l}\text { I am able to repay their past } \\
\text { acts of kindness }\end{array}$ & 6 & 20.0 & 2 & 6.7 & 9 & 30.0 & 13 & 43.3 \\
\hline Caring provides a challenge & 11 & 36.7 & 5 & 16.7 & 8 & 26.7 & 6 & 20.0 \\
\hline $\begin{array}{l}\text { Despite all their problems the } \\
\text { person I care for does not } \\
\text { grumble or moan }\end{array}$ & 15 & 50.0 & 0 & 0 & 9 & 30.0 & 6 & 20.0 \\
\hline $\begin{array}{l}\text { It is nice to see the person I } \\
\text { care for clean, comfortable and } \\
\text { well turned out }\end{array}$ & 2 & 6.7 & 0 & 0 & 7 & 23.3 & 21 & 70 \\
\hline
\end{tabular}


Appendix $\mathrm{H}$

Table 2. Caregiver Responses on Each Item of the CASI $(n=30)$

\section{Level of satisfaction}

Does not None Quite a lot $\begin{gathered}\text { A great } \\ \text { deal }\end{gathered}$
apply

\begin{tabular}{|c|c|c|c|c|c|c|c|c|}
\hline Item & $\mathrm{n}$ & $\%$ & $\mathrm{n}$ & $\%$ & $\mathrm{n}$ & $\%$ & $\mathrm{n}$ & $\%$ \\
\hline $\begin{array}{l}\text { Caring has allowed me to } \\
\text { develop new skills and abilities }\end{array}$ & 10 & 33.3 & 1 & 3.3 & 13 & 43.3 & 6 & 20.0 \\
\hline $\begin{array}{l}\text { The person I care for is } \\
\text { appreciative of what I do }\end{array}$ & 7 & 23.3 & 0 & 0 & 14 & 46.7 & 9 & 30.0 \\
\hline $\begin{array}{l}\text { Caring has brought me closer } \\
\text { to the person I care for }\end{array}$ & 12 & 40.0 & 0 & 0 & 9 & 30.0 & 9 & 30.0 \\
\hline $\begin{array}{l}\text { It's good to see small } \\
\text { improvements in their } \\
\text { condition }\end{array}$ & 10 & 33.3 & 0 & 0 & 10 & 33.3 & 10 & 33.3 \\
\hline $\begin{array}{l}\text { I am able to help the person I } \\
\text { care for reach their full } \\
\text { potential }\end{array}$ & 11 & 36.7 & 1 & 3.3 & 9 & 30.0 & 9 & 30.0 \\
\hline $\begin{array}{l}\text { I am able to repay their past } \\
\text { acts of kindness }\end{array}$ & 6 & 20.0 & 2 & 6.7 & 9 & 30.0 & 13 & 43.3 \\
\hline Caring provides a challenge & 11 & 36.7 & 5 & 16.7 & 8 & 26.7 & 6 & 20.0 \\
\hline $\begin{array}{l}\text { Despite all their problems the } \\
\text { person I care for does not } \\
\text { grumble or moan }\end{array}$ & 15 & 50.0 & 0 & 0 & 9 & 30.0 & 6 & 20.0 \\
\hline $\begin{array}{l}\text { It is nice to see the person I } \\
\text { care for clean, comfortable and } \\
\text { well turned out }\end{array}$ & 2 & 6.7 & 0 & 0 & 7 & 23.3 & 21 & 70 \\
\hline
\end{tabular}




\section{Level of satisfaction}

$\begin{gathered}\text { Does not } \\ \text { apply }\end{gathered}$
None Quite a lot $\begin{gathered}\text { A great } \\ \text { deal }\end{gathered}$

\begin{tabular}{|c|c|c|c|c|c|c|c|c|}
\hline Item & $\mathrm{n}$ & $\%$ & $\mathrm{n}$ & $\%$ & $\mathrm{n}$ & $\%$ & $\mathrm{n}$ & $\%$ \\
\hline $\begin{array}{l}\text { Caring enables me to fulfill my } \\
\text { sense of duty }\end{array}$ & 1 & 3.3 & 2 & 6.7 & 7 & 23.3 & 20 & 66.7 \\
\hline $\begin{array}{l}\text { I am the sort of person who } \\
\text { enjoys helping people }\end{array}$ & 0 & 0 & 1 & 3.3 & 11 & 36.7 & 18 & 60.0 \\
\hline $\begin{array}{l}\text { I get pleasure from seeing the } \\
\text { person I care for happy }\end{array}$ & 0 & 0 & 0 & 0 & 8 & 26.7 & 22 & 73.3 \\
\hline $\begin{array}{l}\text { It's good to help the person I } \\
\text { care for overcome difficulties } \\
\text { and problems }\end{array}$ & 2 & 6.7 & 0 & 0 & 11 & 36.7 & 17 & 56.7 \\
\hline $\begin{array}{l}\text { It's nice when something I do } \\
\text { gives the person I care for } \\
\text { pleasure }\end{array}$ & 2 & 6.7 & 0 & 0 & 8 & 26.7 & 20 & 66.7 \\
\hline $\begin{array}{l}\text { Knowing the person I care for } \\
\text { the way I do, means I can give } \\
\text { better than anyone else }\end{array}$ & 3 & 10.0 & 2 & 6.7 & 8 & 26.7 & 17 & 56.7 \\
\hline $\begin{array}{l}\text { Caring has helped me to grow } \\
\text { and develop as a person }\end{array}$ & 10 & 33.3 & 1 & 3.3 & 7 & 23.3 & 12 & 40.0 \\
\hline $\begin{array}{l}\text { It's nice to feel appreciated by } \\
\text { those family and friends I value }\end{array}$ & 2 & 6.7 & 1 & 3.3 & 13 & 43.3 & 14 & 46.7 \\
\hline $\begin{array}{l}\text { Caring has strengthened close } \\
\text { family ties and relationships }\end{array}$ & 11 & 36.7 & 1 & 3.3 & 8 & 26.7 & 10 & 33.3 \\
\hline $\begin{array}{l}\text { It helps to stop me from feeling } \\
\text { guilty }\end{array}$ & 13 & 43.3 & 1 & 3.3 & 8 & 26.7 & 8 & 26.7 \\
\hline
\end{tabular}


Level of satisfaction

\begin{tabular}{|c|c|c|c|c|c|c|c|c|}
\hline \multirow[b]{2}{*}{ Item } & \multicolumn{2}{|c|}{$\begin{array}{l}\text { Does not } \\
\text { apply }\end{array}$} & \multicolumn{2}{|c|}{ None } & \multicolumn{2}{|c|}{ Quite a lot } & \multicolumn{2}{|c|}{$\begin{array}{l}\text { A great } \\
\text { deal }\end{array}$} \\
\hline & $\mathrm{n}$ & $\%$ & $\mathrm{n}$ & $\%$ & $\mathrm{n}$ & $\%$ & $\mathrm{n}$ & $\%$ \\
\hline $\begin{array}{l}\text { I am able to keep the person I } \\
\text { care for out of an institution }\end{array}$ & 0 & 0 & 0 & 0 & 6 & 20.0 & 24 & 80.0 \\
\hline $\begin{array}{l}\text { I feel that if the situation were } \\
\text { reversed, the person I care for } \\
\text { would do the sane for me }\end{array}$ & 2 & 6.7 & 3 & 10.0 & 10 & 33.3 & 15 & 50.0 \\
\hline $\begin{array}{l}\text { I am able to ensure that the } \\
\text { person I care for has their } \\
\text { needs tended to }\end{array}$ & 0 & 0 & 0 & 0 & 13 & 43.3 & 17 & 56.7 \\
\hline $\begin{array}{l}\text { Caring has given me the } \\
\text { chance to widen my interests } \\
\text { and contacts }\end{array}$ & 20 & 66.7 & 0 & 0 & 5 & 16.7 & 5 & 16.7 \\
\hline $\begin{array}{l}\text { Maintaining the dignity of the } \\
\text { person I care for is important } \\
\text { to me }\end{array}$ & 1 & 3.3 & 1 & 3.3 & 9 & 30.0 & 19 & 63.3 \\
\hline $\begin{array}{l}\text { I am able to test myself and } \\
\text { overcome difficulties }\end{array}$ & 4 & 13.3 & 1 & 3.3 & 6 & 20.0 & 19 & 63.3 \\
\hline $\begin{array}{l}\text { Caring is one way of showing } \\
\text { my faith }\end{array}$ & 5 & 16.7 & 0 & 0 & 8 & 26.7 & 17 & 56.7 \\
\hline $\begin{array}{l}\text { Caring has provided a purpose } \\
\text { to my life that I did not have } \\
\text { before }\end{array}$ & 20 & 66.7 & 0 & 0 & 7 & 23.3 & 3 & 10.0 \\
\hline $\begin{array}{l}\text { At the end of the day I know I } \\
\text { will have done the best I could }\end{array}$ & 2 & 6.7 & 2 & 6.7 & 11 & 36.7 & 15 & 50.0 \\
\hline $\begin{array}{l}\text { Caring is one way of } \\
\text { expressing my love for the } \\
\text { person I care for }\end{array}$ & 1 & 3.3 & 0 & 0 & 7 & 23.3 & 22 & 73.3 \\
\hline $\begin{array}{l}\text { Caring makes me feel needed } \\
\text { and wanted }\end{array}$ & 8 & 26.7 & 2 & 6.7 & 8 & 26.7 & 12 & 40.0 \\
\hline
\end{tabular}

